\title{
Mississippi River: Natchez to Baton Rouge Hydraulic and Sediment Transport Model
}

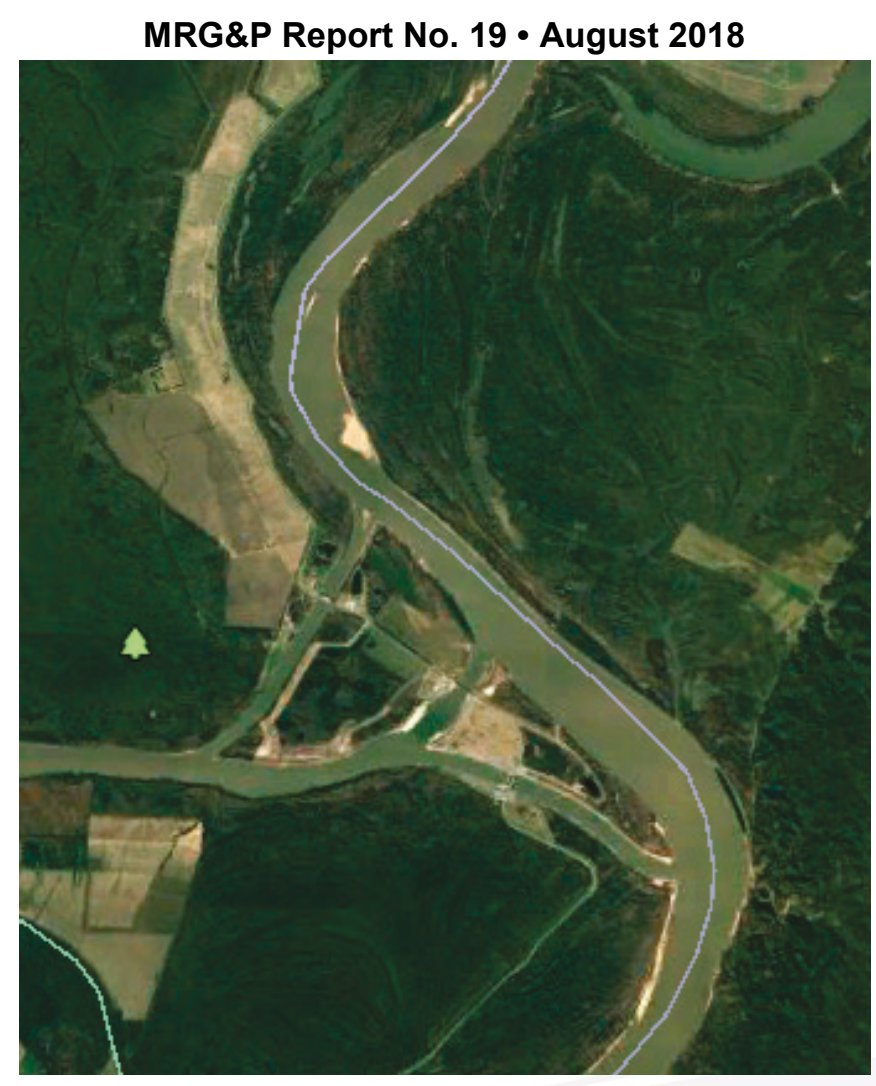

$\mathrm{MRG \& P}$

Mississippi River Geomorphology \&

Potamology Program 


\section{Mississippi River: Natchez to Baton Rouge Hydraulic and Sediment Transport Model}

James R. Leech, David P. May, Tate O. McAlpin

Coastal and Hydraulics Laboratory

U.S. Army Engineer Research and Development Center 3909 Halls Ferry Road

Vicksburg, MS 39180-6199

Final report

Approved for public release; distribution is unlimited.

Prepared for U.S. Army Corps of Engineers, Mississippi Valley Division Mississippi River Geomorphology \& Potamology Program 1400 Walnut Street Vicksburg, MS 39180

Under Project 470711, "Multi-Dimensional Modeling of Mississippi River" 


\section{Abstract}

This report documents the development, calibration, and validation of a hydraulic and sediment transport model of the Mississippi River between Natchez, MS, and Baton Rouge, LA, conducted for the U.S. Army Corps of Engineers, Mississippi Valley Division, Vicksburg, MS, using the Coastal and Hydraulics Laboratory-developed Adaptive Hydraulics numerical code. The numerical model adequately replicates the water levels observed in the field including a wide range of conditions from an extreme flood (Flood of 2011) to an extreme drought (2012). With the inclusion of the Old River Control Complex and Morganza Control Structure, this model is available to evaluate alternative operational procedures and associated relative water level impacts between these two structures for both normal and extreme flow conditions. This study further advanced the goal of the Mississippi River and Tributaries program in terms of developing numerical models to analyze the Lower Mississippi River in terms of short- and long-term impacts to the system.

DISCLAIMER: The contents of this report are not to be used for advertising, publication, or promotional purposes. Citation of trade names does not constitute an official endorsement or approval of the use of such commercial products. All product names and trademarks cited are the property of their respective owners. The findings of this report are not to be construed as an official Department of the Army position unless so designated by other authorized documents. 


\section{Contents}

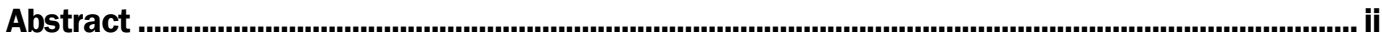

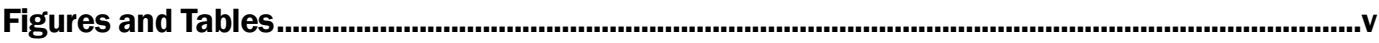

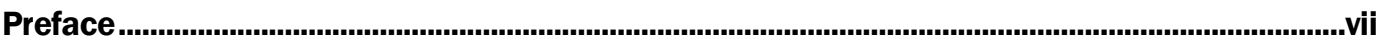

Unit Conversion Factors ................................................................................................................. viii

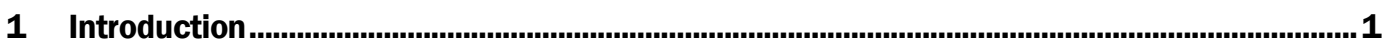

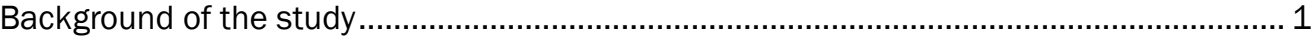

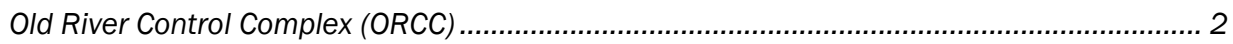

Morganza Control Structure (MCS) ...................................................................................... 2

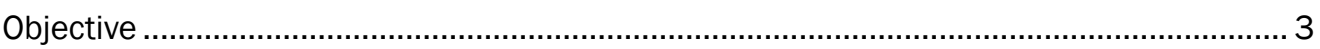

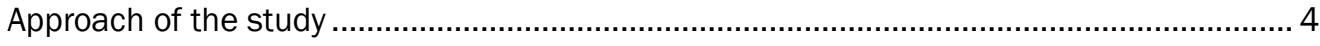

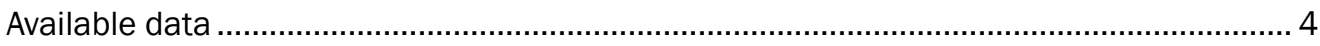

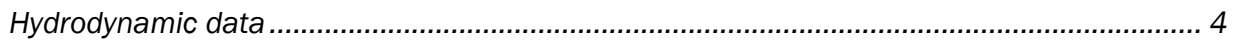

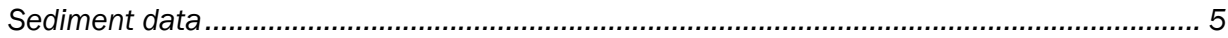

2 Model Description...................................................................................................................... 6

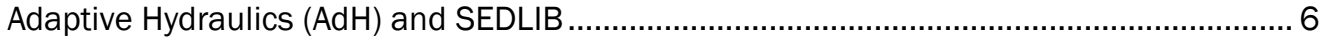

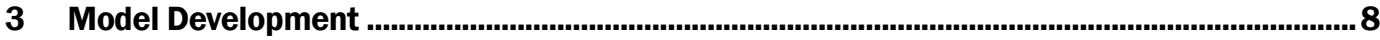

Model mesh development .......................................................................................... 8

Boundary conditions and initialization ................................................................... 10

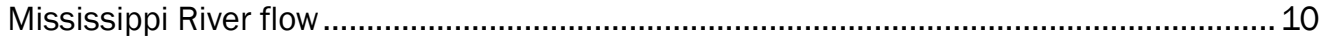

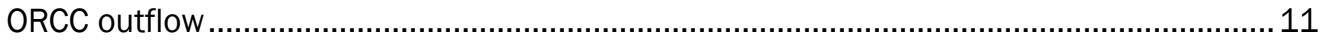

Sediment classes ........................................................................................................ 11

Noncohesive sediment boundary conditions ........................................................ 12

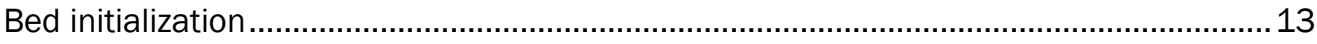

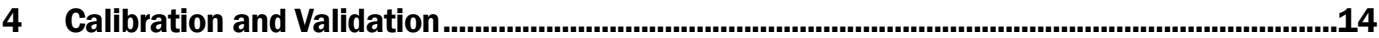

Hydrodynamic calibration and validation ......................................................... 14

Hydrodynamic calibration .............................................................................. 14

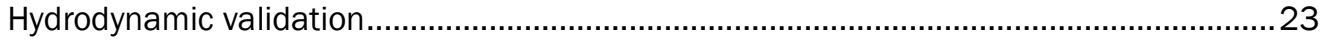

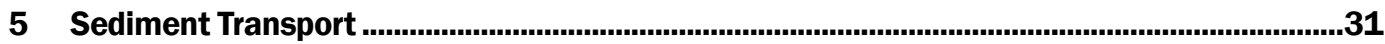

Single beam sediment survey data ....................................................................... 31

Multi-beam sediment survey data ........................................................................ 33

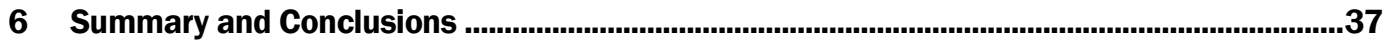

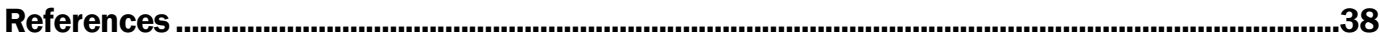

Appendix A: Difference in 2013 and 2011 Single Beam Survey Data and Difference in 2013 and 2011 ADH Model Results from RM 360 to RM 320 
Appendix B: 2015 Normalized Multi-beam Survey Yearly Bed Change Data and the Normalized AdH Model Yearly Bed Change, RM 320 to RM 228

Report Documentation Page 


\section{Figures and Tables}

\section{Figures}

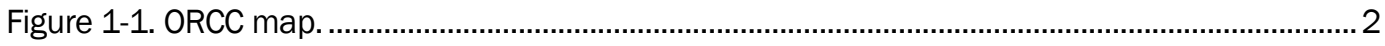

Figure 3-1. Model limits............................................................................................................

Figure 3-2. Model mesh of dikes, channel, and overbank ............................................................10

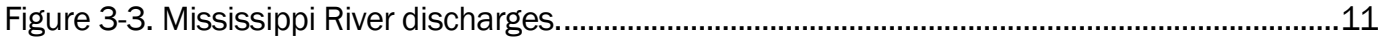

Figure 4-1. River gage locations in the model domain. ...................................................................15

Figure 4-2. Roughness assigned by material type................................................................................16

Figure 4-3. 2010 hydrograph.......................................................................................................

Figure 4-4. 2010 WSE plot: WSE vs. time for Natchez.................................................................18

Figure 4-5. 2010 WSE plot: model vs. field for Natchez..................................................................19

Figure 4-6. 2010 WSE plot: WSE vs. time for Red River Landing. .....................................................19

Figure 4-7. 2010 WSE plot: model vs. field for Red River Landing. ……………………………......20

Figure 4-8. 2010 WSE plot: WSE vs. time for Bayou Sara.................................................................20

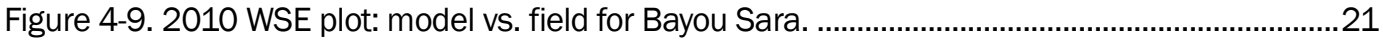

Figure 4-10. 2010 WSE plot: WSE vs. time for St. Francisville...........................................................21

Figure 4-11. 2010 WSE plot: model vs. field for St. Francisville.......................................................22

Figure 4-12. 2010 WSE plot: WSE vs. time for Baton Rouge............................................................22

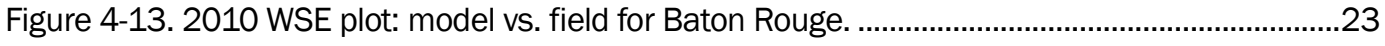

Figure 4-14. 2011-2013 hydrograph. ...........................................................................................23

Figure 4-15. 2011-2013 WSE plot: WSE vs. time for Natchez.........................................................24

Figure 4-16. 2011-2013 WSE plot: model vs. field for Natchez. …………………….....................25

Figure 4-17. 2011-2013 WSE plot: WSE vs. time for Red River Landing...........................................25

Figure 4-18. 2011-2013 WSE plot: model vs. field for Red River Landing......................................26

Figure 4-19. 2011-2013 WSE plot: WSE vs. time for Bayou Sara. ....................................................26

Figure 4-20. 2011-2013 WSE plot: model vs. field for Bayou Sara...................................................27

Figure 4-21. 2011-2013 WSE plot: WSE vs. time for St. Francisville. ...............................................2

Figure 4-22. 2011-2013 WSE plot: model vs. field for St. Francisville.............................................28

Figure 4-23. 2011-2013 WSE plot: WSE vs. time for Baton Rouge..................................................28

Figure 4-24. 2011-2013 WSE plot: model vs. field for Baton Rouge. ..............................................29

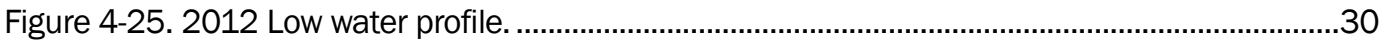

Figure 5-1. Difference in 2013 and 2011 single beam survey data from RM 360 to RM 355 .

Figure 5-2. Difference in 2013 and 2011 model results from RM 360 to RM 355.......................32

Figure 5-3. Difference in 2013 and 2011 single beam survey data from RM 335 to RM

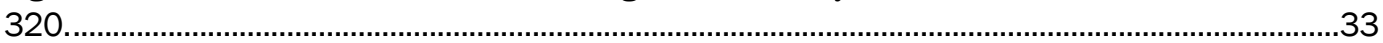

Figure 5-4. Difference in 2013 and 2011 model results from RM 335 to RM 320.........................33

Figure 5-5. Normalized observed yearly bed change, RM 324 to RM 305.....................................35

Figure 5-6. Normalized model yearly bed change, RM 324 to RM 305............................................35 
Figure 5-7. Normalized observed yearly bed change, RM 305 to RM 285 .....................................36

Figure 5-8. Normalized model yearly bed change, RM 305 to RM 285 ............................................36

Figure A-1. Difference in 2013 and 2011 single beam survey data from RM 360 to RM

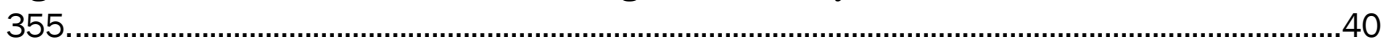

Figure A-2. Difference in 2013 and 2011 model results from RM 360 to RM 355........................40

Figure A-3. Difference in 2013 and 2011 single beam survey data from RM 355 to RM

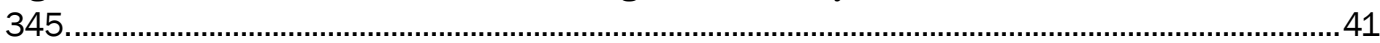

Figure A-4. Difference in 2013 and 2011 model results from RM 355 to RM 345.........................41

Figure A-5. Difference in 2013 and 2011 single beam survey data from RM 345 to RM 330 .

Figure A-6. Difference in 2013 and 2011 model results from RM 345 to RM 330.........................42

Figure A-7. Difference in 2013 and 2011 single beam survey data from RM 335 to RM 320 .

Figure A-8. Difference in 2013 and 2011 model results from RM 335 to RM 320.........................43

Figure B-1. Normalized observed yearly bed change, RM 324 to RM 305. .....................................44

Figure B-2. Normalized model yearly approximation, RM 324 to RM 305.......................................44

Figure B-3. Normalized observed yearly bed change, RM 305 to RM 285.....................................45

Figure B-4. Normalized model yearly bed change, RM 305 to RM 285 ...........................................45

Figure B-5. Normalized observed yearly bed change, RM 285 to RM 255....................................46

Figure B-6. Normalized model yearly bed change, RM 285 to RM 255 ..........................................46

Figure B-7. Normalized observed yearly bed change, RM 255 to RM 230........................................4 47

Figure B-8. Normalized model yearly bed change, RM 255 to RM 230.............................................4

Figure B-9. Normalized observed yearly bed change, RM 240 to RM 228....................................48

Figure B-10. Normalized model yearly bed change, RM 240 to RM 228. .........................................48

\section{Tables}

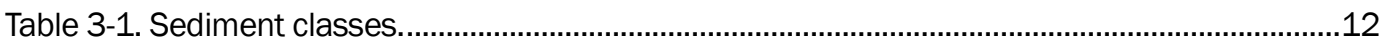

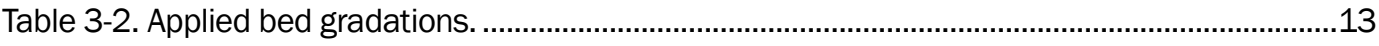

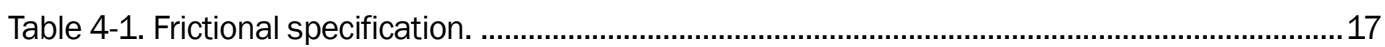




\section{Preface}

The research documented in this report was conducted as part of the Mississippi River Geomorphology and Potamology (MRG\&P) Program, Project 470711, "Multi-Dimensional Modeling of Mississippi River." The MRG\&P is part of the Mississippi River and Tributaries Program (MR\&T) and is managed by the U.S. Army Corps of Engineers (USACE), Mississippi Valley Division (MVD), and Districts. At the time of publication of this report, the MRG\&P Technical Director was Dr. Ty V. Wamsley. The MVD Commander was MG Richard G. Kaiser. The MVD Director of Programs was James A. Bodron.

Mississippi River engineering direction and policy advice were provided by the Mississippi River Commission. The Commission members were MG Kaiser, USACE; the Honorable Sam E. Angel; the Honorable James Reeder; the Honorable Norma Jean Mattei, PhD; RDML Shepard Smith, National Oceanic and Atmospheric Administration; BG Mark Toy, USACE; and BG Paul E. Owen, USACE.

The work was performed by the River Engineering Branch of the Flood and Storm Protection Division, U.S. Army Engineer Research and Development Center, Coastal and Hydraulics Laboratory (ERDC-CHL). At the time of publication, Mr. Keith Flowers was Chief, CEERD-HF-R; Dr. Cary Talbot was Chief, CEERD-HF. The Acting Director of CHL was Mr. Jeffery R. Eckstein.

COL Ivan P. Beckman was the Commander of ERDC, and Dr. David W. Pitman was the Director. 


\section{Unit Conversion Factors}

\begin{tabular}{|c|c|c|}
\hline Multiply & By & To Obtain \\
\hline acres & $4,046.873$ & square meters \\
\hline acre-feet & $1,233.5$ & cubic meters \\
\hline cubic feet & 0.02831685 & cubic meters \\
\hline cubic yards & 0.7645549 & cubic meters \\
\hline feet & 0.3048 & meters \\
\hline inches & 0.0254 & meters \\
\hline knots & 0.5144444 & meters per second \\
\hline miles (nautical) & 1,852 & meters \\
\hline miles (U.S. statute) & $1,609.347$ & meters \\
\hline miles per hour & 0.44704 & meters per second \\
\hline pounds (mass) & 0.45359237 & kilograms \\
\hline pounds (mass) per cubic foot & 16.01846 & kilograms per cubic meter \\
\hline pounds (mass) per cubic inch & $2.757990 \mathrm{E}+04$ & kilograms per cubic meter \\
\hline pounds (mass) per square foot & 4.882428 & kilograms per square meter \\
\hline pounds (mass) per square yard & 0.542492 & kilograms per square meter \\
\hline square feet & 0.09290304 & square meters \\
\hline square miles & $2.589998 E+06$ & square meters \\
\hline square yards & 0.8361274 & square meters \\
\hline tons (force) & $8,896.443$ & newtons \\
\hline tons (force) per square foot & 95.76052 & kilopascals \\
\hline tons (long) per cubic yard & $1,328.939$ & kilograms per cubic meter \\
\hline tons $(2,000$ pounds, mass $)$ & 907.1847 & kilograms \\
\hline tons ( 2,000 pounds, mass) per square foot & $9,764.856$ & kilograms per square meter \\
\hline yards & 0.9144 & meters \\
\hline
\end{tabular}




\section{Introduction}

\section{Background of the study}

The Mississippi River and Tributaries (MR\&T) Project is a complex, comprehensive water resources project authorized by the 1928 Flood Control Act following the devastating 1927 flood. The MR\&T Project provides flood damage reduction within the alluvial valley and navigation improvement of the Lower Mississippi River (LMR). The LMR extends approximately 1,000 miles from Cairo, IL, to the Gulf of Mexico. The primary elements of the MR\&T Project include levees, floodways and diversion structures, tributary basin improvements, and channel improvement features such as meander cutoffs, bank stabilization, dikes, and dredging. The historical, present, and future morphology of the LMR reflects an integration of all of these features in combination with natural factors: floods and droughts, hurricanes, tectonic activity, geologic outcrops, climatic variability, subsidence, and sea level rise. Understanding how these various factors affect the short- and long-term morphology of the LMR is a complex challenge for the river engineers and scientists responsible for managing this system for flood damage reduction, navigation, habitat restoration, and reduction of the loss of coastal marshes and wetlands in Louisiana. This study was completed to further advance the goal of developing numerical models to analyze the LMR in terms of short- and long-term impacts to the system.

The stretch of river between Natchez and Baton Rouge is a complex fluvial waterway with two large flow control structures, miles of levees, and extensive overbank floodplains. USACE (2012) emphasized the importance of having available numerical models for the Morganza Control Structure (MCS) and Old River Control Complex (ORCC) during flooding conditions, but the benefit extends beyond temporary flooding situations to more common flows and associated morphology. Bell et al. (2017) detail modeling of the Morganza Floodway during the 2011 flood but neglect the hydraulics and sediment transport on the river side of the structure. This study details the development of a numerical model for hydraulics and sediment transport in the Mississippi River between Natchez and Baton Rouge during the flood of 2011 and the drought of 2012. This model includes impacts associated with the operation of the ORCC and the MCS. 


\section{Old River Control Complex (ORCC)}

The ORCC (Figure 1-1) is located on the west bank of the Mississippi River approximately 48 miles northwest of Baton Rouge, LA, and 37 miles south-southwest of Natchez, MS. The complex regulates the diversion of flow and sediment from the Mississippi River to the Atchafalaya River and the Red River Backwater Area. The complex is operated to maintain a $30 \%-70 \%$ flow split between the Atchafalaya and Mississippi Rivers as estimated from rating curves at the Simmesport and Red River Landing gages downstream of the complex. Since 1977, the complex has been operated to maintain the $30 \%-70 \%$ flow split as closely as practical on a daily basis. On average, approximately $23 \%$ of the Mississippi River flow is diverted through the complex, but the daily diversion percentage can vary significantly in response to the variations in the relative contribution of the Red River to the Mississippi River flow.

Figure 1-1. ORCC map.

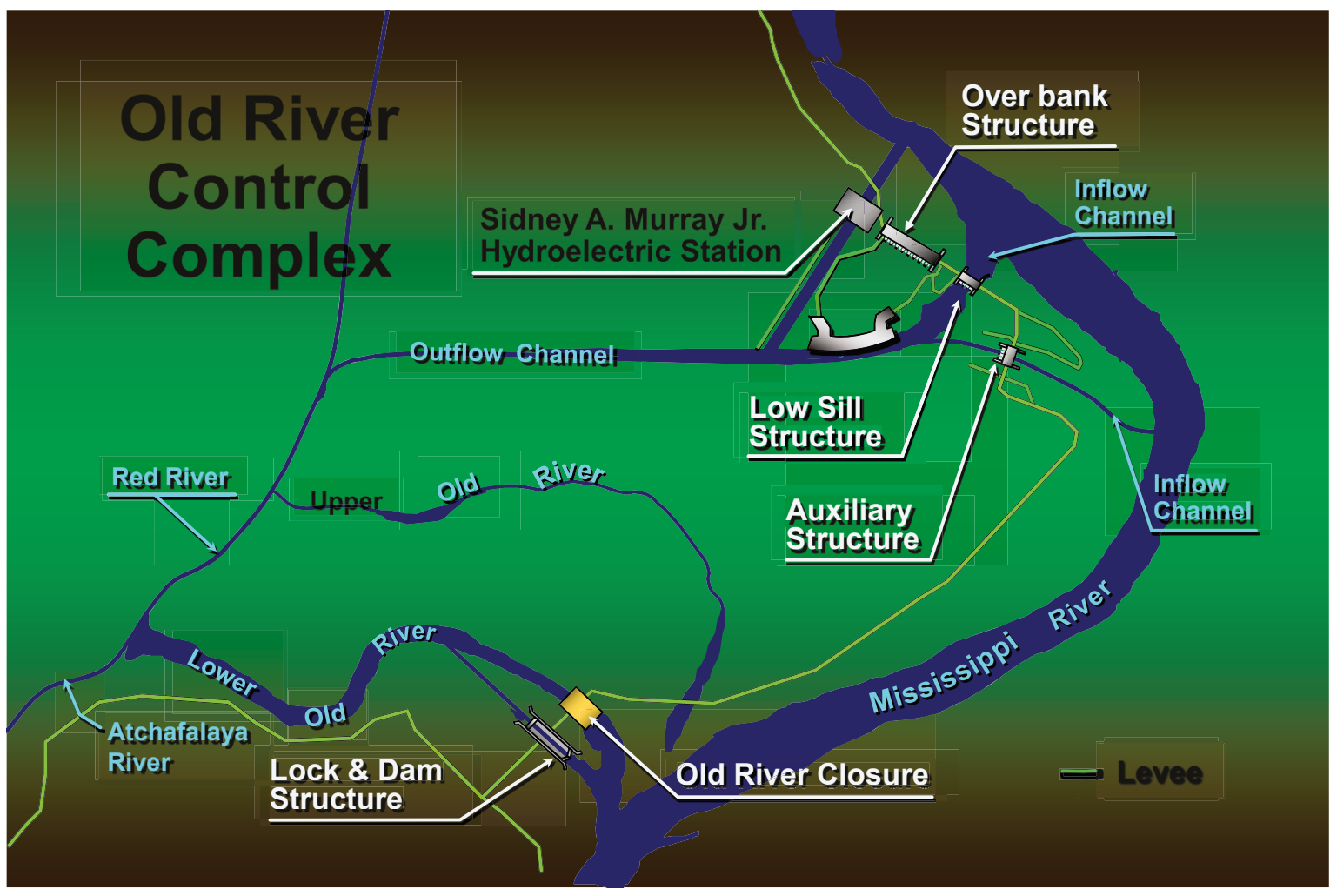

\section{Morganza Control Structure (MCS)}

The MCS was completed in 1955 at a cost of $\$ 10,000,000$ (USACE 1999). The structure consists of a vertical lift-gate controlled concrete weir 4,160 feet $(\mathrm{ft}$ ) long. The gated portion is 3,906 ft long with approaches on 
each side $127 \mathrm{ft}$ long. The gated portion consists of a weir at $37.5 \mathrm{ft}$ National Geodetic Vertical Datum of 1929 (NGVD29), which has 125 bays, each $28 \mathrm{ft}$, 3 inches (in.) wide, separated by 36 in. wide piers (USACE 2014a). It was designed to pass up to 600,000 cubic feet per second (cfs) of water west through the Atchafalaya Basin to the Gulf of Mexico to alleviate pressure on the mainline levees downstream along the Mississippi River. The structure has only been operated twice (1973 and 2011). Per USACE (2014b), the operation of the MCS was clarified as such:

- The MCS shall be operated to ensure the water stage on the river side of the structure does not exceed $57 \mathrm{ft}$ when there is a 10-day forecast of a Mississippi River discharge of 1,500,000 cfs and rising.

- The MCS shall be operated to limit the rise of water in the floodway to $1 \mathrm{ft}$ per day for the first 3 days of operation, as measured at the northeast corner of the East Atchafalaya Basin Protection Levee. This is a clarification of an existing requirement in the present approved Water Control Manual. Meeting this requirement will typically require a small initial structure opening 3 days in advance of full operation, though exact operations will depend on river conditions.

- After Floodway operation, some structure bays may be left open to help drain the forebay area more quickly, so long as stages in the Floodway are not permitted to increase. This is also a clarification of an operation that is allowed in the existing approved manual.

- The gage opening/closing sequence will be changed to decrease scour damage in the tailbay.

\section{Objective}

The initial statement of work included a two-dimensional (2D) numerical hydraulic and sediment transport model study to evaluate flows between the ORCC and MCS during the 2011 flood event. The scope of the study was revised by the Mississippi Valley Division to extend the model limits from Natchez, MS, to Baton Rouge, LA, including approximately 150 miles of Mississippi River channel. The reason for this change was to match a three-dimensional (3D) numerical model domain being created by the New Orleans District (MVN). The new hydrograph for the study was between March 2011 and July 2013. The study reach includes areas of responsibility for both the Vicksburg District (MVK) and MVN. MVK is responsible for the area from River Mile (RM) 363 to 324, and MVN is responsible for the area from RM 324 to 228. 
The multi-dimensional model presented in this report is a model application using the Adaptive Hydraulics (AdH) numerical model code, which is developed and supported at the Coastal and Hydraulics Laboratory (CHL) at the U.S. Army Engineer Research and Development Center (ERDC). AdH is linked to SEDLIB (Brown et al. 2014), a sediment transport library that is also developed and supported at CHL. The model simulates hydrodynamic and sedimentation processes in the Mississippi River between Natchez, MS, and Baton Rouge, LA, and adjacent portions of the Mississippi River and its floodplains. The model limits included 28 dikes between Natchez and the MCS. This study provides a means of determining the accuracy of the numerical model in terms of predicting morphological behavior for this important stretch of river while also providing a comparison dataset for other model studies in the area.

\section{Approach of the study}

The approach for this study is as follows:

- Assemble and analyze all data pertinent to numerical model development (e.g., bathymetry, infrastructure, roughness characteristics, boundary condition data).

- Develop the computational mesh.

- Calibrate and validate the hydrodynamics.

- Incorporate sediment transport into the numerical model.

The results of these tasks are contained in this report.

\section{Available data}

\section{Hydrodynamic data}

Discharge estimates were available for Tarbert Landing along with estimates of discharge for the three structures comprising the ORCC. Utilizing these estimates, an inflow estimate was determined for the upstream inflow boundary located at Nachez, MS. The water level calibration and validation were completed using daily water level gage measurements at Natchez, Red River, Bayou Sara, St. Francisville, and Baton Rouge. 


\section{Sediment data}

Sediment data available for analyses of model results consisted of singlebeam bed surveys from Natchez (RM 363) to RM 324 and multi-beam data from RM 324 to Baton Rouge (RM 228.4). Single-beam survey data were provided by the MVK for 2011 and 2013 and a longitudinal water surface profile for 2012. Multi-beam survey data was provided by the MVN for 2004 and 2013.

The model hydrograph was 14 March 2011 through 28 July 2013. This time period included the flood of 2011 and a 7-month drought during 2012. These were two extreme events on two different ends of the flow spectrum. 


\section{Model Description}

\section{Adaptive Hydraulics (AdH) and SEDLIB}

The AdH is a finite element model that is capable of simulating $3 \mathrm{D}$ Navier Stokes equations, 2D and 3D shallow water equations, and groundwater equations. It can be used in a serial or multiprocessor mode on personal computers, UNIX, Silicon Graphics, and CRAY operating systems. For this study, AdH is applied in 2D depth-averaged mode.

The adaptive aspect of AdH is its ability to dynamically refine the mesh in areas where more resolution is needed at certain times due to changes in the flow and/or transport conditions. AdH can simulate the transport of conservative constituents, such as dye clouds, as well as sediment transport that is coupled to bed and hydrodynamic influences. The ability of AdH to allow the domain to wet and dry as the river stage changes is important in accurately simulating the Mississippi River as it can possess vastly different flow rates and water levels.

SEDLIB is a sediment transport library developed at ERDC. (Brown 2012a,b). It is capable of solving problems consisting of multiple grain sizes, cohesive and noncohesive sediment types, and multiple bed layers. It calculates erosion and deposition processes simultaneously and simulates such bed processes as armoring, consolidation, and discrete depositional strata evolution.

The SEDLIB library system is designed to link to any appropriate hydrodynamic code. The hydrodynamic code must be capable of performing advection diffusion calculations for a constituent. SEDLIB interacts with the parent code by providing sources and sinks to the advection diffusion solver in the parent code. The solver is then used to calculate both bedload and suspended load transport for each grain class. The sources and sinks are passed to the parent code via an explicit bed sediment flux for each grain class.

This tool has been developed at CHL and has been used to model sediment transport in such varied environments as the Mississippi River, tidal conditions in southern California, and vessel traffic in the Houston Ship Channel. 
The AdH /SEDLIB sediment model contributes several important capabilities to the current study, including the following:

- Quasi 3D flow and transport formulations, which use analytical and semi-empirical methods to approximate the $3 \mathrm{D}$ character of the flow and sediment transport phenomena (Brown 2008, 2012a).

- The ability to model the impact of helical flow through a river bendway on the suspended and bedload sediment transport, by utilizing the bendway vorticity transport algorithm given by Bernard (1992).

- The SEDLIB module is equipped to simulate multi-grain class suspended load and bedload sediment transport phenomena. It is also equipped to handle generalized multi-grain class bed processes, including armoring, sorting, erosion to a solid boundary, and the storage of discrete depositional strata.

- The unstructured model mesh employed by AdH permits very high resolution in areas of interest and high-fidelity resolution of shoreline geometry. 


\section{Model Development}

\section{Model mesh development}

The model mesh extends from Natchez, MS, approximately 63 RMs upstream of the ORCC on the Mississippi River to Baton Rouge, LA, approximately 92 miles downstream of the ORCC. The mesh extends east and west to the elevation of highest flood for the period of record or to the levees, where applicable. A total of 28 river training structures (dikes), 32 revetments, and the Hog's Point trench filled revetment are identified and resolved explicitly in the model. The Old River Overbank and MCS are also included in the model. Figure 3-1 shows the complete model domain.

The mesh elevation data were specified utilizing 2004 LiDAR data for the floodplain, 2004 multi-beam bathymetry data for the channel from Baton Rouge to RM 324, and 2011 single-beam bathymetry data for the channel from RM 324 to Natchez. The mesh domain includes 331,251 acres over 452,000 elements, and approximately 227,000 nodes. The mesh resolution (Figure 3-2) is set such that the river channel has 50-meter (m) spacing on average, the mesh resolution decreases toward the mesh boundaries and increases near the river training structures. The horizontal coordinate system used for this application is State Plane Coordinate System (NAD27), Louisiana South (FIPS 1702) zone, in meters. The vertical coordinate system is North American Vertical Datum of 1988 (NAVD88), in meters. 
Figure 3-1. Model limits.

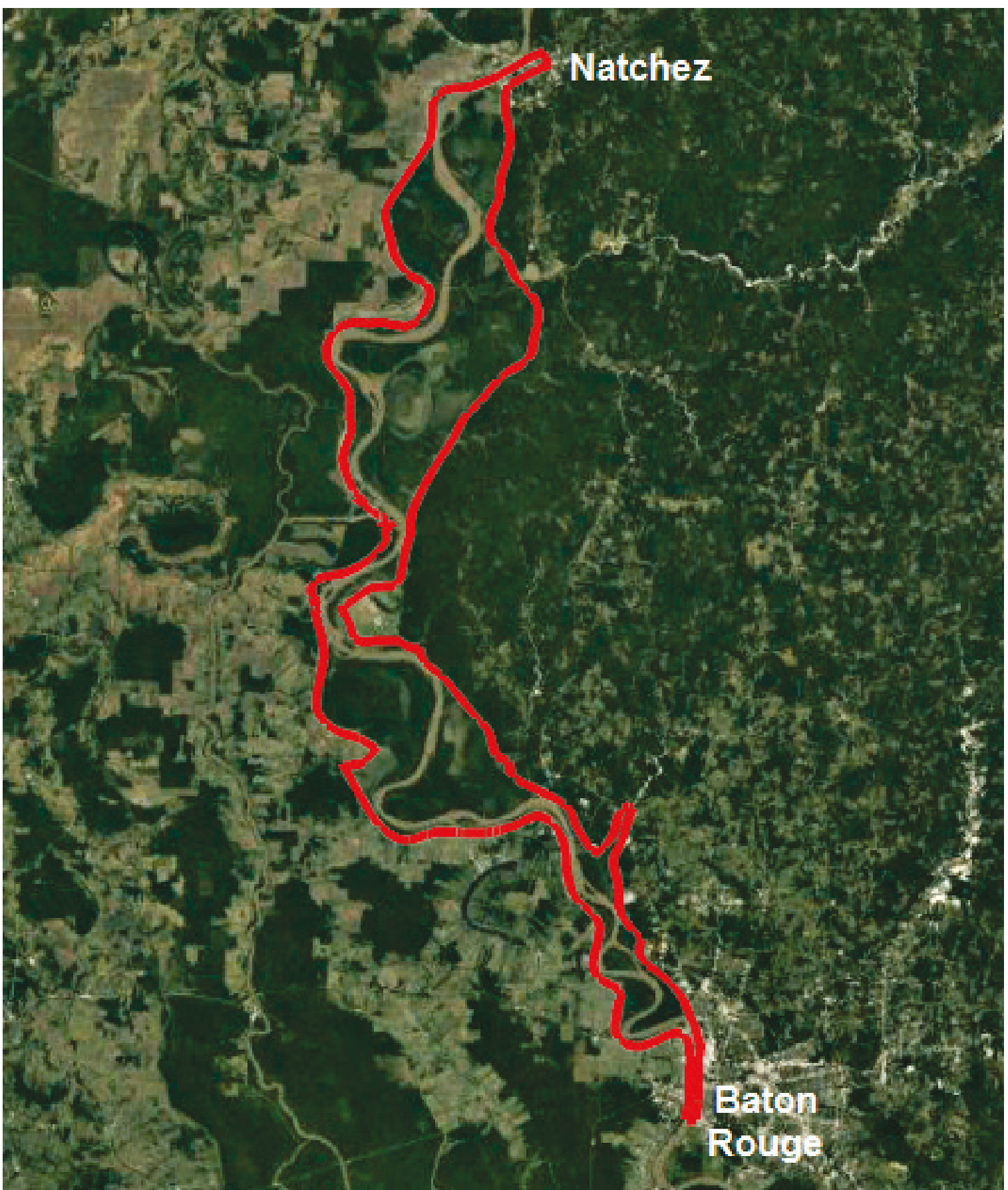


Figure 3-2. Model mesh of dikes, channel, and overbank.

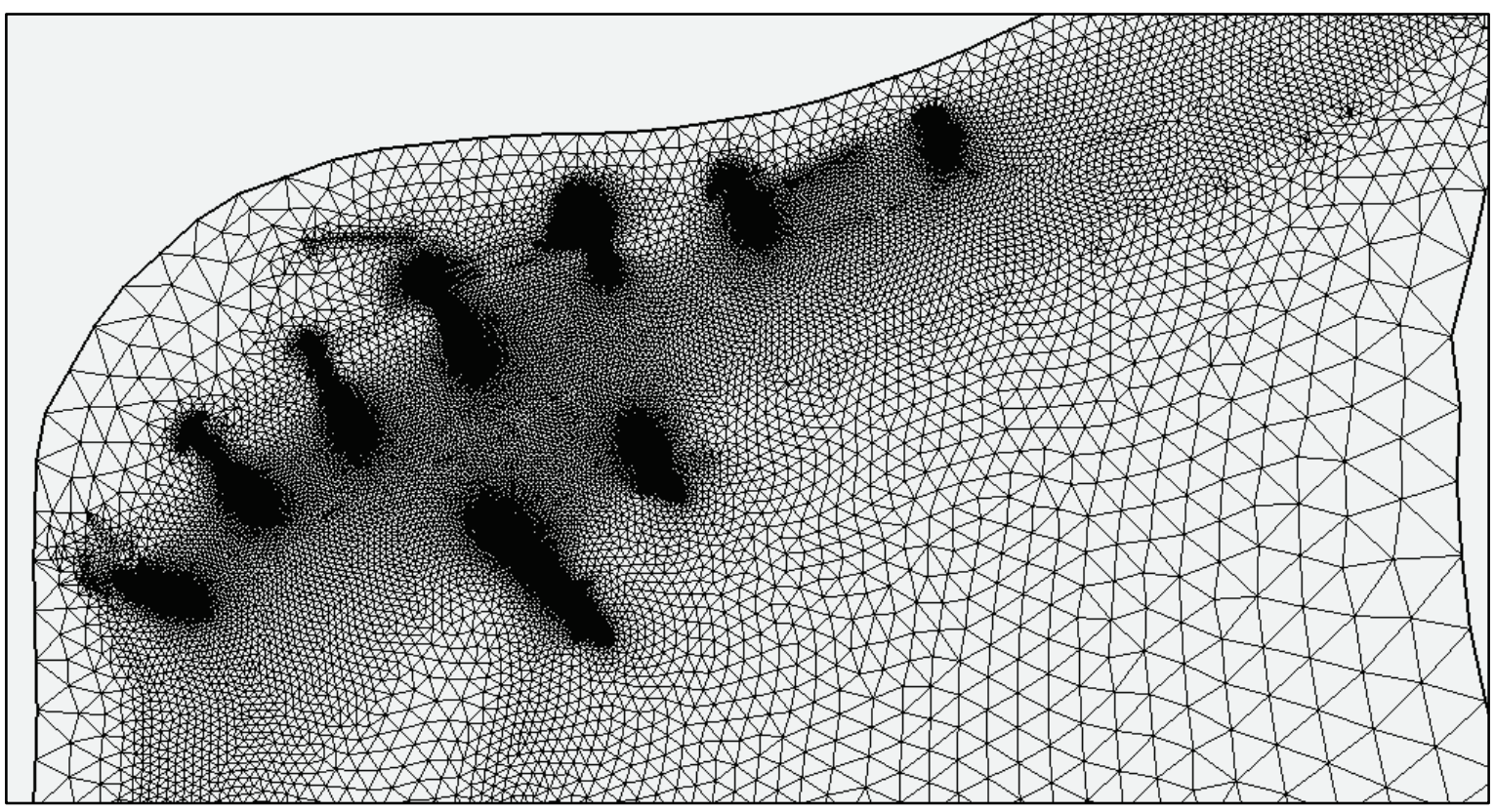

\section{Boundary conditions and initialization}

The model is driven by flows on the Mississippi River and flows through ORCC and MCS with a tailwater specification at the downstream boundary using the Baton Rouge recorded gage data. A hydrograph is simulated to determine the accuracy of the model in replicating the observed conditions in the field under time-varying conditions. Boundary condition data are obtained from several different sources and checked for quality prior to usage in the numerical model. For this study, boundary condition data are processed for 2010 to 2013 , so any time during these 3 years, data are available to be modeled.

\section{Mississippi River flow}

The Mississippi River flows are necessary at the upstream model boundary. The only discharge values on the Mississippi River in the vicinity of the model boundary are Natchez to the north and Red River (Tarbert Landing) to the south. The discharge measurements recorded at Natchez were only recorded every 2 weeks. The reported values at Red River (Tarbert Landing) are provided daily based on a known relationship between discharge and stage values read at the Red River Landing gage. To establish a model inflow discharge value at Natchez, the Tarbert Landing discharges were added to the ORCC discharges (Figure 3-3). These values (ORCC + Tarbert Landing) were compared to the limited 
Natchez values for consistency. These comparisons (Figure 3-3) indicate the validity of adding the ORCC and Tarbert Landing discharges to obtain an appropriate value to apply at Natchez each day.

Figure 3-3. Mississippi River discharges.

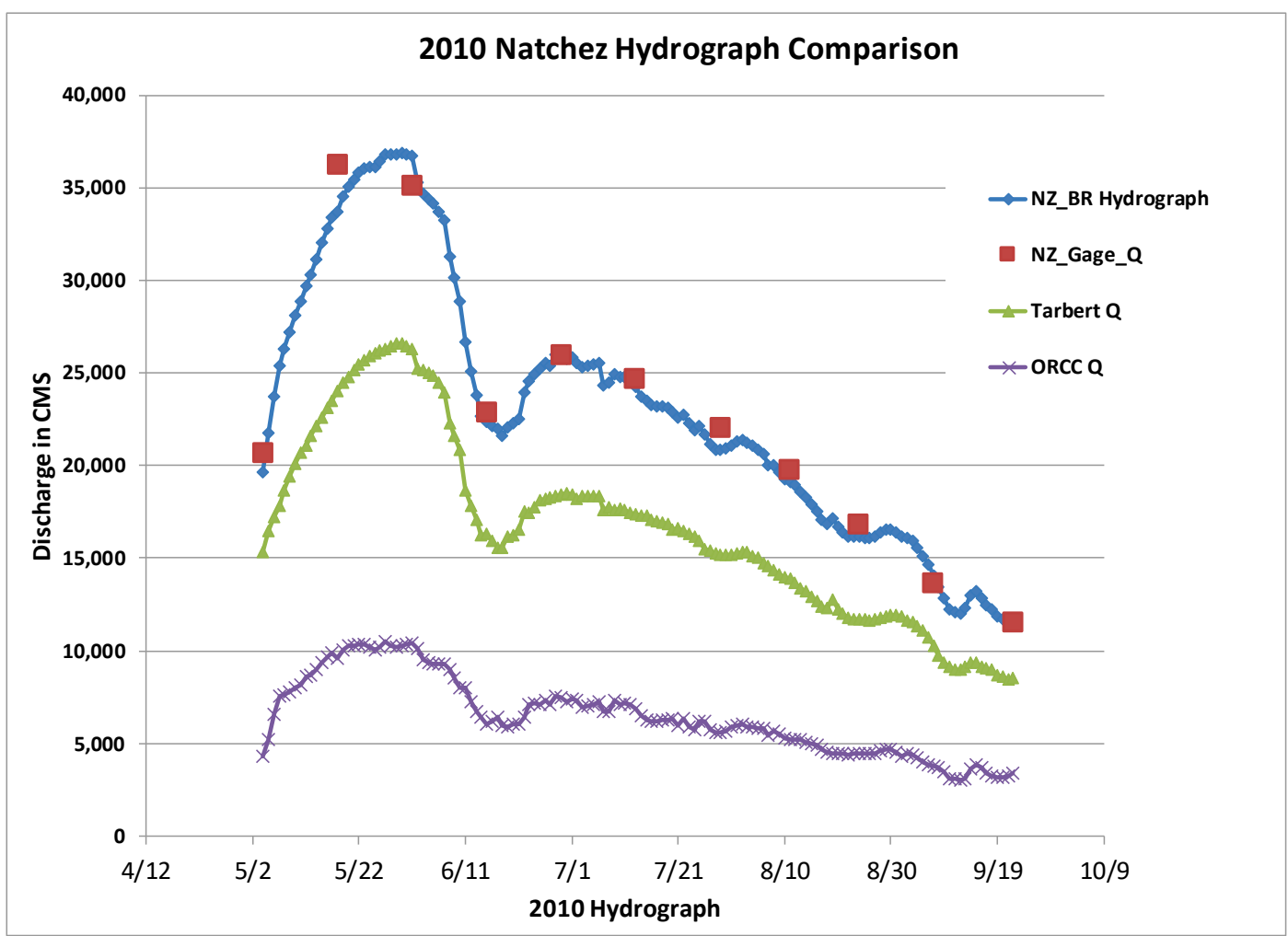

\section{ORCC outflow}

The ORCC includes three discharge locations: the Hydropower structure, the Low Sill structure, and the Auxiliary structure (as shown in Figure 1-1). These outflows from the Mississippi River are controlled by a combination of flow in the Red River and the Mississippi River such that only $70 \%$ of the total flow passes down the Mississippi River and the remaining 30\% passes through the ORCC and into the Atchafalaya River. These flows are estimated daily for each of the three structures. The numerical model removed the appropriate flow at each structure individually with the total removed shown in Figure 3-3.

\section{Sediment classes}

The sediment is modeled in terms of discrete grain classes. The full range of noncohesive sediment classes found in the bed material for this portion of the river is represented in the model simulations. These grain size 
classes are consistent with the American Geophysical Union scale (Lane 1947). This is also consistent with previous studies in this area (Heath et al. 2015). The discrete grain classes simulated are provided in Table 3-1.

Table 3-1. Sediment classes.

\begin{tabular}{|l|c|c|}
\hline Sediment Class & Abbreviation & Diameter (millimeter) \\
\hline Very fine sand & VFS & 0.088 \\
\hline Fine sand & FS & 0.177 \\
\hline Medium sand & MS & 0.354 \\
\hline Coarse sand & CS & 0.707 \\
\hline Very coarse sand & VCS & 1.41 \\
\hline Very fine gravel & VFG & 2.83 \\
\hline Fine gravel & FG & 5.66 \\
\hline
\end{tabular}

\section{Noncohesive sediment boundary conditions}

Based on previous model studies, the sand and gravel sediments (noncohesive sediments) are modeled using the following transport functions:

- Bed-load transport - van Rijn (1984)

- Suspended Load - Wright and Parker (2004)

- Hiding factor - Egiazaroff (1965).

The inflowing boundary condition (upstream of the ORCC) is represented with an equilibrium sediment boundary condition. This boundary condition applies an inflow concentration that is consistent with the transport functions and the bed sediment at the boundary. This boundary condition is used, in lieu of observations, for the following reasons:

- The observed data are not segregated into discrete grain classes: the use of observed data would require an approximation of this partitioning, which introduces significant uncertainty.

- Inconsistencies between observed concentrations and the concentrations calculated by the transport functions can result in significant erosion or deposition of sediment at the inflow boundary.

- The model upstream of Natchez is simulated with a fixed bed: this allows the model to adjust to any spurious sediment loads introduced at the boundary without influencing the conveyance capacity of the river. 


\section{Bed initialization}

The sediment bed is initialized as follows:

- The initial bed consists of six bed layers.

- The top four bed layers are zero thickness layers: these are used to store depositional layers during the model simulation.

- The bottom two layers are defined by an elevation horizon: that is, their thickness varies spatially and is defined by the difference between the defined elevation of the top of the bed layer and the local elevation of the bed (mesh elevation).

- The grain composition of the layers are taken from data collected in the river. They represent typical gradation in the river for lateral bars and point bars (top layer sediment) and deep thalweg sediments (bottom layer sediment).

- The initial bed layer thicknesses were specified based on an inputted elevation and the mesh elevation. This allowed for a spatially varying initial bed layer thickness. The initial thickness of a bed layer is the difference between each nodal elevation and the inputted bed layer elevation. Utilizing the elevation allows the thalwag of the river to armor quicker than specifying a bed layer thickness everywhere. The bed layer elevation and grain composition of the bed layers for the main channel above Baton Rouge were based on previous experience in this area and are given in Table 3-2.

Table 3-2. Applied bed gradations.

\begin{tabular}{|c|c|c|c|c|c|c|c|c|}
\hline Layer & $\begin{array}{c}\text { Bed Layer Elevation } \\
\text { (meters, NAVD88) }\end{array}$ & VFS & FS & MS & CS & VCS & VFG & FG \\
\hline 1 & -23 & 0.08 & 0.08 & 0.58 & 0.13 & 0.05 & 0.04 & 0.04 \\
\hline 2 & -18 & 0.1 & 0.1 & 0.63 & 0.14 & 0.03 & 0 & 0 \\
\hline
\end{tabular}

To initialize the bed, the model was simulated for approximately 12 months from 14 March 2011 to 14 March 2012, without allowing the bed elevations to change. This initializes the bed by allowing the grain size distribution to vary spatially in a manner consistent with the local bed shear stresses. This adjusted bed distribution was utilized as the initial bed for all subsequent sediment transport model simulations discussed in this report. 


\section{Calibration and Validation}

\section{Hydrodynamic calibration and validation}

The model roughness parameters were adjusted within an acceptable range as part of the calibration process to obtain adequate water level comparisons for the available gages. As part of the model calibration process, a mesh convergence test was performed using the mesh adaption feature within $\mathrm{AdH}$.

Note that bed shear stresses in AdH are not computed by direct application of Manning's equation. Rather, it is computed by an analytic depth-integration of the logarithmic velocity profile so that the computed shear stress is valid for the entire range of depth to roughness ratios. The resulting shear stress is essentially the same as what is obtained from Manning's equation for flows with roughness to depth ratios in the Manning's range.

\section{Hydrodynamic calibration}

The hydrodynamic calibration consisted of adjusting model roughness values, ensuring that the model resolution was properly converged. One of the primary sites where model bathymetry (and geometry) was found to be of significance was associated with the deposition in the approach channels to the Low Sill and Auxiliary Structures during the 2012 drought and overbank areas that were subject to wetting and drying.

Initial tests consisted of running steady state flow conditions for mid-bank and flood stages and adjusting the roughness values to match water surface elevations (WSE) at the Natchez, Red River, Bayou Sara, St. Francisville, and Baton Rouge river gages (Figure 4-1). 
Figure 4-1. River gage locations in the model domain.

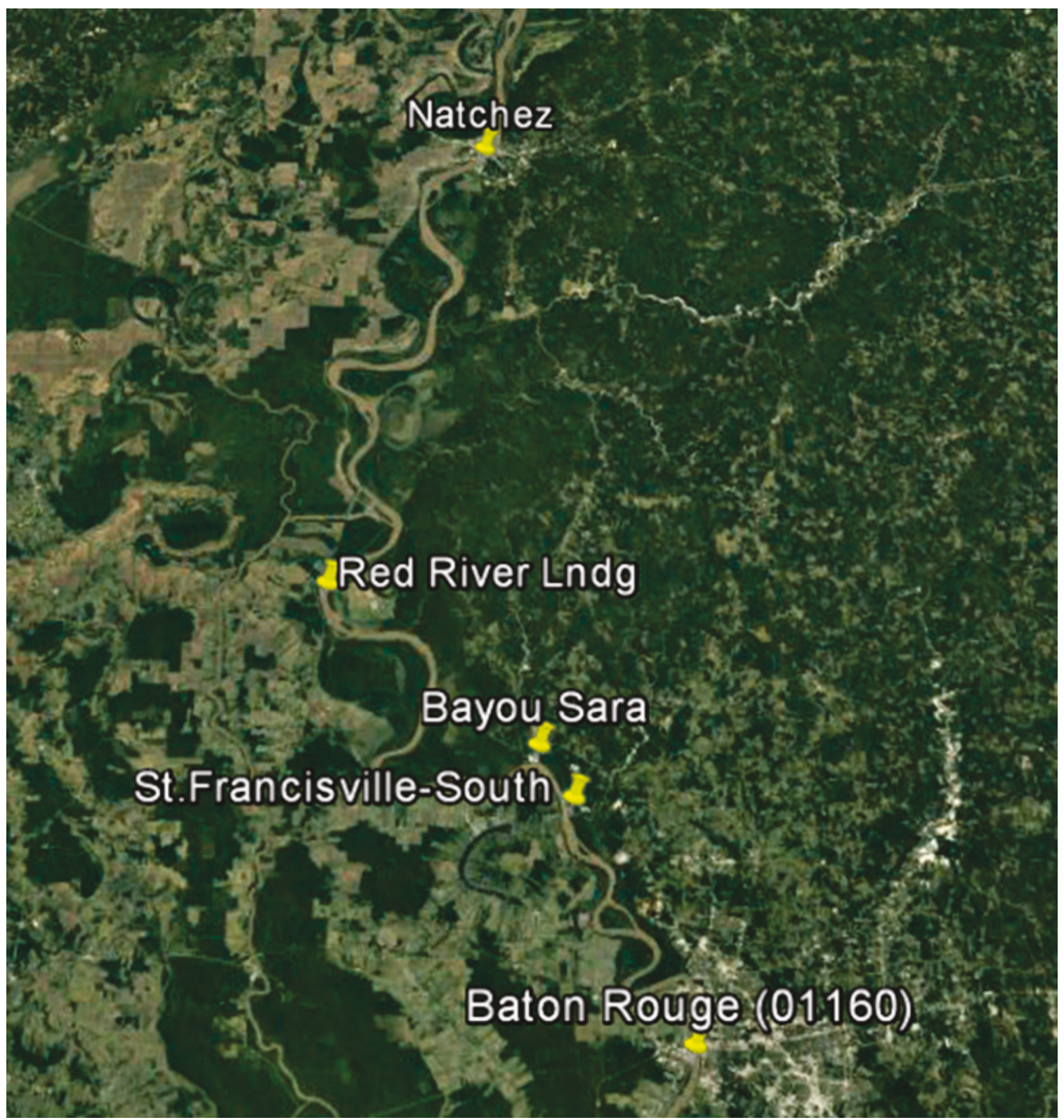

Manning's $n$-values were assigned by material type (Figure 4-2). Multiple tests were conducted by adjusting the roughness values for different water levels to determine the channel frictions during low water flows and then to determine the overbank frictions during high flows. 
Figure 4-2. Roughness assigned by material type.

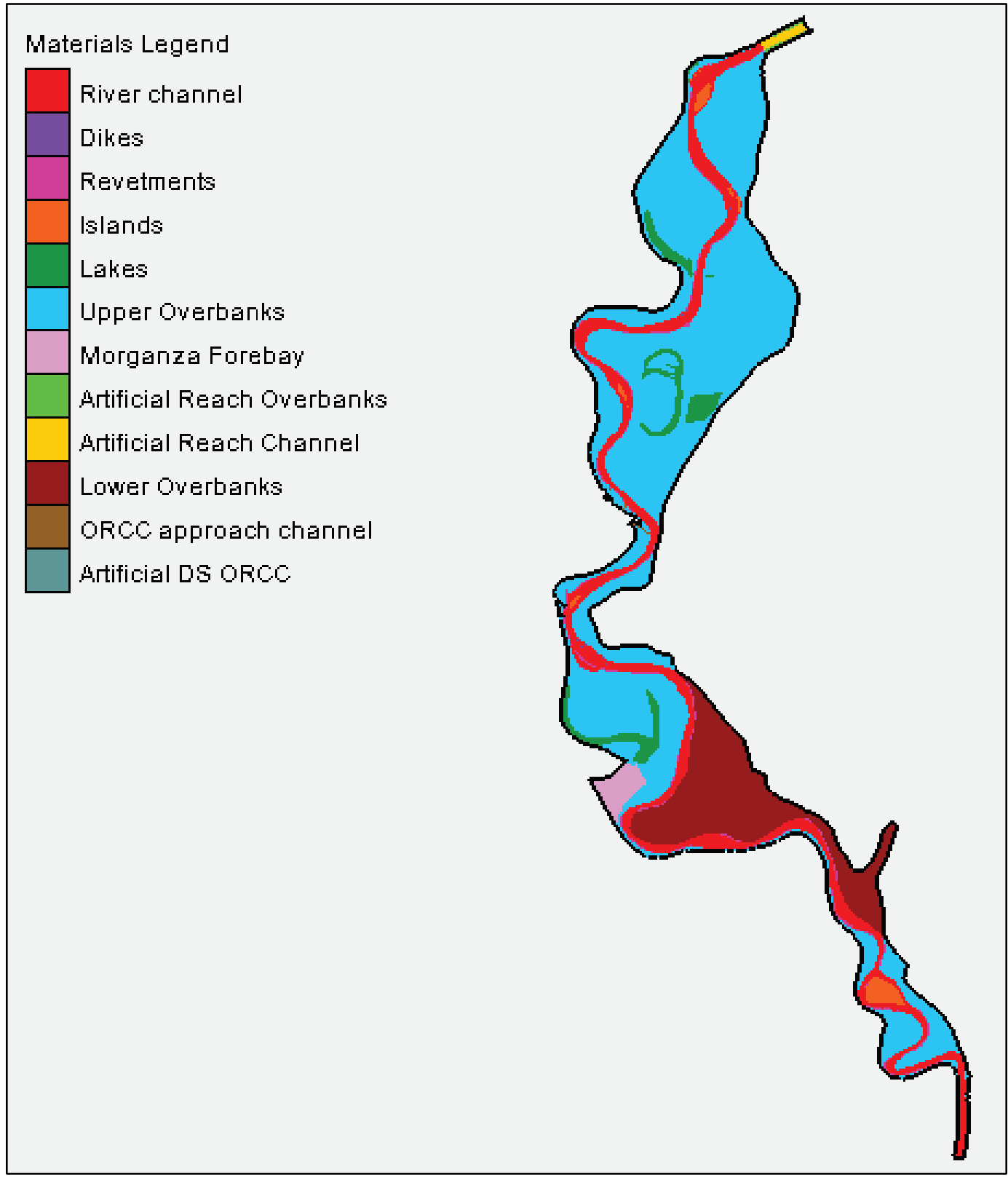

Second, a 2010 hydrograph (Figure 4-3) was simulated to check roughness values for a dynamic simulation. The time period of 4 May $2010-22$ September 2010 was selected as these stages and discharges represented a common range of conditions. Simulations included vorticity and adaption. 
Figure 4-3. 2010 hydrograph.

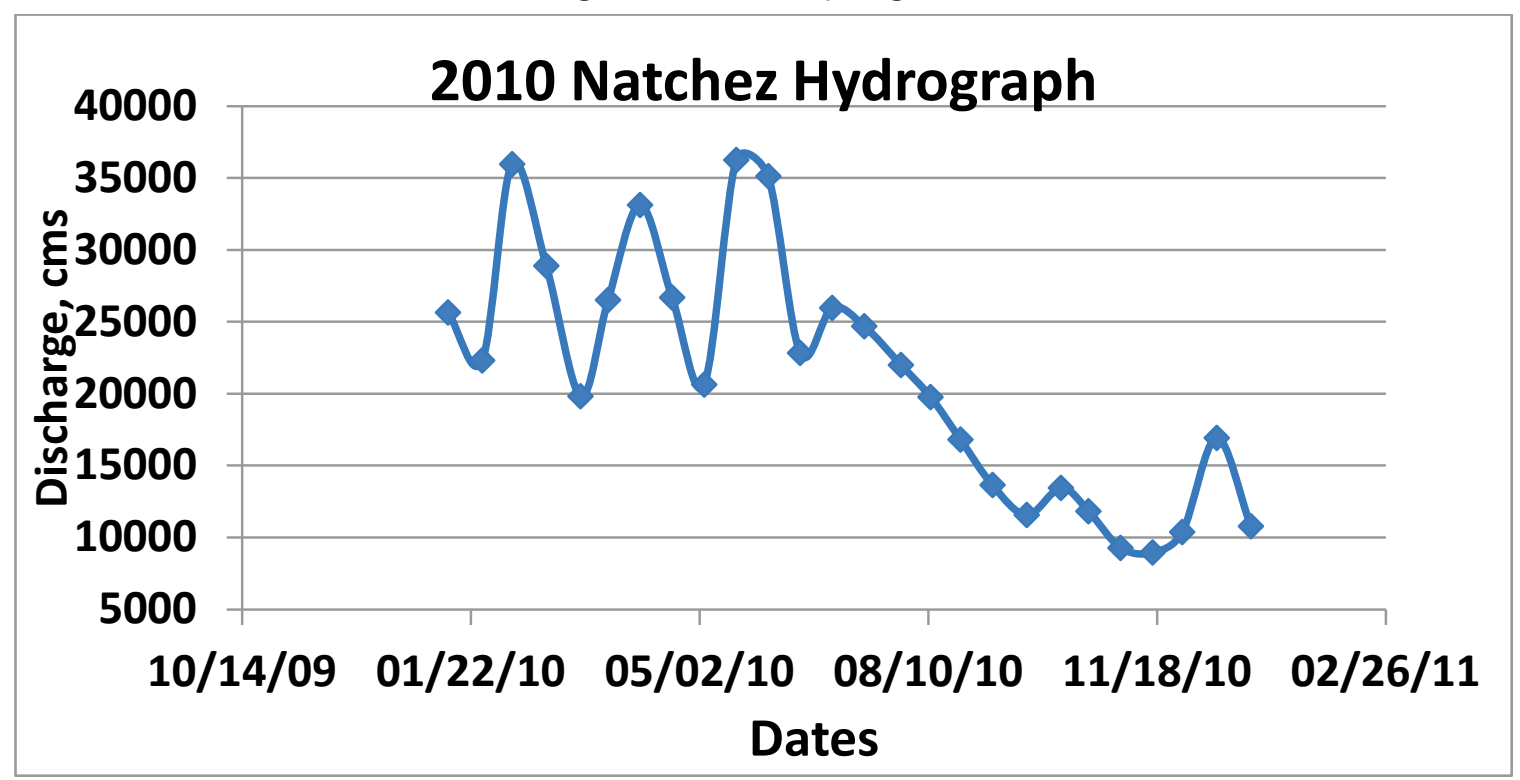

The calibrated Manning's $n$ roughness values (Figure 4-2) were specified as shown in Table 4-1.

Table 4-1. Frictional specification.

\begin{tabular}{|l|c|}
\hline Model Area & Manning's $n$-value \\
\hline Channel & 0.026 \\
\hline Dikes & 0.035 \\
\hline Revetments & 0.026 \\
\hline Islands & 0.11 \\
\hline Lakes in the floodplain & 0.02 \\
\hline Overbanks & 0.056 \\
\hline Morganza Forebay & 0.02 \\
\hline Artificial reach overbank & 0.056 \\
\hline Artificial reach channel & 0.026 \\
\hline Lower reach overbank & 0.0475 \\
\hline ORCC channels & 0.026 \\
\hline $\begin{array}{l}\text { Artificial downstrean ORCC } \\
\text { (nearfield of ORCC structures) }\end{array}$ & 0.026 \\
\hline
\end{tabular}


Using the roughness values in Table 4-1, the 2010 hydrograph was simulated and produced the following WSE plots (Figures 4-4 through 4-13) for each gage in the model domain. Note that rivergages.com did not provide a conversion to NAVD88 for the Natchez gage. For this gage, the mean of the field data was shifted such that the mean of the field matched the mean of the model. The remaining gages did have a reference to NAVD88, and as such, no shift was applied to these observations. The Baton Rouge gage had a gap in the data at the end of the simulation (after 30 August). This is the straight-line portion in Figure 4-12. During the lapse in data gap, the WSE at Baton Rouge gage location was calculated using the slope of WSE from St. Francisville (upstream gage) to Donaldsonville (downstream gage).

Figure 4-4. 2010 WSE plot: WSE vs. time for Natchez.

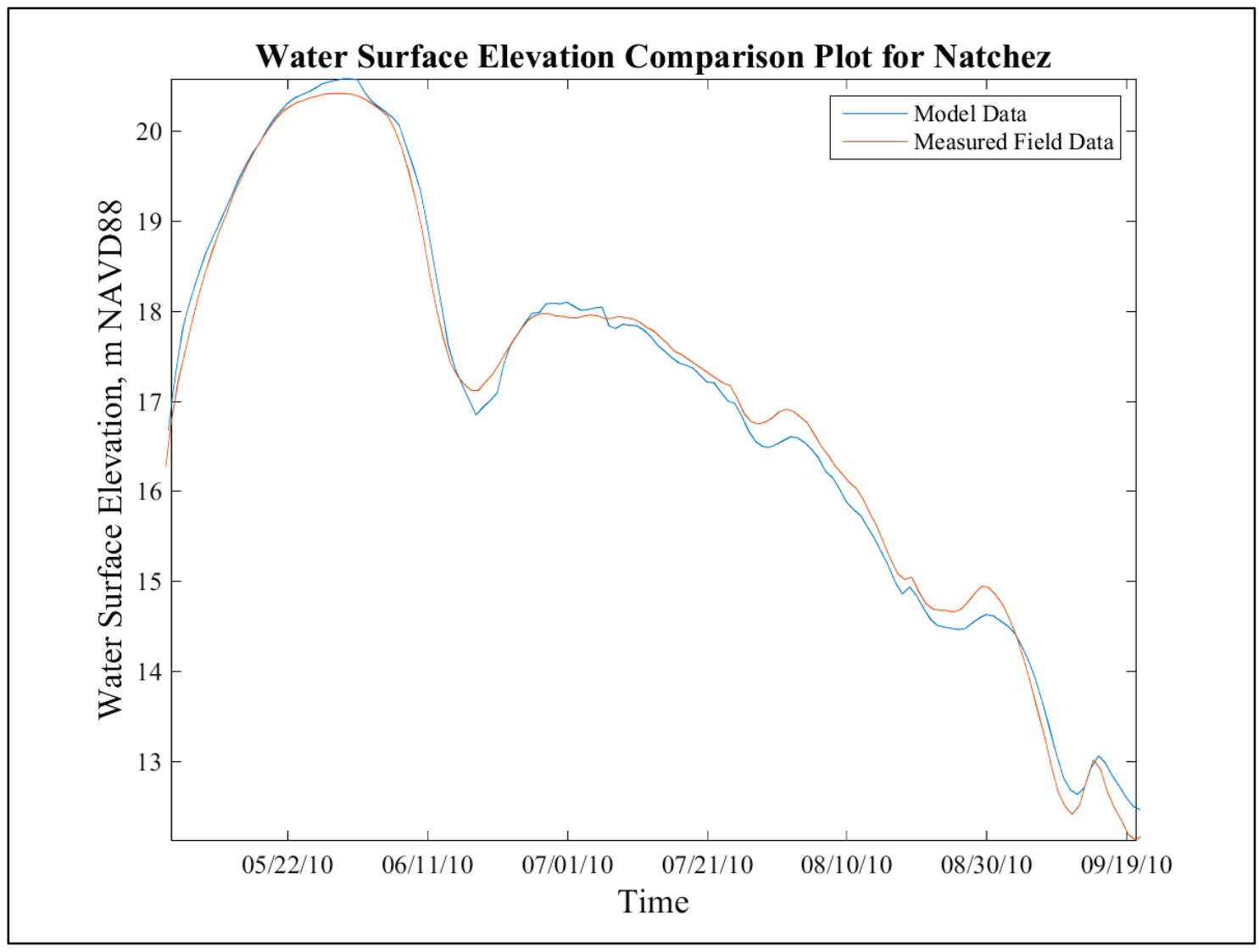


Figure 4-5. 2010 WSE plot: model vs. field for Natchez.

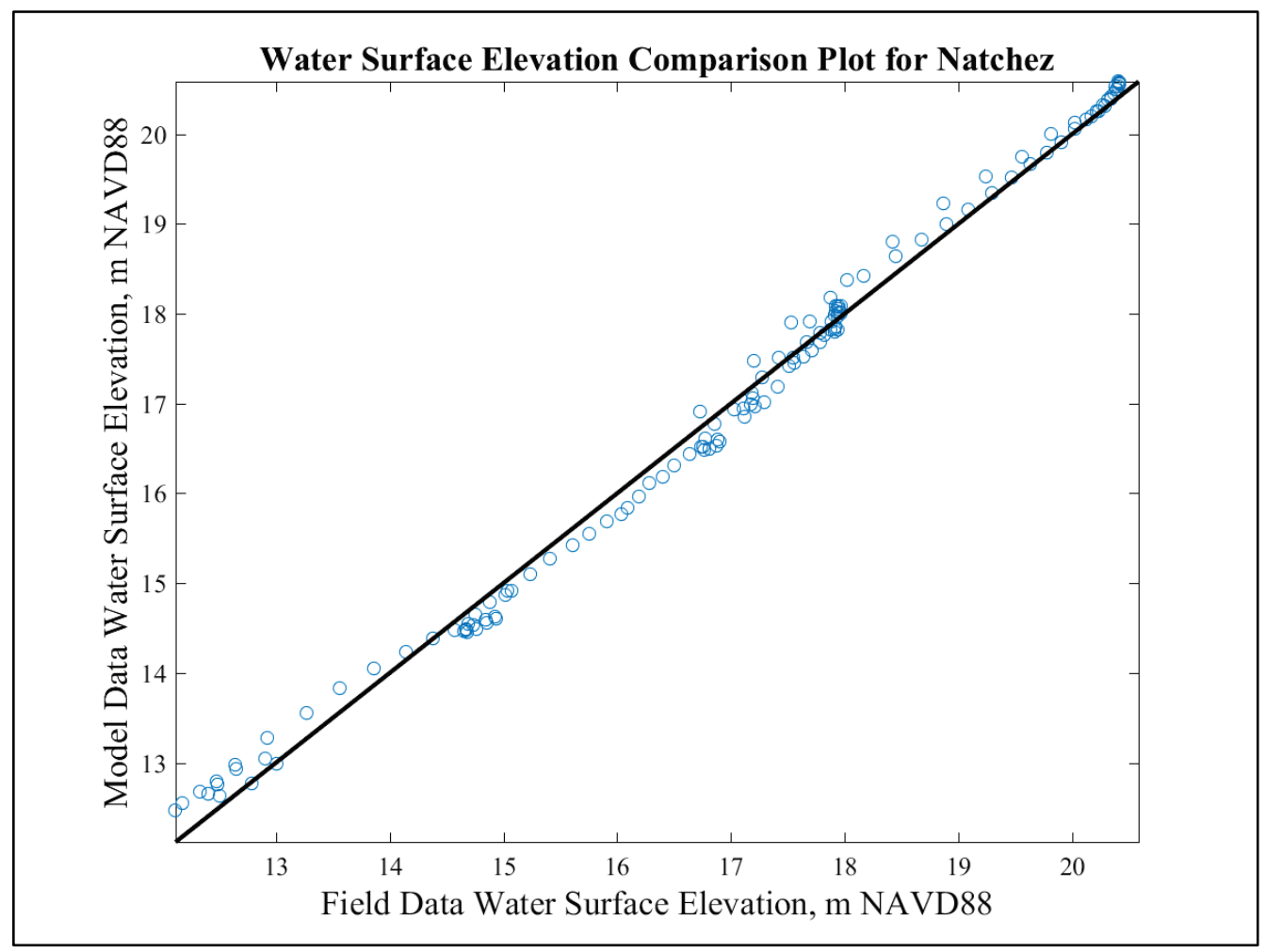

Figure 4-6. 2010 WSE plot: WSE vs. time for Red River Landing.

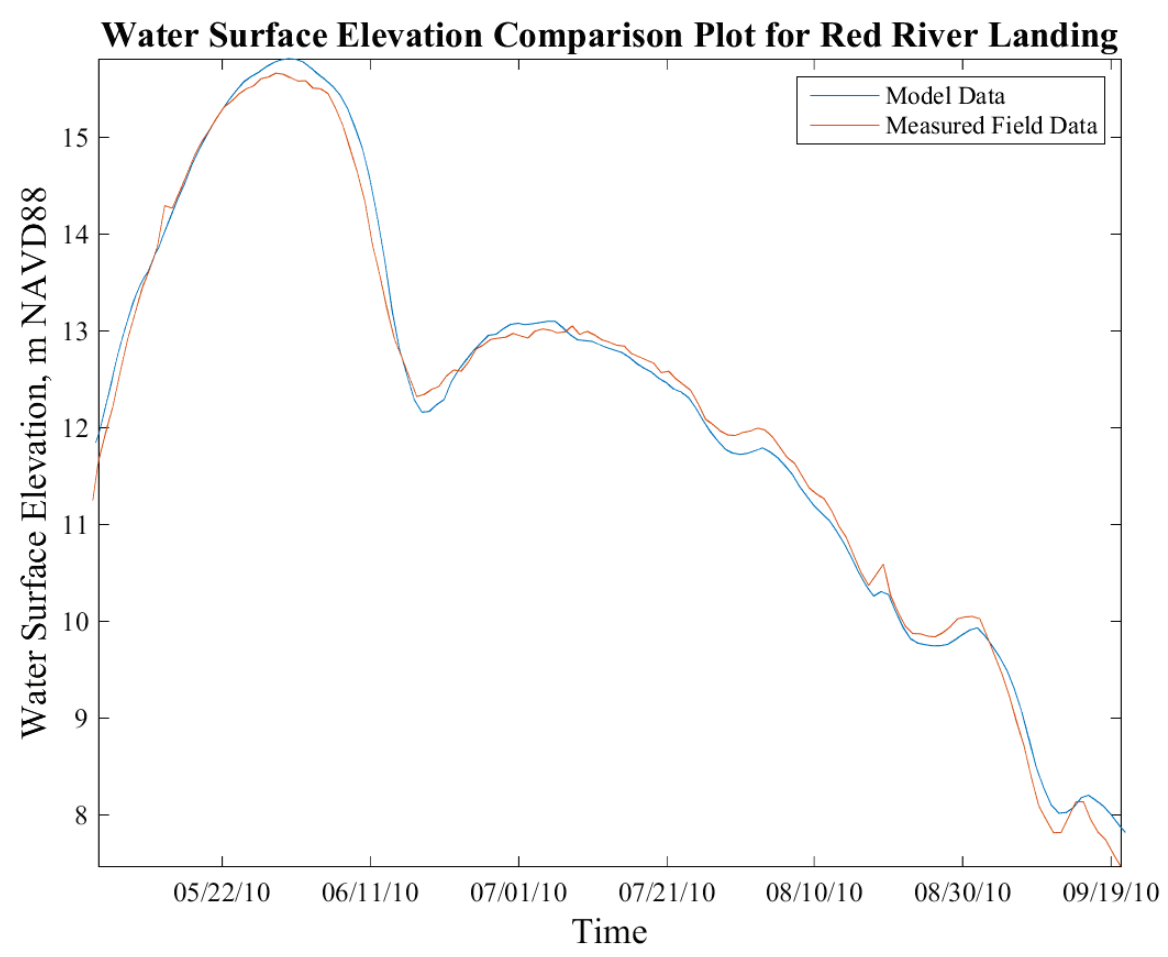


Figure 4-7. 2010 WSE plot: model vs. field for Red River Landing.

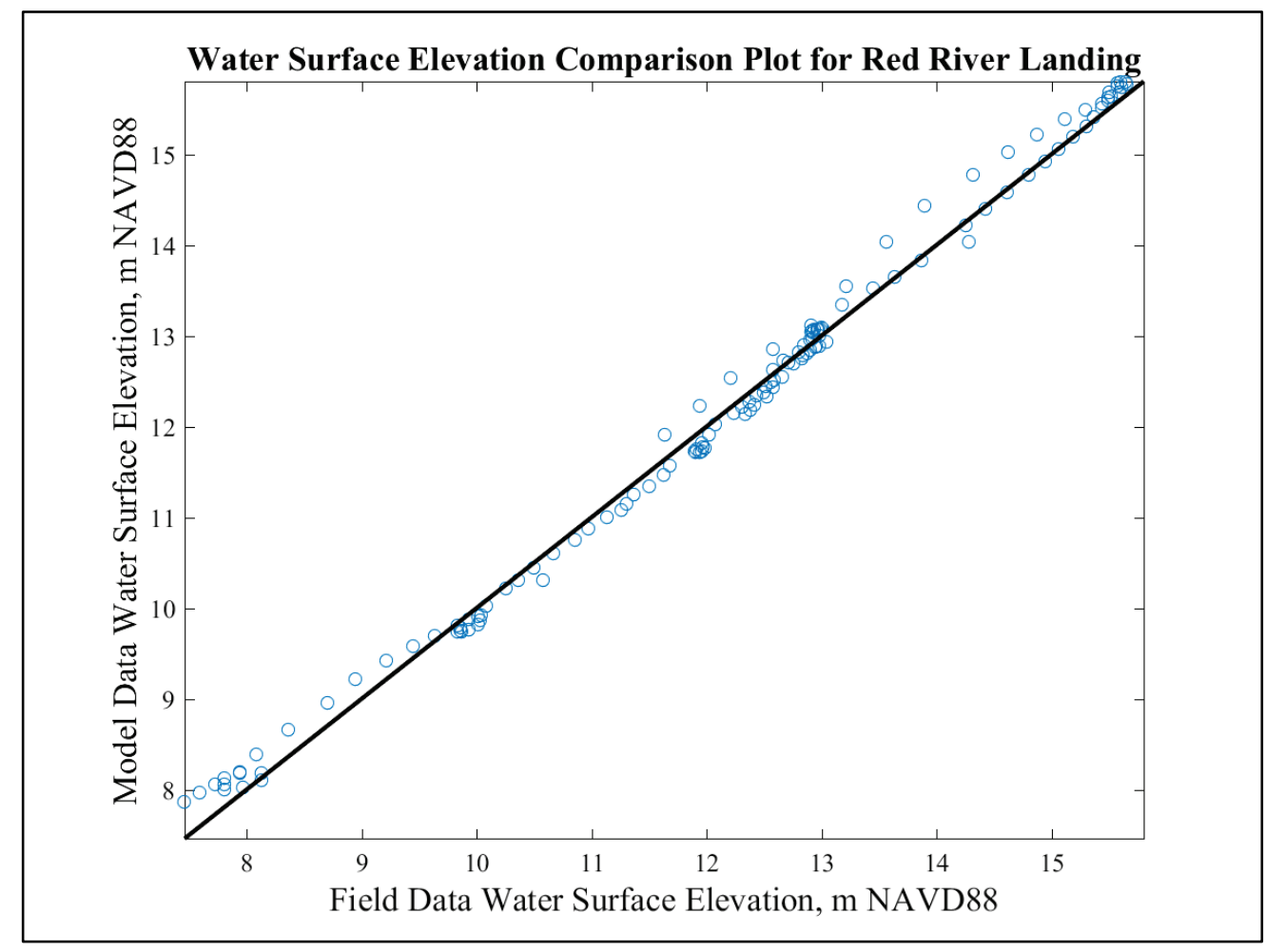

Figure 4-8. 2010 WSE plot: WSE vs. time for Bayou Sara.

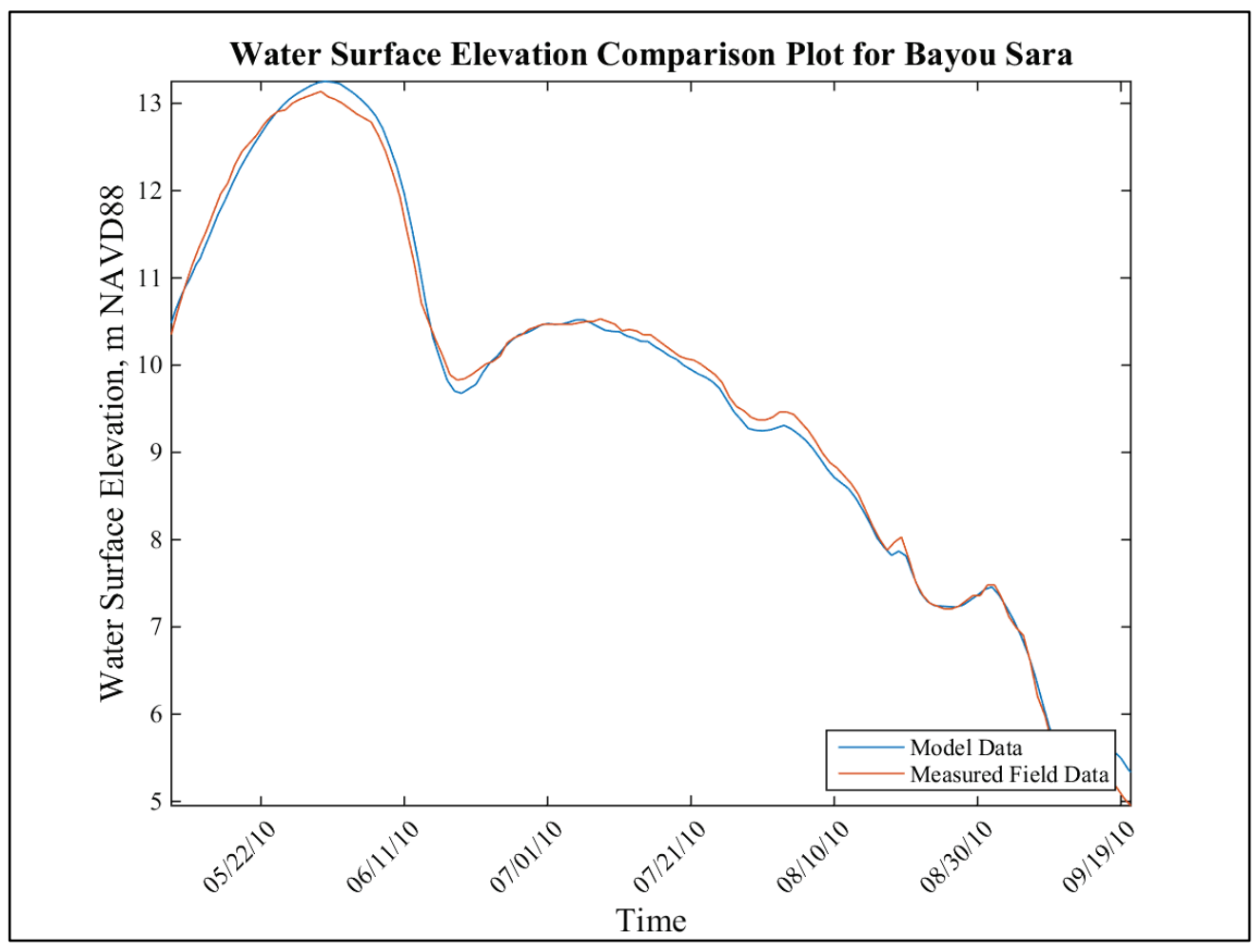


Figure 4-9. 2010 WSE plot: model vs. field for Bayou Sara.

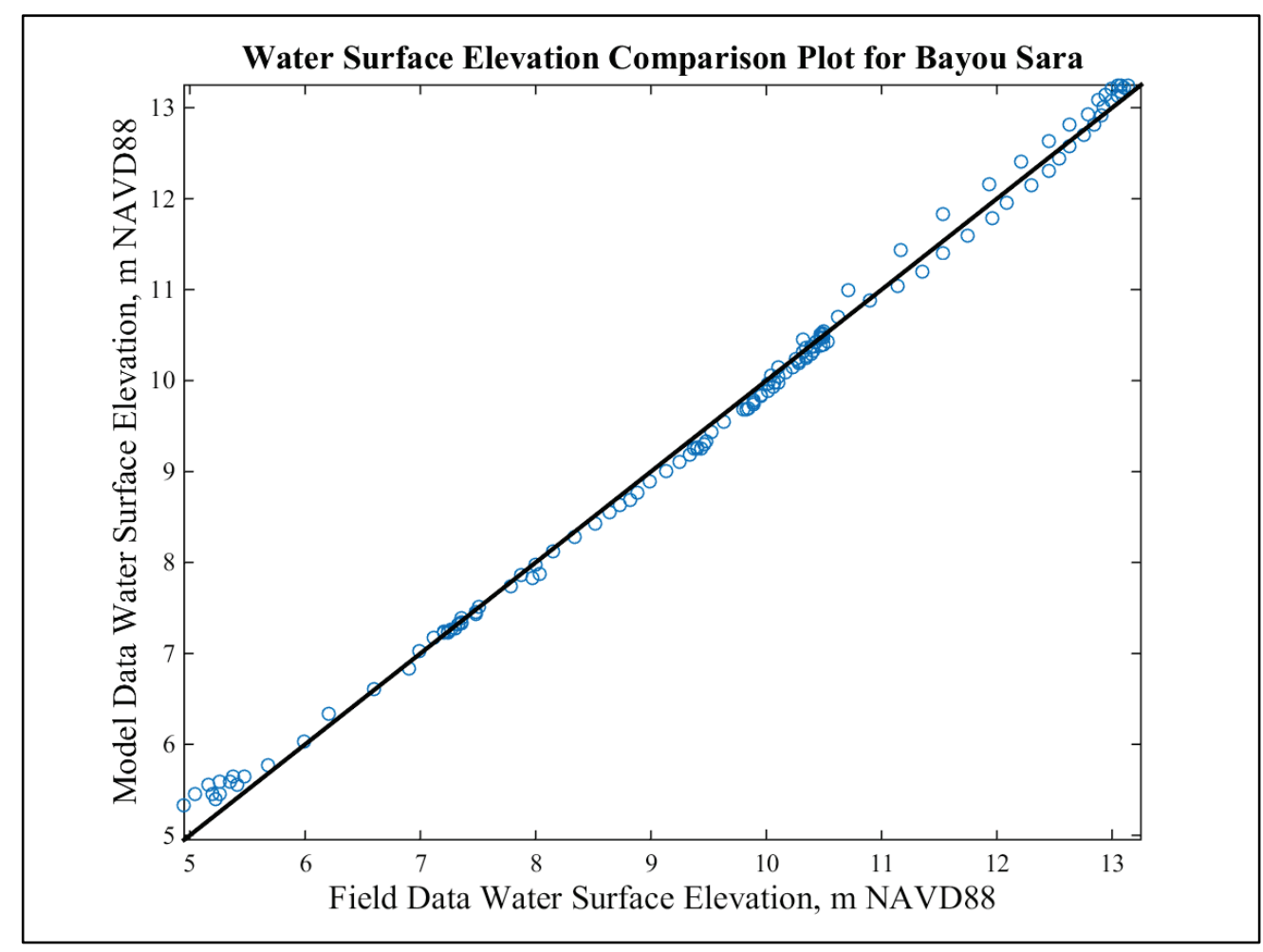

Figure 4-10. 2010 WSE plot: WSE vs. time for St. Francisville.

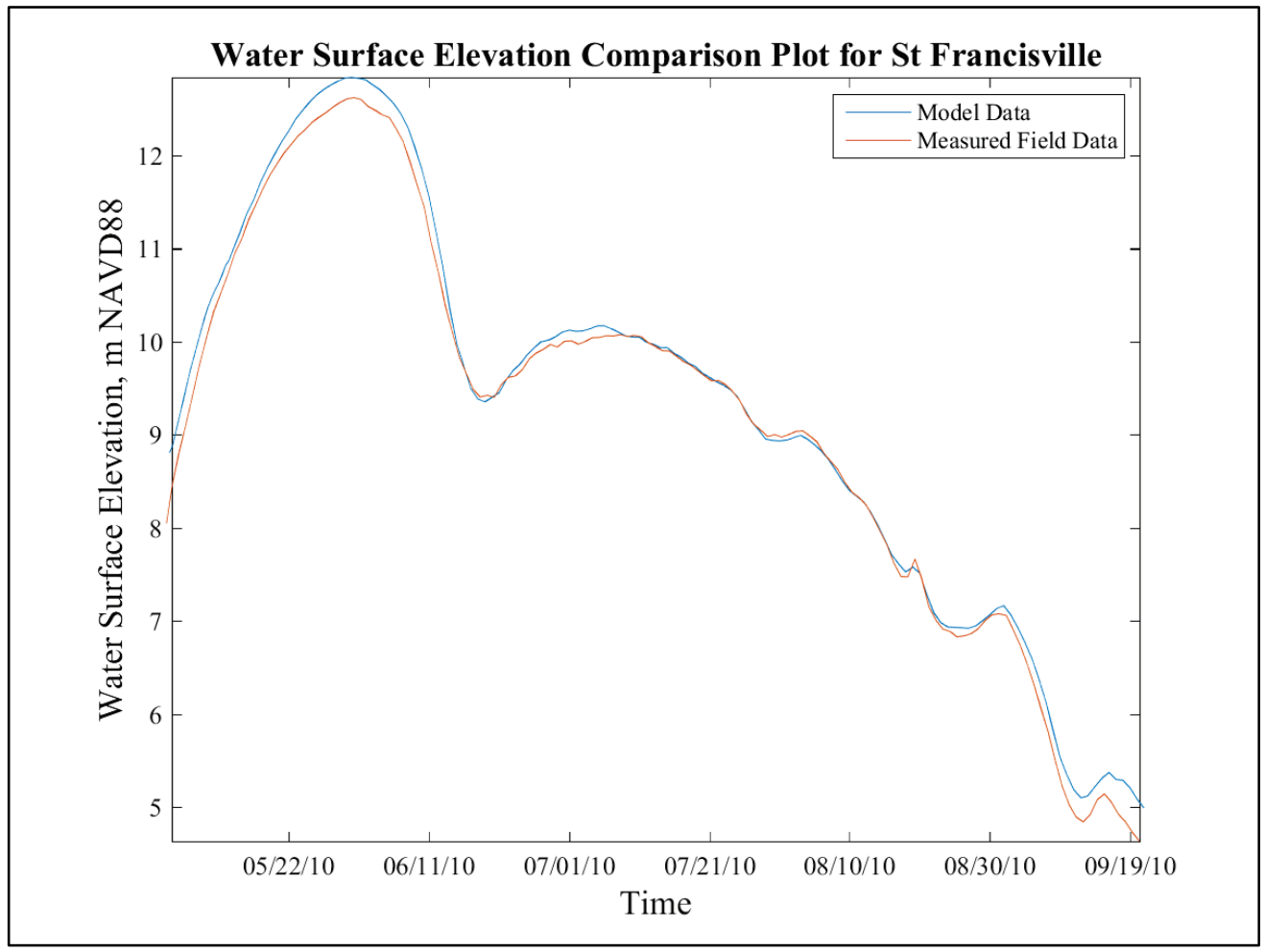


Figure 4-11. 2010 WSE plot: model vs. field for St. Francisville.

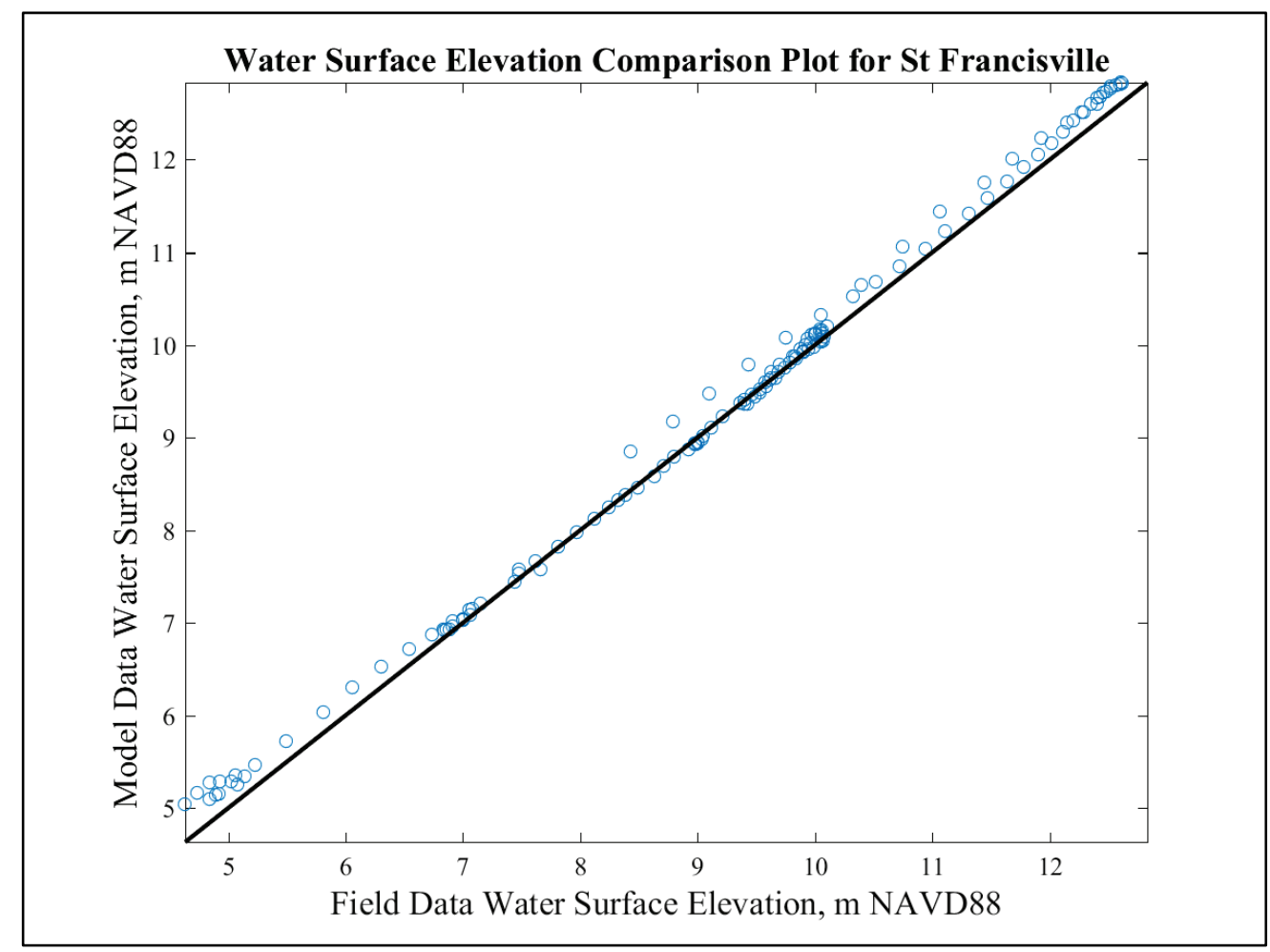

Figure 4-12. 2010 WSE plot: WSE vs. time for Baton Rouge.

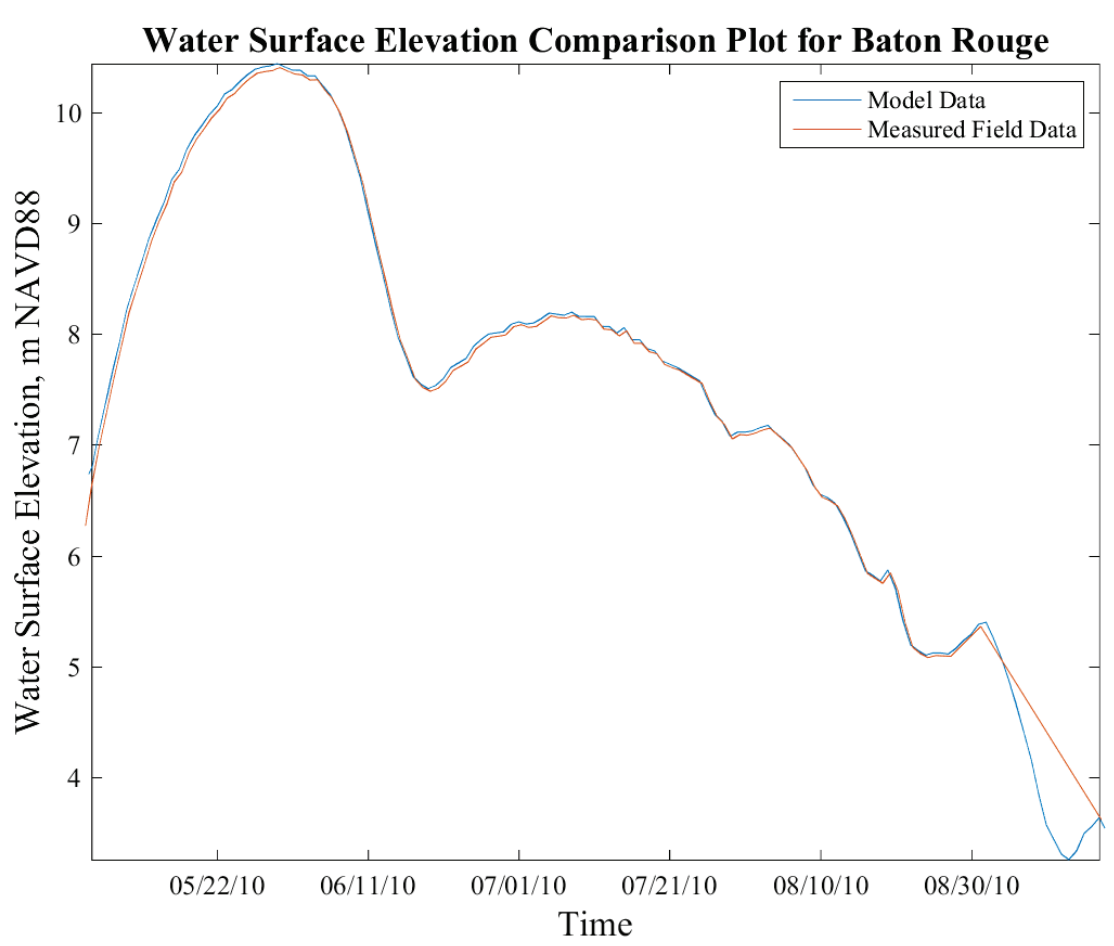


Figure 4-13. 2010 WSE plot: model vs. field for Baton Rouge.

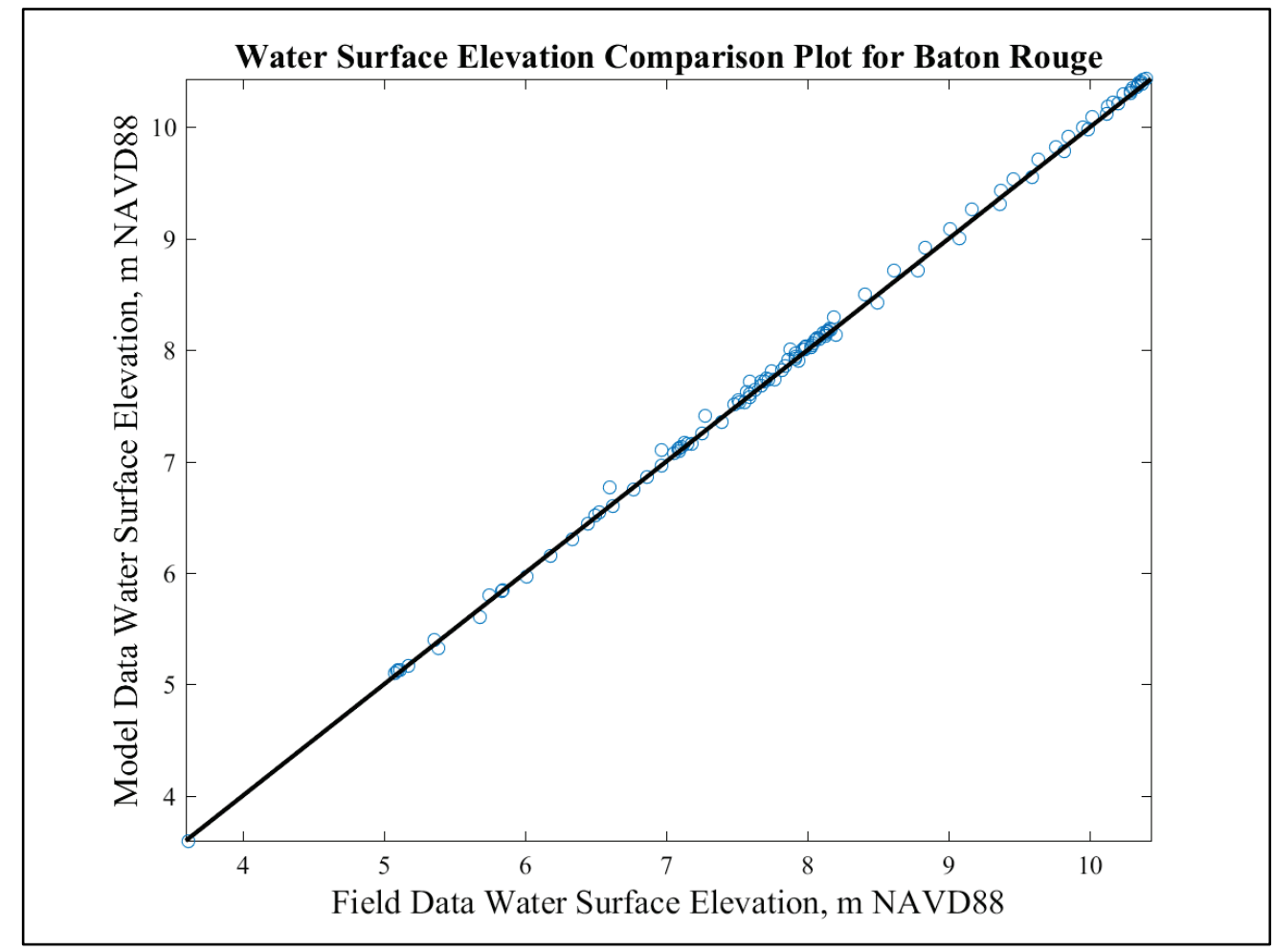

\section{Hydrodynamic validation}

The hydrodynamic validation was performed using the same parameters determined from the calibration simulations. The model validation compared modeled results to observed values of stage and discharge for 4 March 2011-28 July 2013 (hydrograph provided in Figure 4-14).

Figure 4-14. 2011-2013 hydrograph.

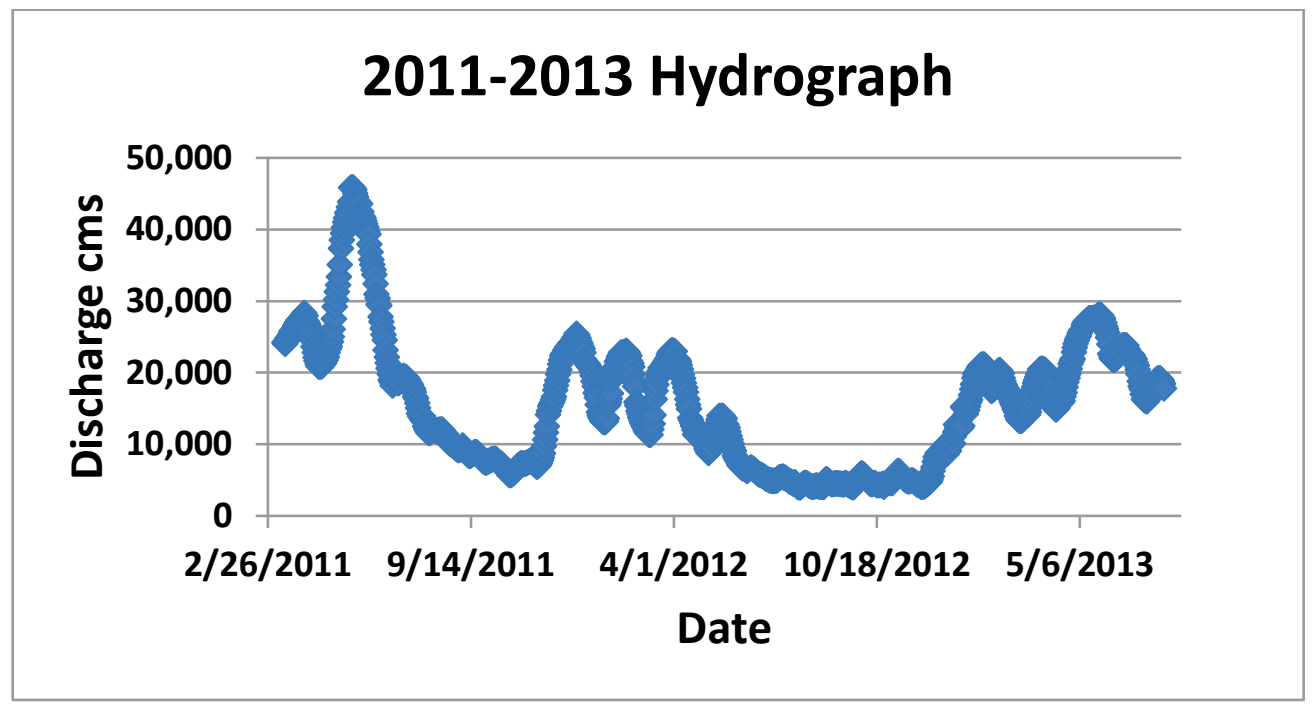


The 2011-2013 hydrograph was simulated and produced the following WSE plots (Figures 4.15 through 4.24) for each river gage in the model domain. Note that the Natchez gage did not include a conversion to NAVD88. For this gage the mean of the field data was shifted such that the mean of the field matched the mean of the model. The remaining gages did have a reference to NAVD88, and as such, no shift was applied to these gages.

Figure 4-15. 2011-2013 WSE plot: WSE vs. time for Natchez.

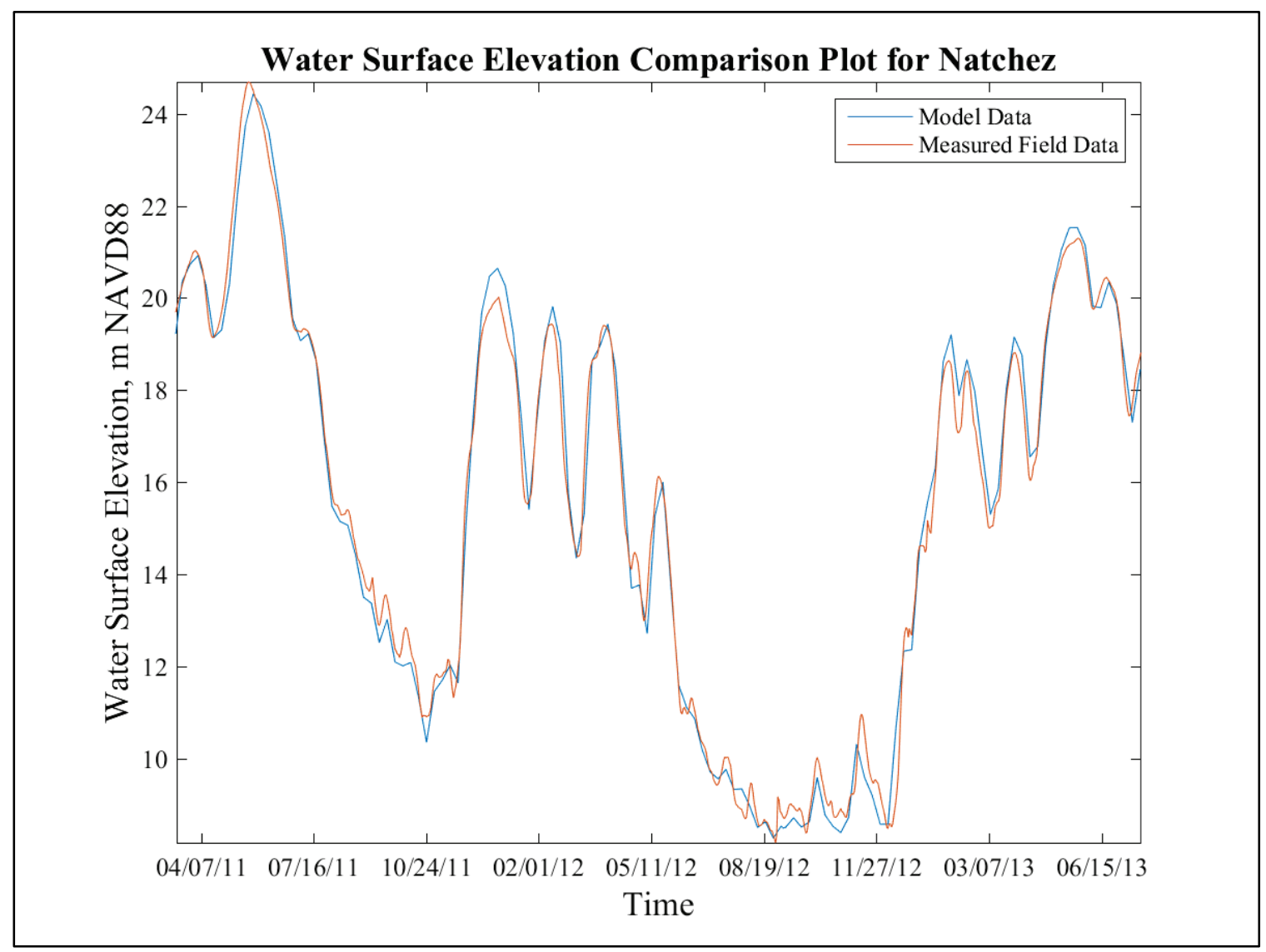


Figure 4-16. 2011-2013 WSE plot: model vs. field for Natchez.

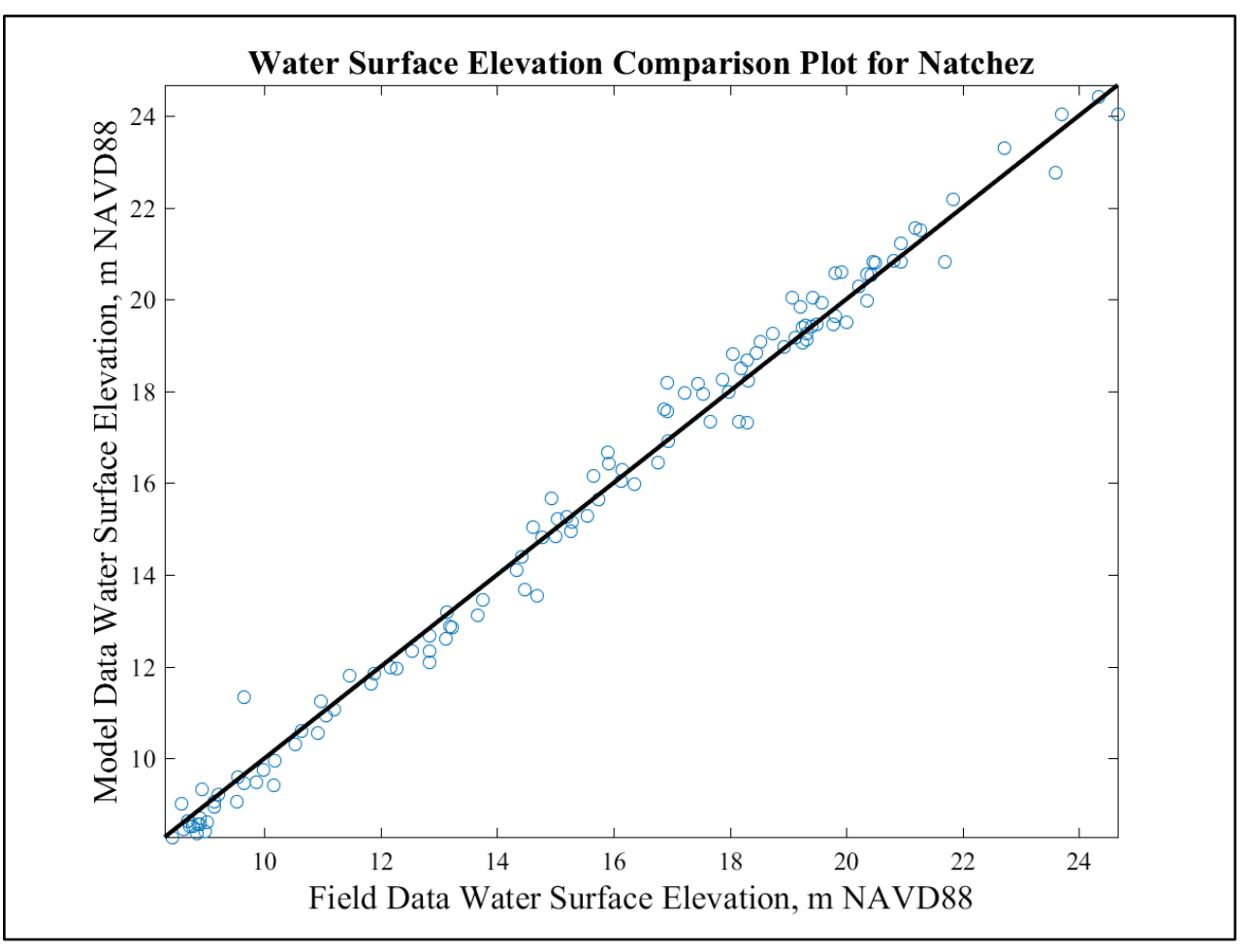

Figure 4-17. 2011-2013 WSE plot: WSE vs. time for Red River Landing.

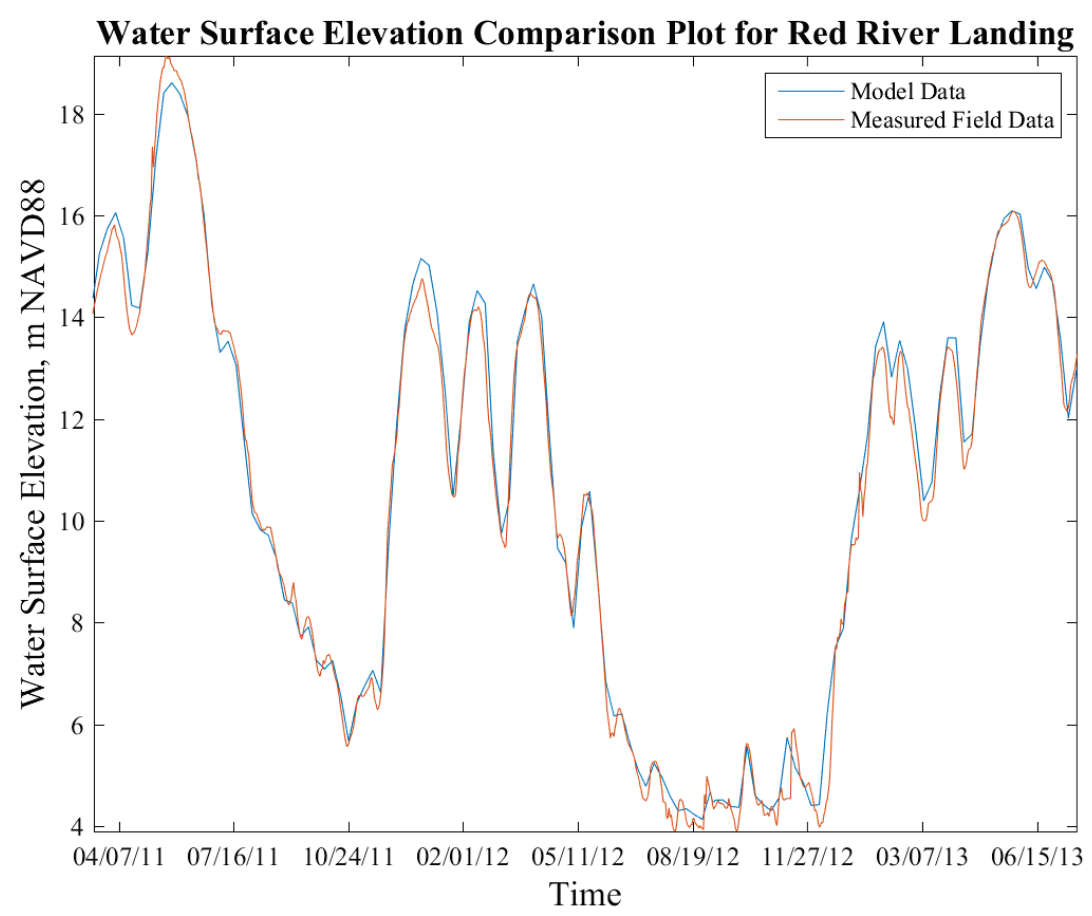


Figure 4-18. 2011-2013 WSE plot: model vs. field for Red River Landing.

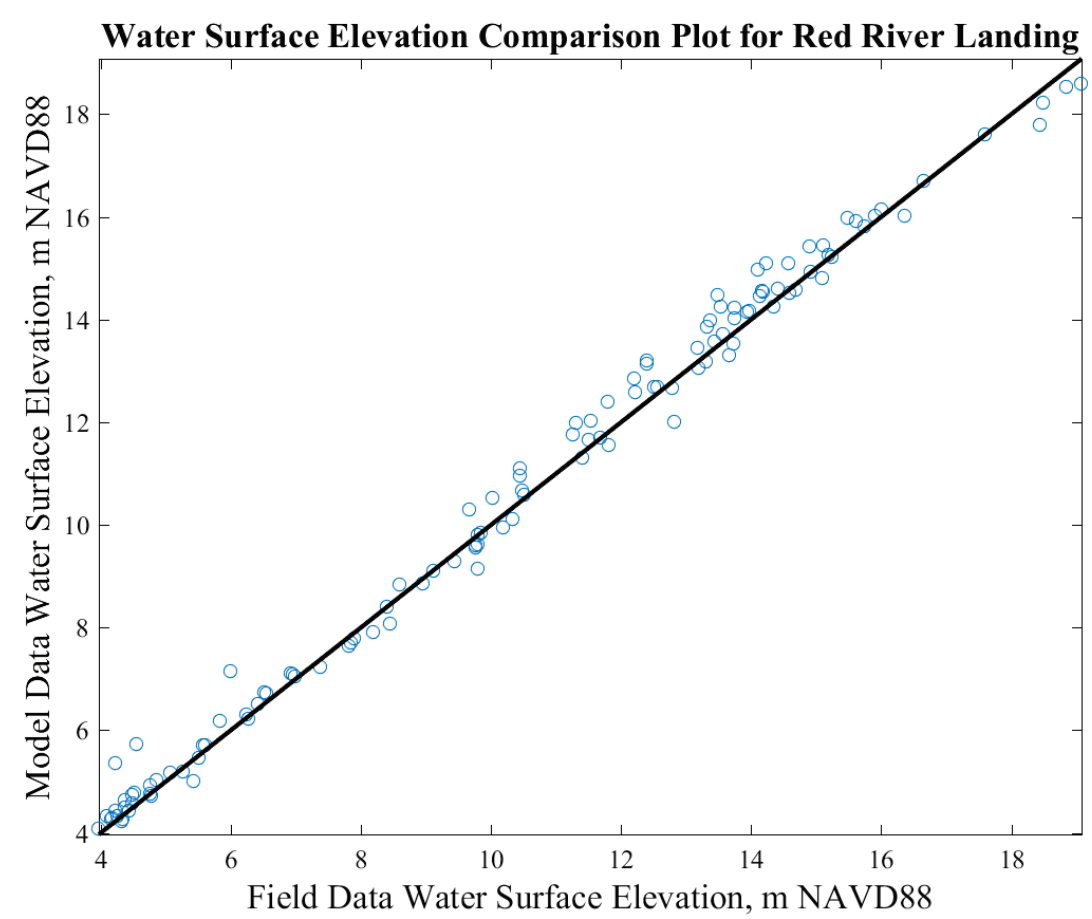

Figure 4-19. 2011-2013 WSE plot: WSE vs. time for Bayou Sara.

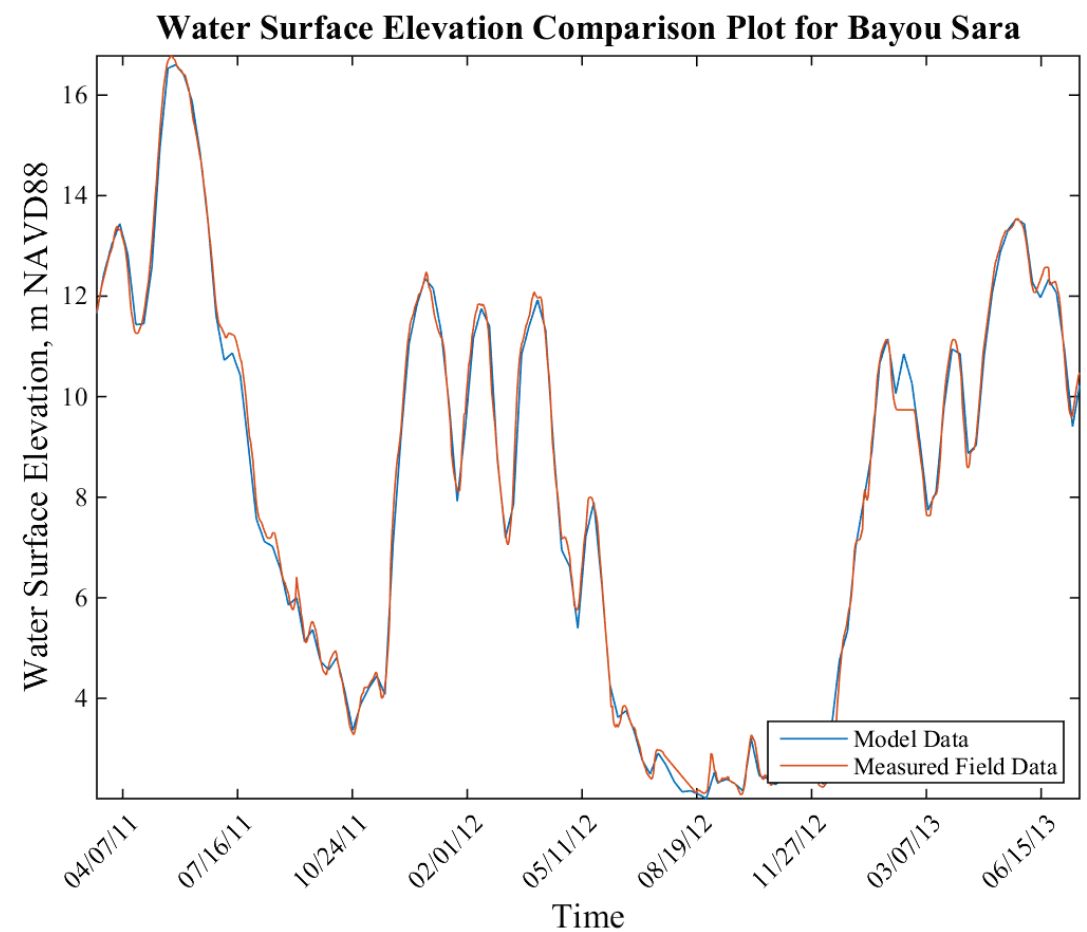


Figure 4-20. 2011-2013 WSE plot: model vs. field for Bayou Sara.

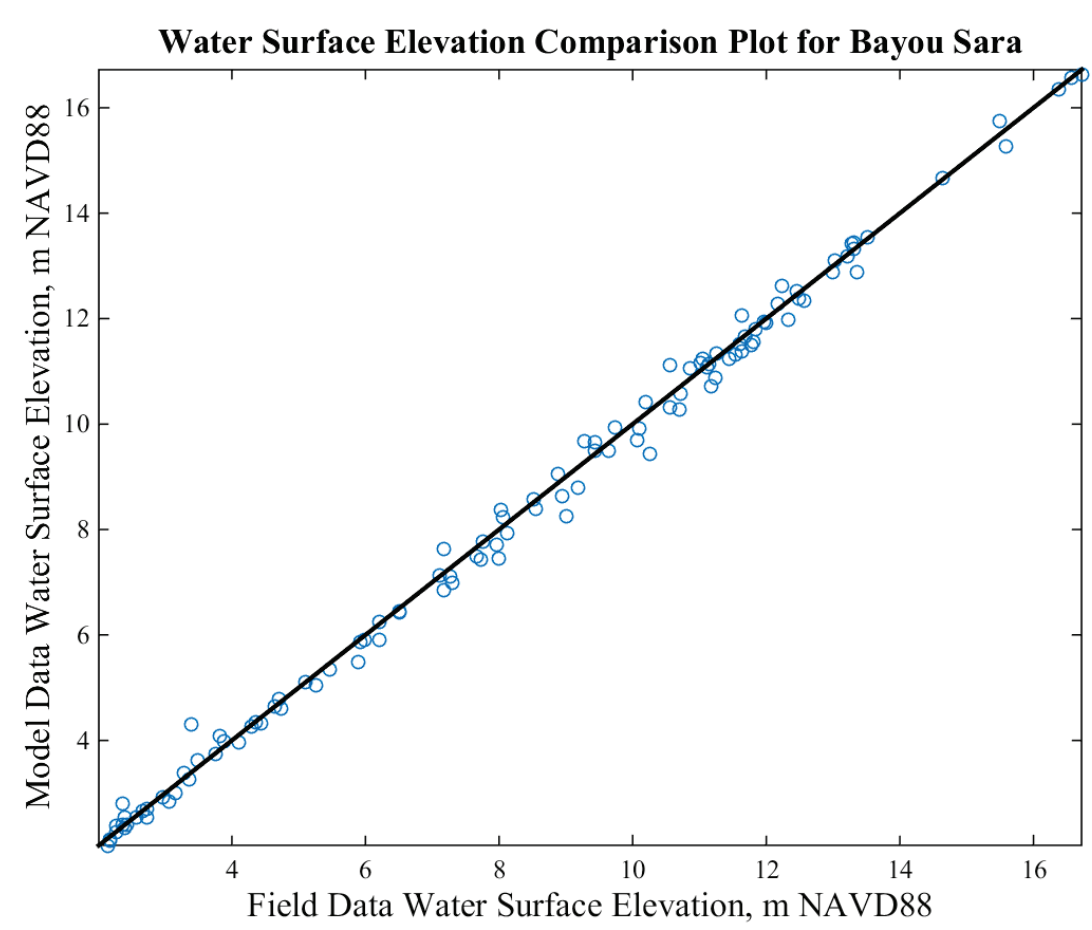

Figure 4-21. 2011-2013 WSE plot: WSE vs. time for St. Francisville.

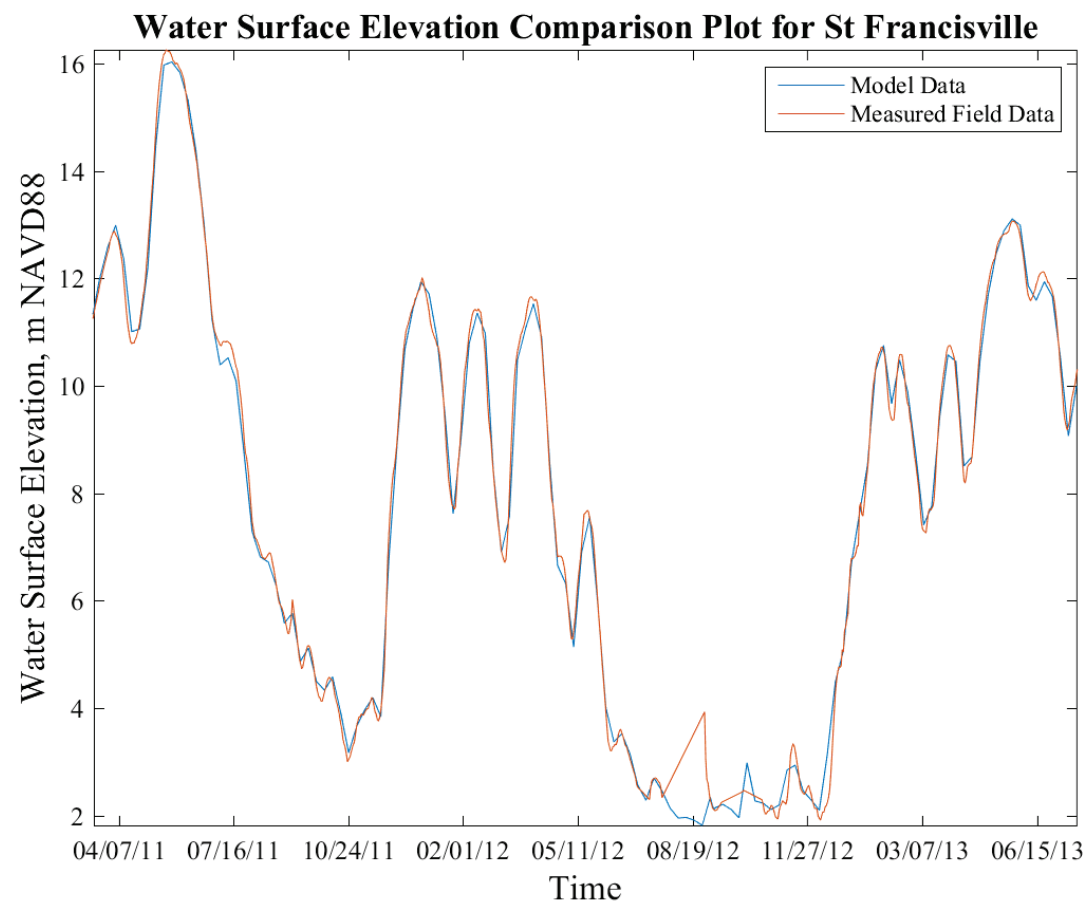


Figure 4-22. 2011-2013 WSE plot: model vs. field for St. Francisville.

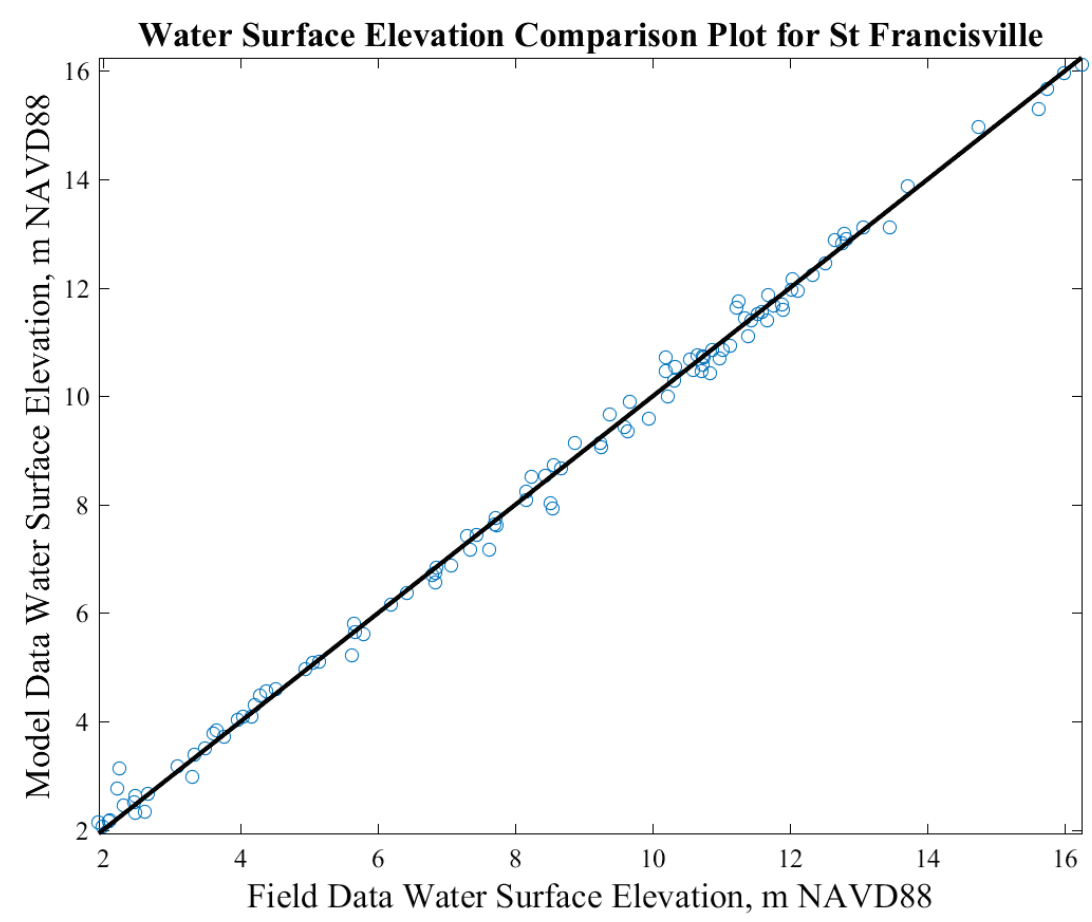

Figure 4-23. 2011-2013 WSE plot: WSE vs. time for Baton Rouge.

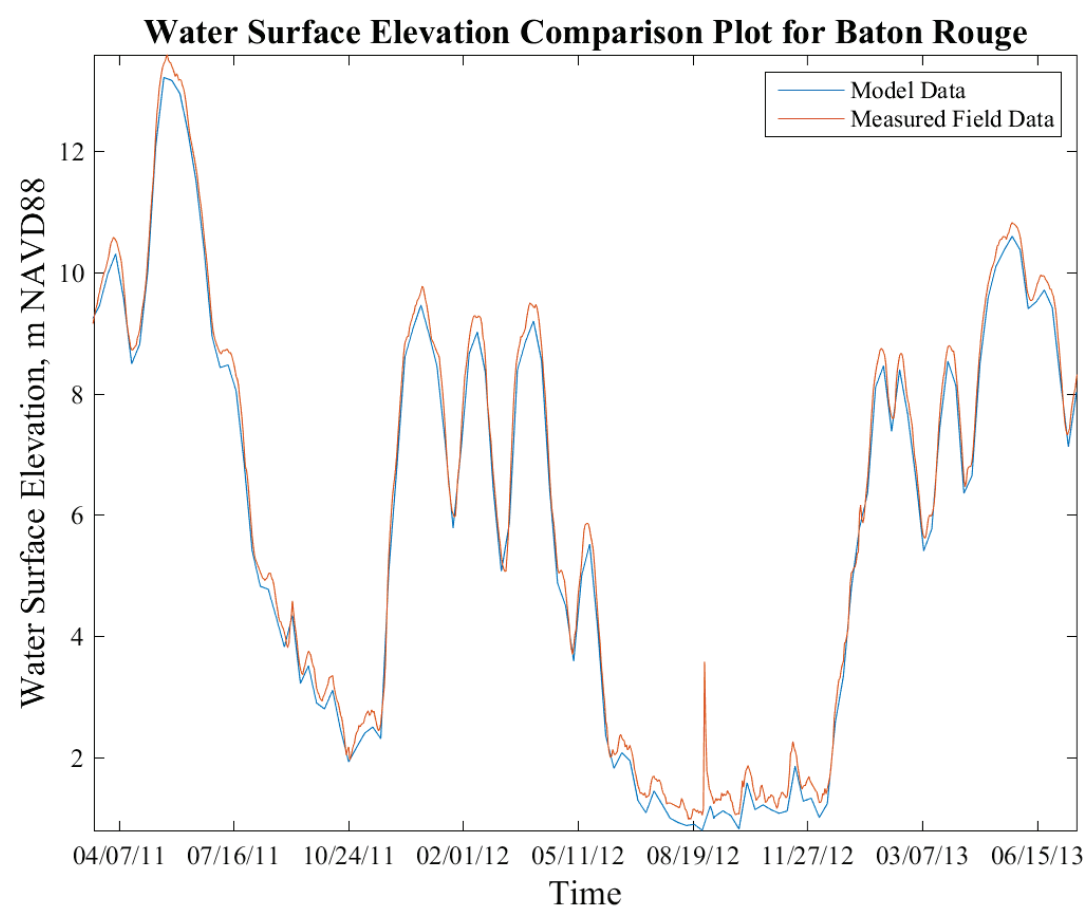


Figure 4-24. 2011-2013 WSE plot: model vs. field for Baton Rouge.

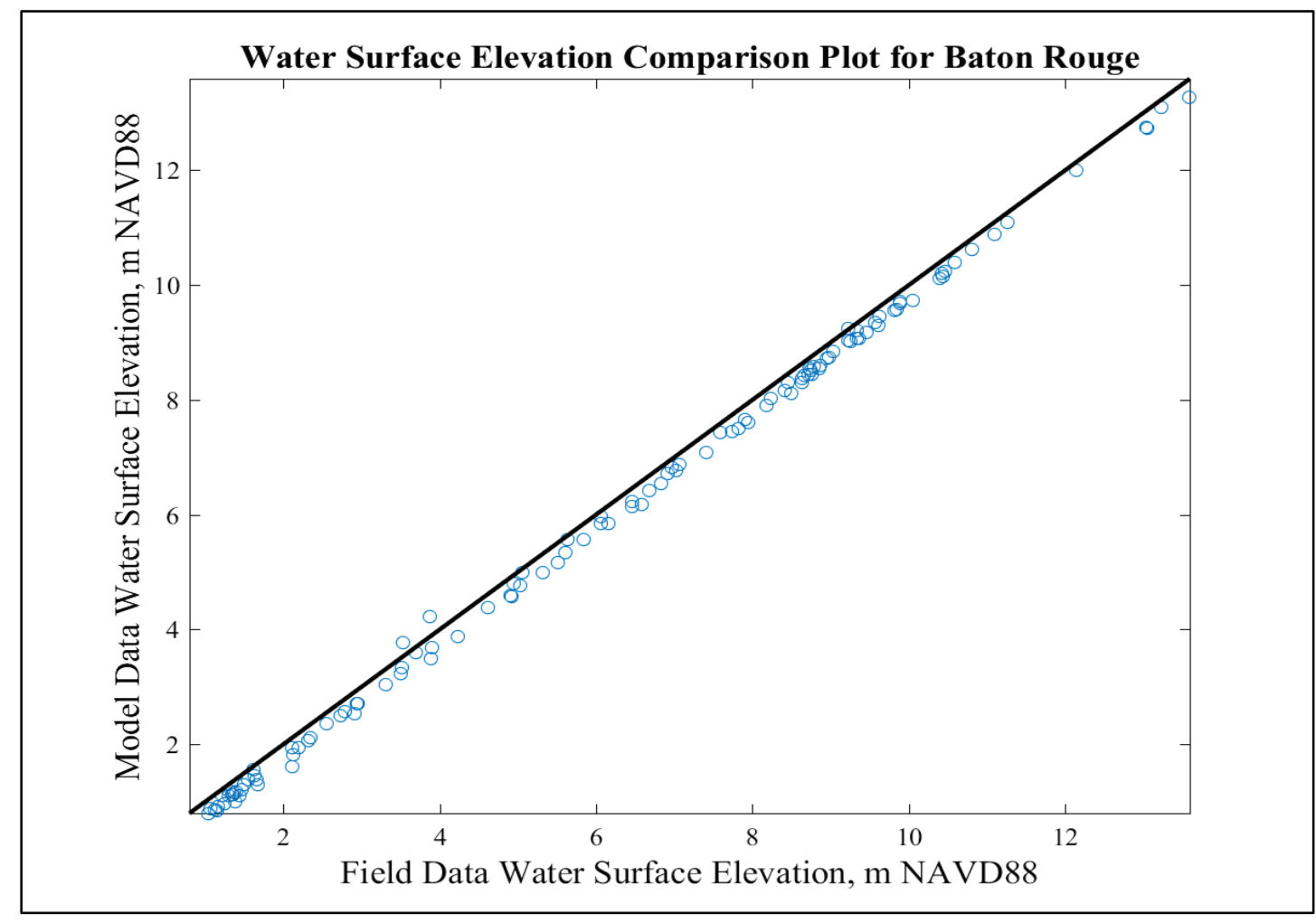

The relative roughness values for the channel and floodplain result in accurate water levels, but without acoustic Doppler current profiler (ADCP) velocity/discharge comparisons, the flow split between the floodplain and main channel may or may not be accurate.

\section{Low water profile}

An extreme drought occurred between April and November 2012. Due to the rare occurrence of such an extreme low water event, water level profile measurements were taken. Figure 4-25 shows a comparison of the model and field longitudinal WSE profiles. The 2012 low-water profile survey data on the Mississippi River were collected using an Applanix POS_MV system mounted on a $21 \mathrm{ft}$ long survey boat capable of speeds up to 40 miles per hour. The vertical data were converted to NAVD88 using the National Geodetic Survey conversion package GEOID 12A. CHL personnel collected a water surface profile on the Mississippi River from 4 to 6 September 2012. Data collection began at the mouth of the White River at RM 600 and continued to below New Orleans at RM 88. The domain reach was surveyed on 5 September 2012. While the field profile was collected over a day, the model profile is an instantaneous value at noon on 5 September 2012. 
Figure 4-25. 2012 Low water profile.

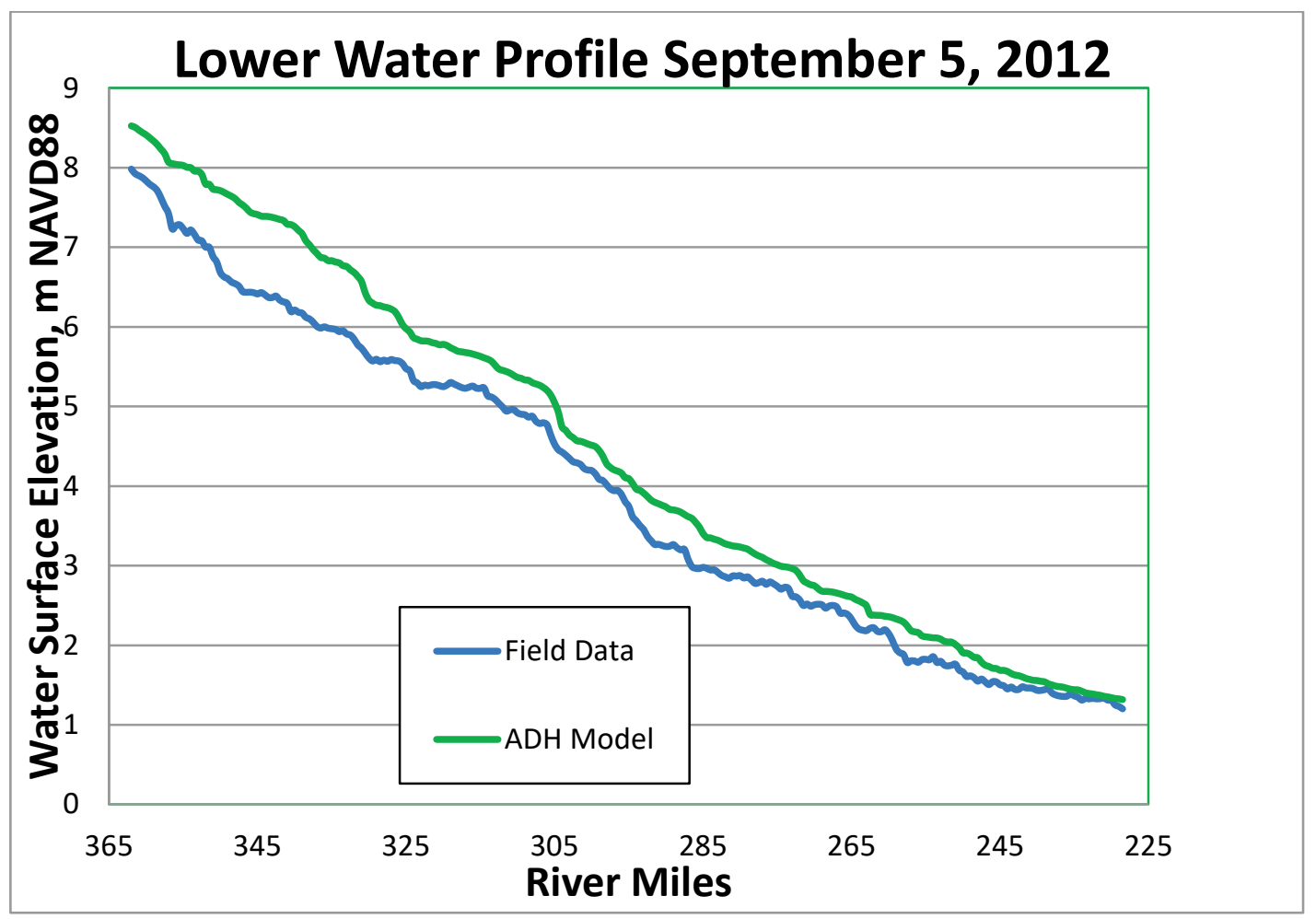

The WSE in Figure 4-25 was for an extreme drought condition. AdH does overestimate the WSE profile for extreme low water conditions. For the lower half of the model, the overestimation by AdH is less usually less than $0.5 \mathrm{~m}$, but the upper reach has overestimated values of as much as $1.0 \mathrm{~m}$. The overestimation is expected to be primarily due to some combination of the channel friction and the dikes. While the influence of any error in the specification of these two parameters is negligible at higher water levels, it becomes more important during extreme low flow conditions. This is expected to have minimal impacts on the longer-term bed evolution. Additional effort should be expended improving these comparisons before utilizing this model to analyze impacts during extreme drought conditions. 


\section{Sediment Transport}

The sediment transport model was not calibrated. The bed gradations and initialization, and the sediment boundary conditions, were determined according to the protocol discussed in Chapter 3. Once these were established, the model was simulated for 14 March 2011 to 28 July 2013 and compared to observed data. There was no adjustment of coefficients as there were limited data to justify any significant modification of model parameters and the purpose of this study was to analyze the impact of the various transport options.

\section{Single beam sediment survey data}

MVK is responsible for the area from RM 363 to 324 (Natchez to the vicinity of ORCC). This reach of the Mississippi River was surveyed using single beam survey data every year and every 2 miles of river. The exception being 2012 when the river experienced an extreme drought at which time the MVK engineers ordered the previously discussed low-water profile instead of the normal cross-sectional surveys.

The single beam survey data were input into the model and interpolated to the mesh to compare to model sediment deposition/erosion patterns and amounts. Figure 5-1 is the difference in the 2013 and 2011 single beam survey data from RM 360 to RM 355. Figure 5-2 shows the model bed change for the same reach over the same time period. Figures $5^{-1}$ and 5-2 and Figures 5-3 and 5-4 depict the comparisons between modeled and observed bed change. There is a tendency for the model to overpredict deposition and erosion but in general does replicate the patterns of deposition and erosion. The model appears to be more accurate for RM 360 to RM 345 and less accurate RM 345 to RM 320. These figures show the difference from 2013 to 2011. Additional plots for the entire reach between Natchez (RM 363) and ORCC (RM 324) are presented in Appendix A. 
Figure 5-1. Difference in 2013 and 2011 single beam survey data from RM 360 to RM 355.

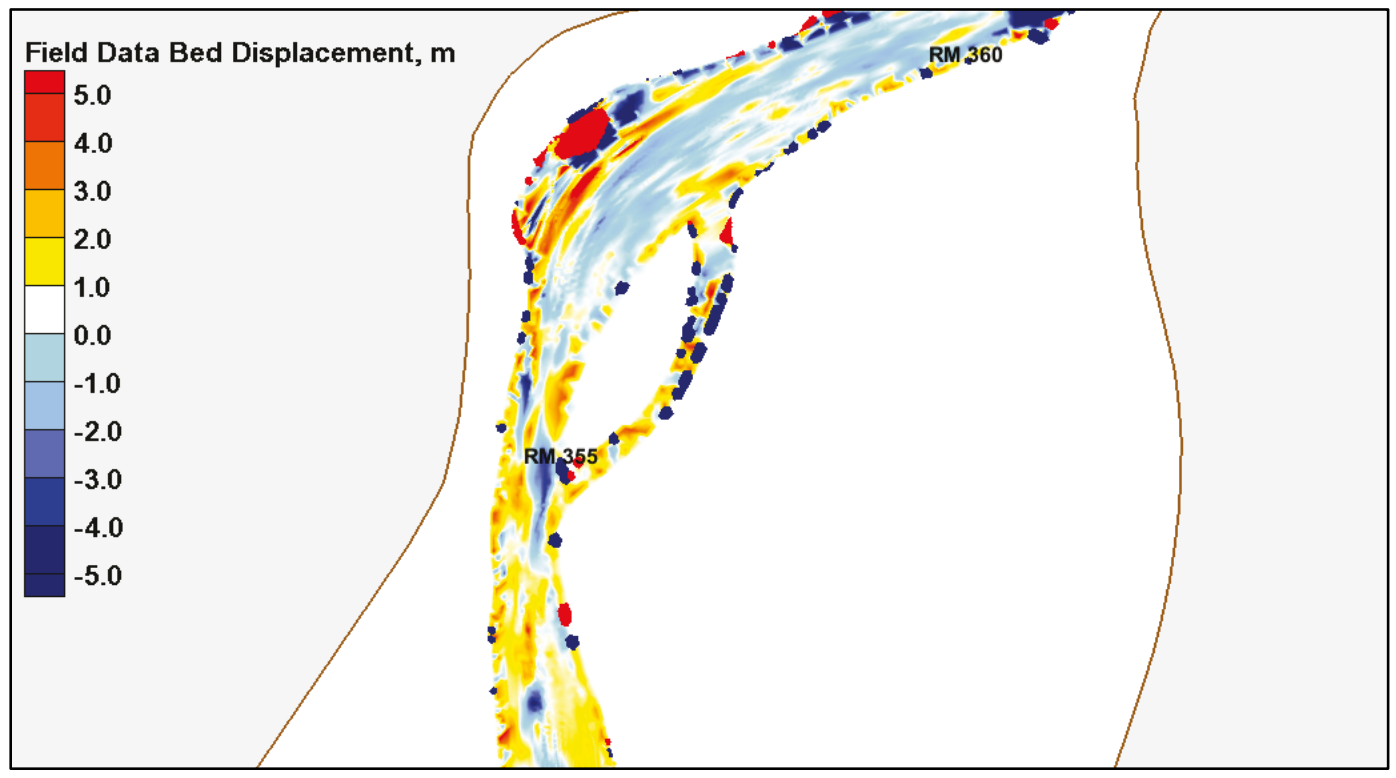

Figure 5-2. Difference in 2013 and 2011 model results from RM 360 to RM 355.

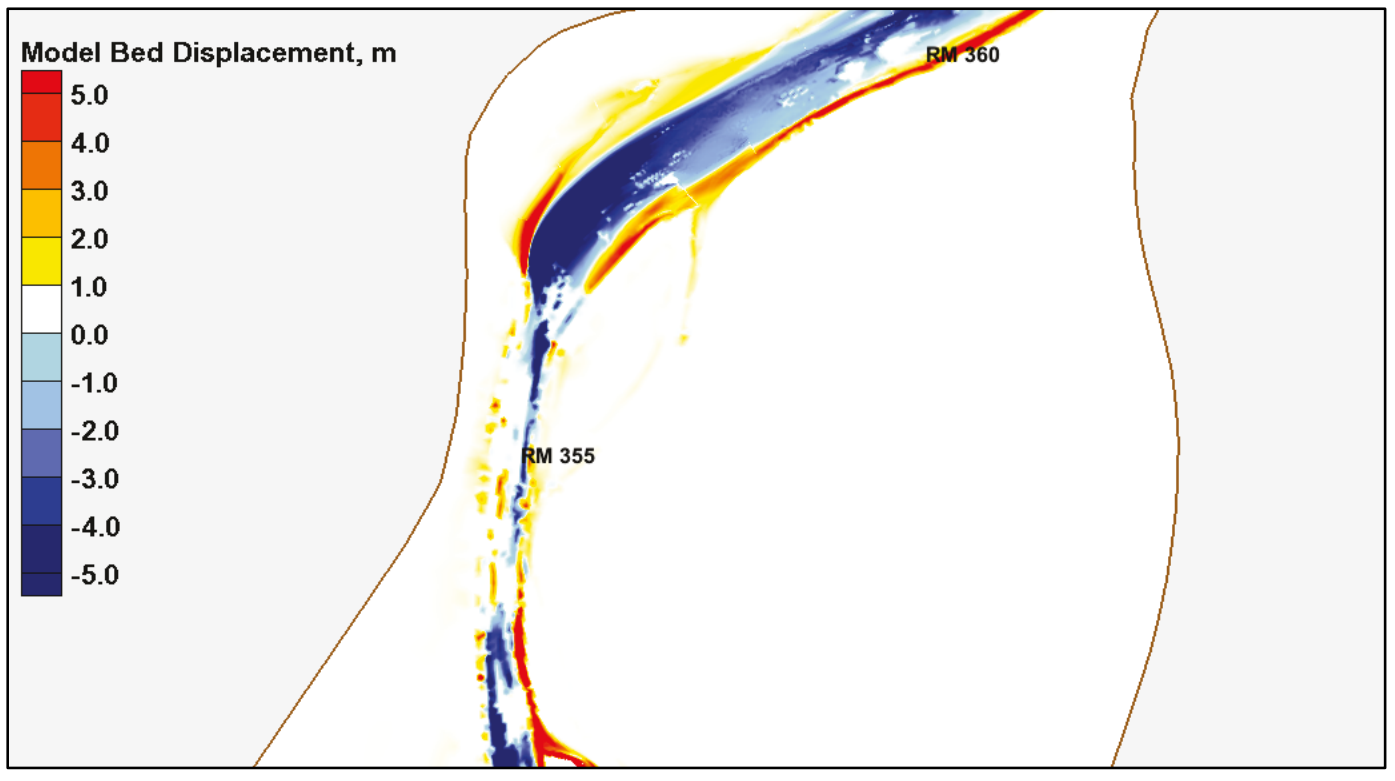


Figure 5-3. Difference in 2013 and 2011 single beam survey data from RM 335 to RM 320.

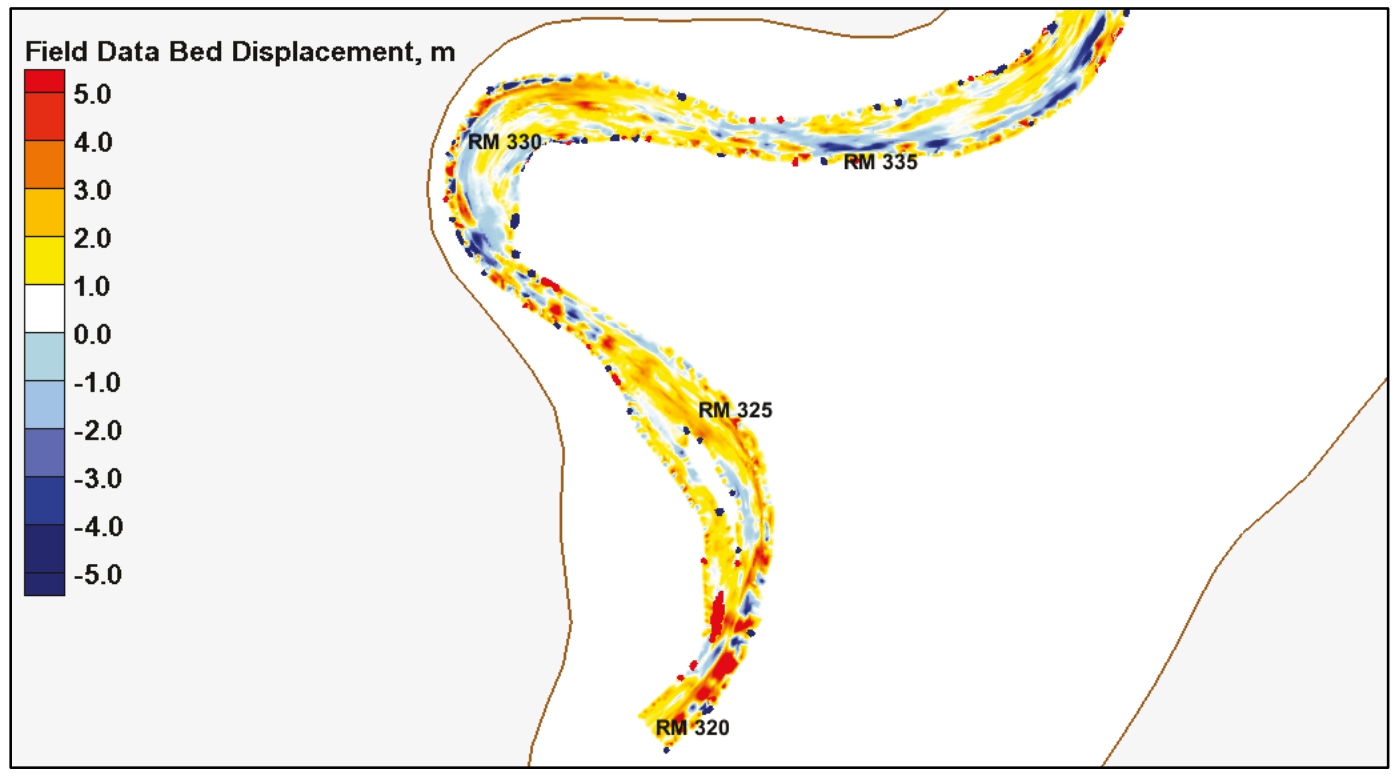

Figure 5-4. Difference in 2013 and 2011 model results from RM 335 to RM 320.

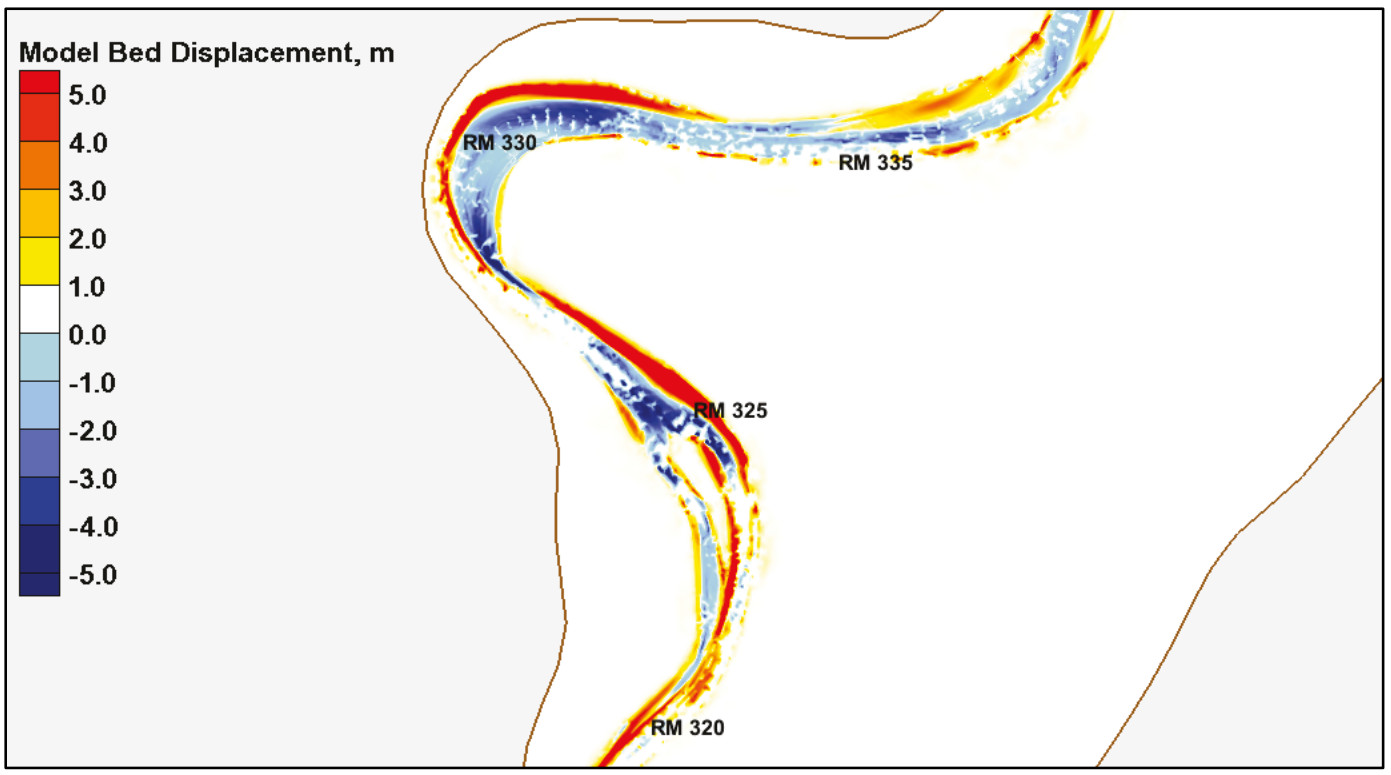

\section{Multi-beam sediment survey data}

MVN is responsible for the area from RM 324 to 228 (ORCS to vicinity of Baton Rouge) and provided a 2013 multi-beam data set. This reach of the Mississippi River was surveyed using multi-beam survey technology from January 2013 through July 2013 for a comprehensive bank-to-bank survey. The mesh was developed using 2004 multi-beam elevation data. Since the model simulations did not coincide with the two multi-beam measurements, direct comparisons were not possible. In an effort to utilize 
the available data, an average annual bed change rate was determined between the 2013 survey and the 2004 survey. While not useful for quantitative comparisons, this did provide an opportunity for qualitative comparisons. The Mississippi River hydrograph for 2004 to 2013 was analyzed to identify flood, drought, and average years. The simulated time period was also utilized to determine a flood, drought, and average yearly bed change. Utilizing these observations and model results, a qualitative comparison of the scour/deposition amounts and patterns was accomplished.

The sediment transport model simulated 14 March 2011 through 28 July 2013. From this model simulation, a representative flood year (March 2011 to March 2012), drought year (March 2012 to March 2013), and average year (January 2013 to July 2013 actually 7 months) were obtained. The average year was normalized over a year since it was only 7 months by multiplying the deposition/erosion by $12 / 7$. Since the model was not simulated for the entire 2004 to 2013 time period, a weighted average was performed utilizing the previously discussed modeled flood, drought, and average year to obtain annualized bed change rates to compare to the observed annual bed change rate obtained from the 2013 survey. The weighted average was determined by identifying the number of corresponding flood, drought, and average years from 2004 to 2013. From analyzing the hydrograph for each calendar year from 2004 to 2013, it was determined there were 2 flood years (2008 and 2011), 1 drought year (2012) and 7 average years (2004, 2005, 2006, 2007, 2009, 2010, and 2013). To obtain an annualized bed change rate that would be comparable to the available field data, the following weighted average was performed:

$$
\text { Normalized bed change }=\frac{2 * \text { flood } \mathrm{yr}+1 * \text { drought } \mathrm{yr}+7 * \text { average yr }}{10 \mathrm{yr}}
$$

While this method includes inherent uncertainty in the comparisons, it was the only option short of simulating the entire period of data, which was beyond the scope of this project. This uncertainty in the comparisons could be rectified by simulating the entire period between measurements.

Figure 5-5 depicts the field data annualized bed change from $\mathrm{Rm} 324$ to Rm 305. Data were not collected for RM 314 to RM 307 in the vicinity of Tarbert Landing. Figure 5-6 shows the approximate modeled yearly rate 
for RM 324 to RM 305. Figures 5-7 and 5-8 show the same comparison for RM 305 to RM 285.

There is a tendency for the model to overpredict deposition and erosion. Comparisons to sediment fluxes and concentrations could provide insight to determine which parameters are resulting in the overestimation of the erosion/deposition amounts. Additional plots showing different portions of the entire reach between ORCC (RM 324) and Baton Rouge (RM 228) are presented in Appendix B.

Figure 5-5. Normalized observed yearly bed change, RM 324 to RM 305.

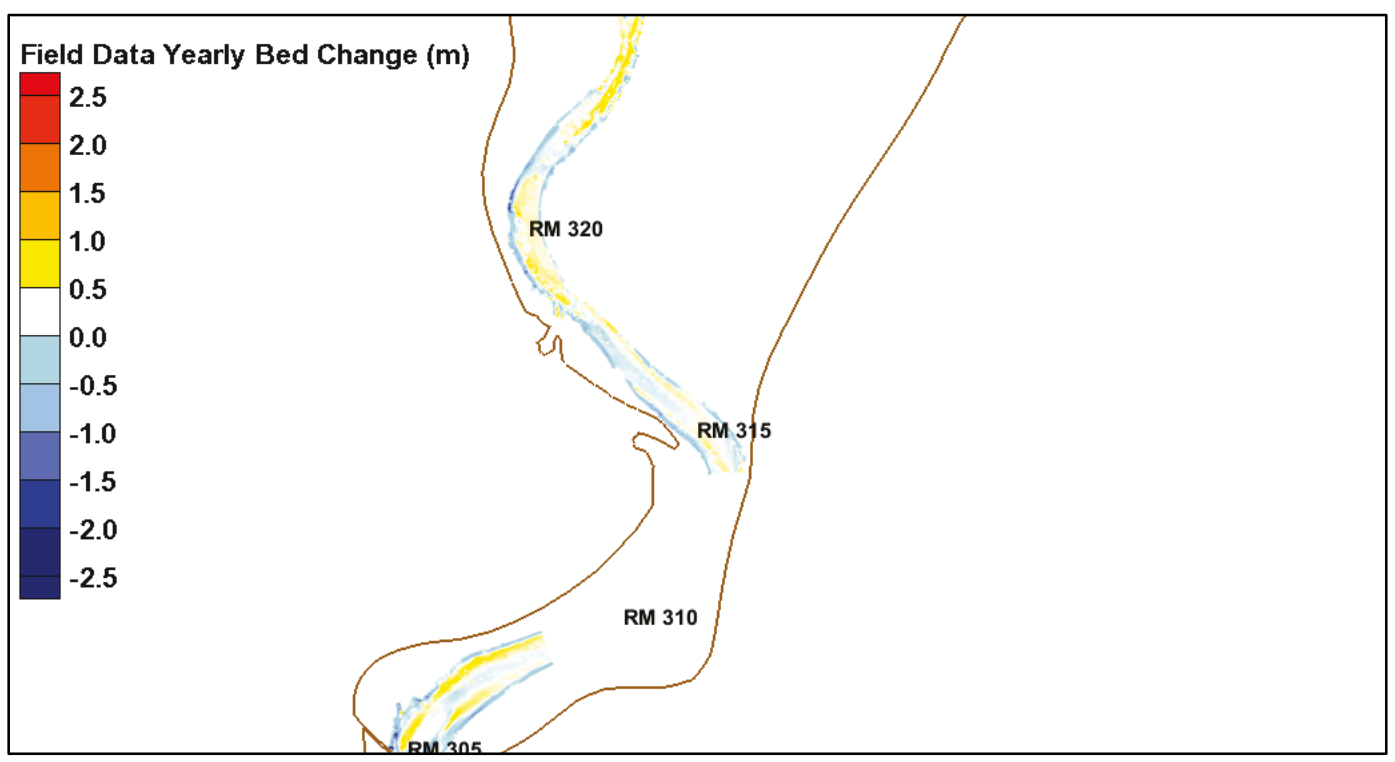

Figure 5-6. Normalized model yearly bed change, RM 324 to RM 305.

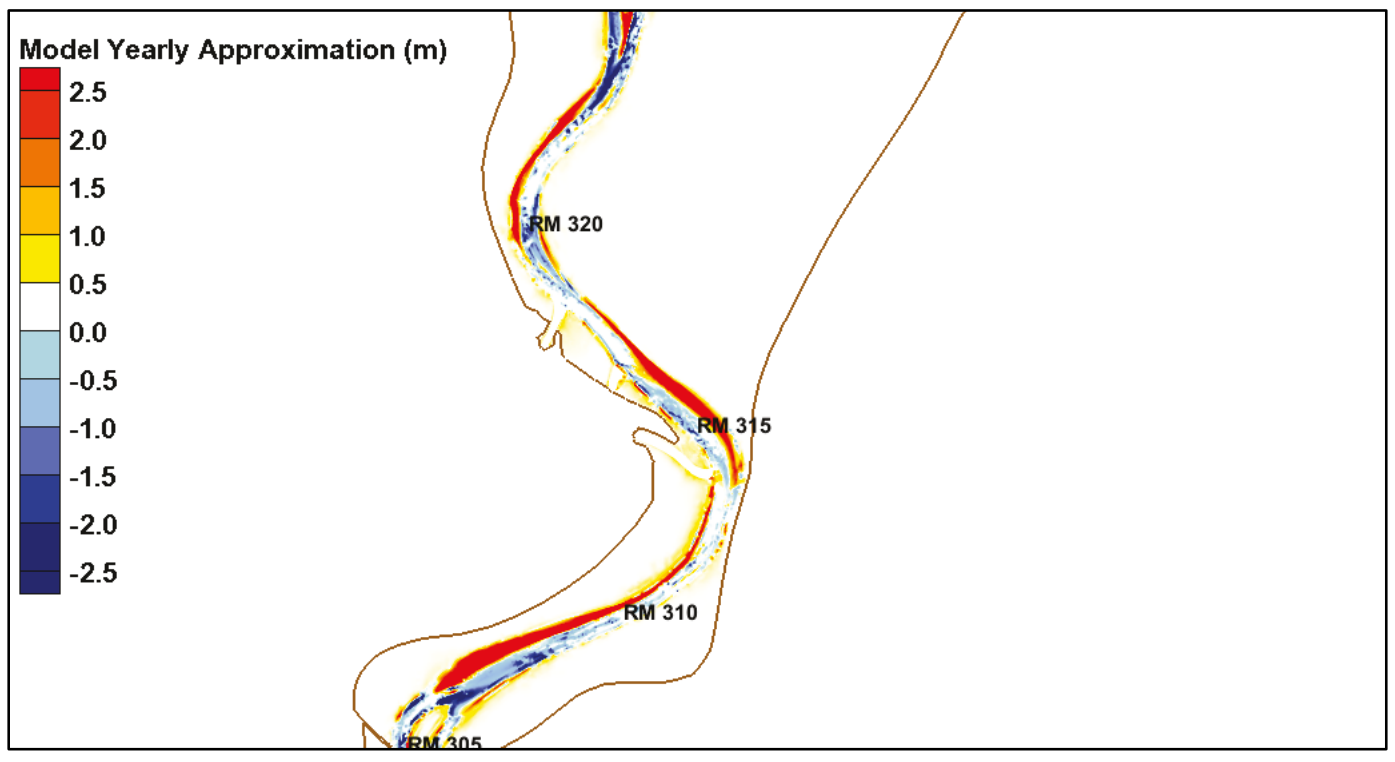


Figure 5-7. Normalized observed yearly bed change, RM 305 to RM 285.

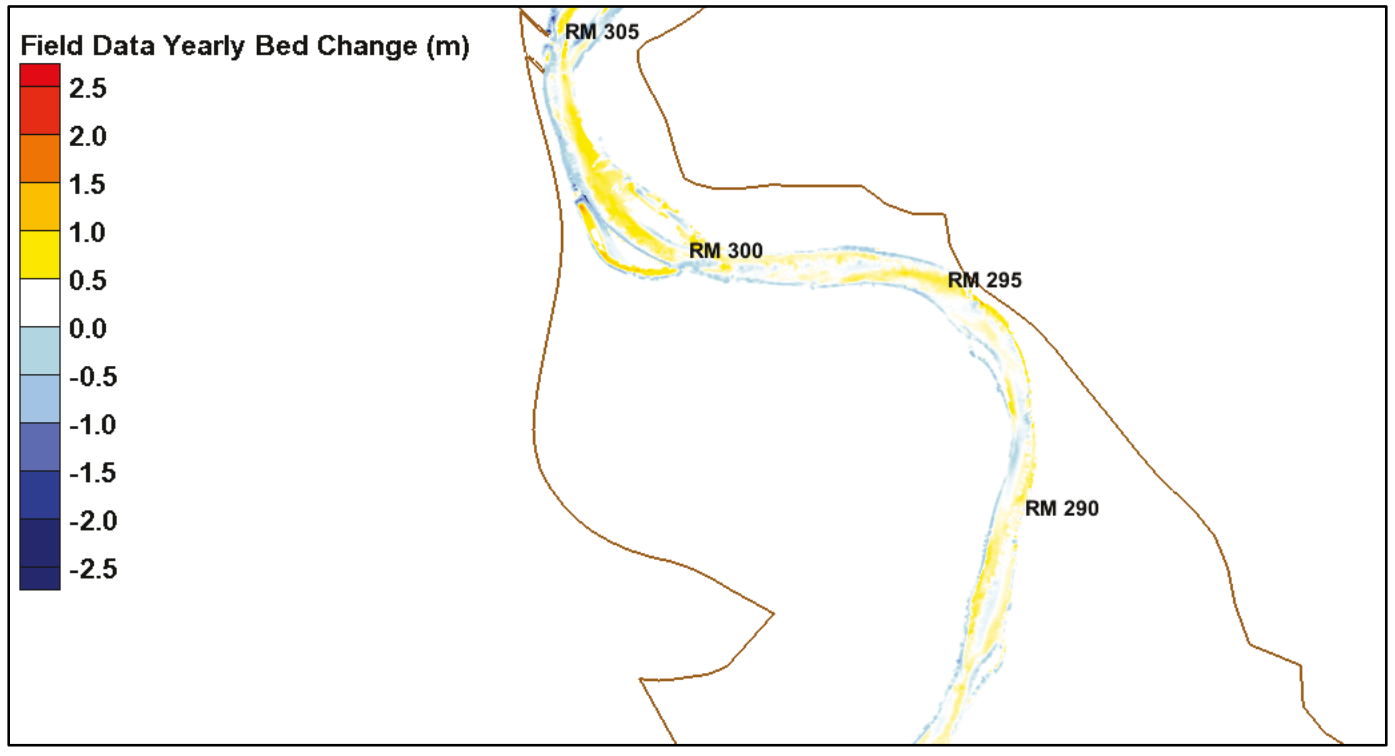

Figure 5-8. Normalized model yearly bed change, RM 305 to RM 285.

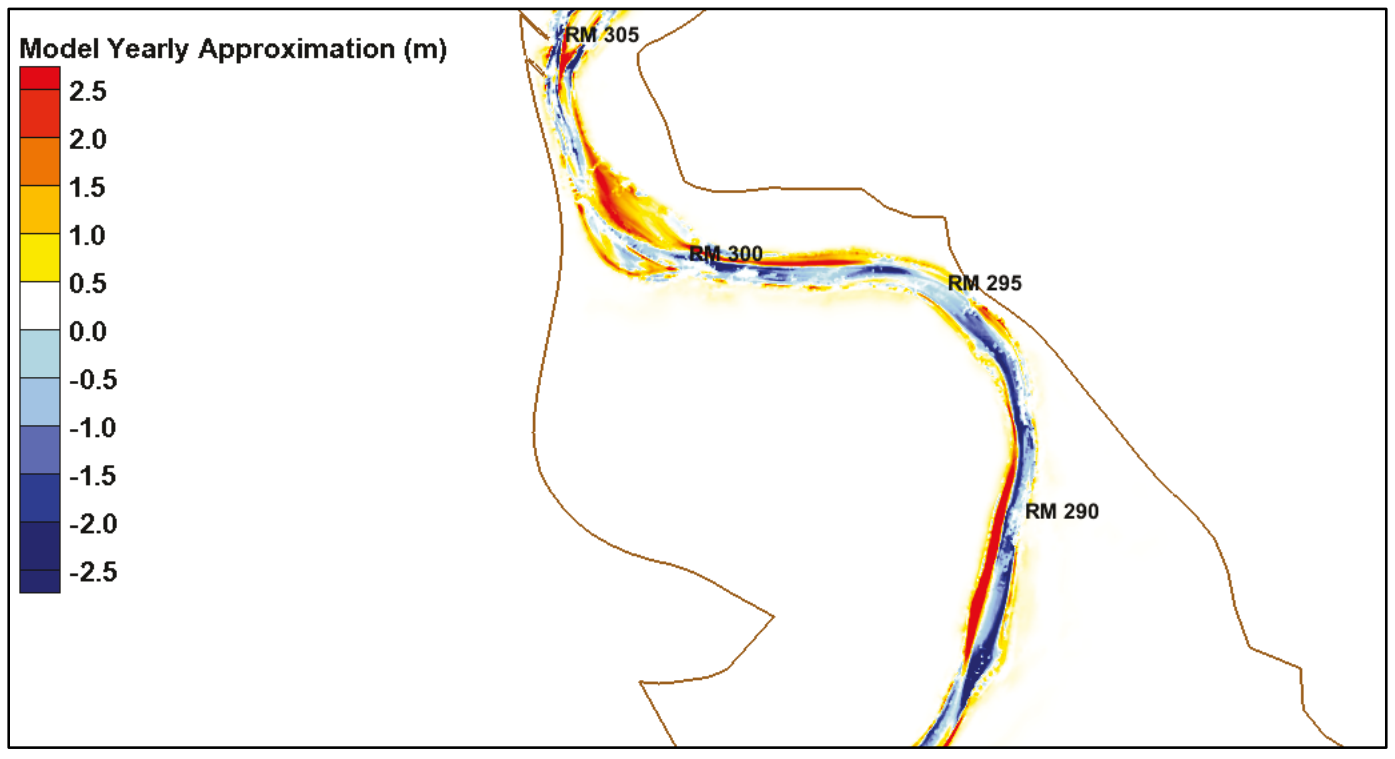




\section{Summary and Conclusions}

The numerical model adequately replicates the water levels observed in the field. This includes a wide range of conditions from an extreme flood (Flood of 2011) to an extreme drought (2012). The numerical model simulated both of these events concurrently indicating a wide range of applicability for this particular model. With the inclusion of the ORCC and MCS, this model is available to evaluate alternative operational procedures and associated relative water level impacts between these two structures for both normal and extreme flow conditions.

The sediment transport comparisons consisted of comparing to erosion/deposition patterns and amounts. The numerical model does a reasonable job replicating the erosion/deposition patterns but overestimates the actual erosion/deposition amounts. There are several possible reasons why the erosion/deposition amounts are overestimated.

- The relative roughness values for the channel and floodplain could be incorrect resulting in accurate water levels but inaccurate flow distributions. This could be tested with some targeted ADCP transects that measure the flow split between the floodplain and the main channel.

- The method utilized to compare the simulated results for one time period to the two survey datasets for a longer time period (RM 324 to RM 228) inherently creates error in the comparisons. This could be corrected by simulating the entire period of record between the two survey datasets.

- There is a lack of a thorough sediment validation effort. Additional comparisons to sediment fluxes and concentrations could provide insight to determine which parameters are resulting in the overestimation of the erosion/deposition amounts. 


\section{References}

Bell, Gary L., Nathan D. Clifton, and David D. Abraham. 2017. Phase One -

Hydrodynamics in the Morganza Floodway. MRG\&P Report No. 13. Vicksburg, MS: U.S. Army Engineer Research and Development Center.

Bernard, B. 1992. Depth-Average Numerical Modeling for Curved Channels. Technical Report HL-92-9. Vicksburg, MS: U.S. Army Research and Development Center.

Brown, Gary L. 2012a. "A Quasi-3D Suspended Sediment Model Using a Set of Correction Factors Applied to a Depth Averaged Advection Diffusion Equation." In Proceedings, IIHR 3rd International Shallow Flows Symposium, University of Iowa.

Brown, Gary L. 2012b. "Modification of the Bed Sediment Equations of Spasojevic and Holly (1993) to Account for Variable Porosity, Variable Grain Specific Gravity, and Nonerodable Boundaries." In Proceedings, IIHR 3rd International Shallow Flows Symposium, University of Iowa.

Brown, Gary L. 2008. “Approximate Profile for Nonequilibrium Suspended Sediment.” Journal of Hydraulic Engineering 134(7): 1,010-1,014.

Brown, G. L., C. Trahan, J. N. Tate, and G. Savant. 2014. SEDLIB Multiple Grain Sized Mixed Sediment Library: Technical Manual, v1.2. Vicksburg, MS: U.S. Army Engineer Research and Development Center.

Egiazaroff, L. V. 1965. "Calculation of Non-Uniform Sediment Concentration.” Journal of Hydraulics Division, ASCE 91(HY4): 225-248.

Heath, Ronald E., Gary L. Brown, Charles D. Little, Thad C. Pratt, Jay J. Ratcliff, David D. Abraham, David W. Perkey, Naveen B. Ganesh, S. Keith Martin, and David P. May. 2015. Old River Control Complex Sedimentation Investigation. MRG\&P Report No. 16. Vicksburg, MS: U.S. Army Research and Development Center.

Lane, E. W. 1947. "Report on the Subcommittee on Sediment Terminology." Transactions, American Geophysical Union 28(6): 936-938.

USACE. 1999. Flood Control, Mississippi River \& Tributaries Atchafalaya Basin, Morganza Floodway, LA. Morganza Control Structure Periodic Inspection Report No. 8. Vicksburg, MS: USACE, Mississippi Valley Division.

USACE. 2012. Mississippi River and Tributaries System: 2011 Post-Flood Report. Vicksburg, MS: USACE, Mississippi Valley Division.

USACE. 2014a. Morganza Control Structure: Mississippi River and Tributaries Project - Lower Mississippi River Basin, Louisiana. New Orleans, LA: USACE, New Orleans District.

USACE. 2014b. Morganza Floodway Interim Water Control Manual: Proposed Clarifications to the Standing Instructions. New Orleans, LA: USACE, New Orleans District. 
van Rijn, L. C. 1984. “Sediment Transport, Part I: Bed Load Transport.” J. Hydr. Engrg. 110: 1431. DOI:10.1061/(ASCE)0733-9429(1984)110:10(1431).

Wright, S., and G. Parker. 2004."Flow Resistance and Suspended Load in Sand-Bed Rivers: Simplified Stratification Model." Journal of Hydraulic Engineering 130(8): 796. 


\section{Appendix A: Difference in 2013 and 2011 Single Beam Survey Data and Difference in 2013 and 2011 ADH Model Results from RM 360 to RM 320}

Figure A-1. Difference in 2013 and 2011 single beam survey data from RM 360 to RM 355.

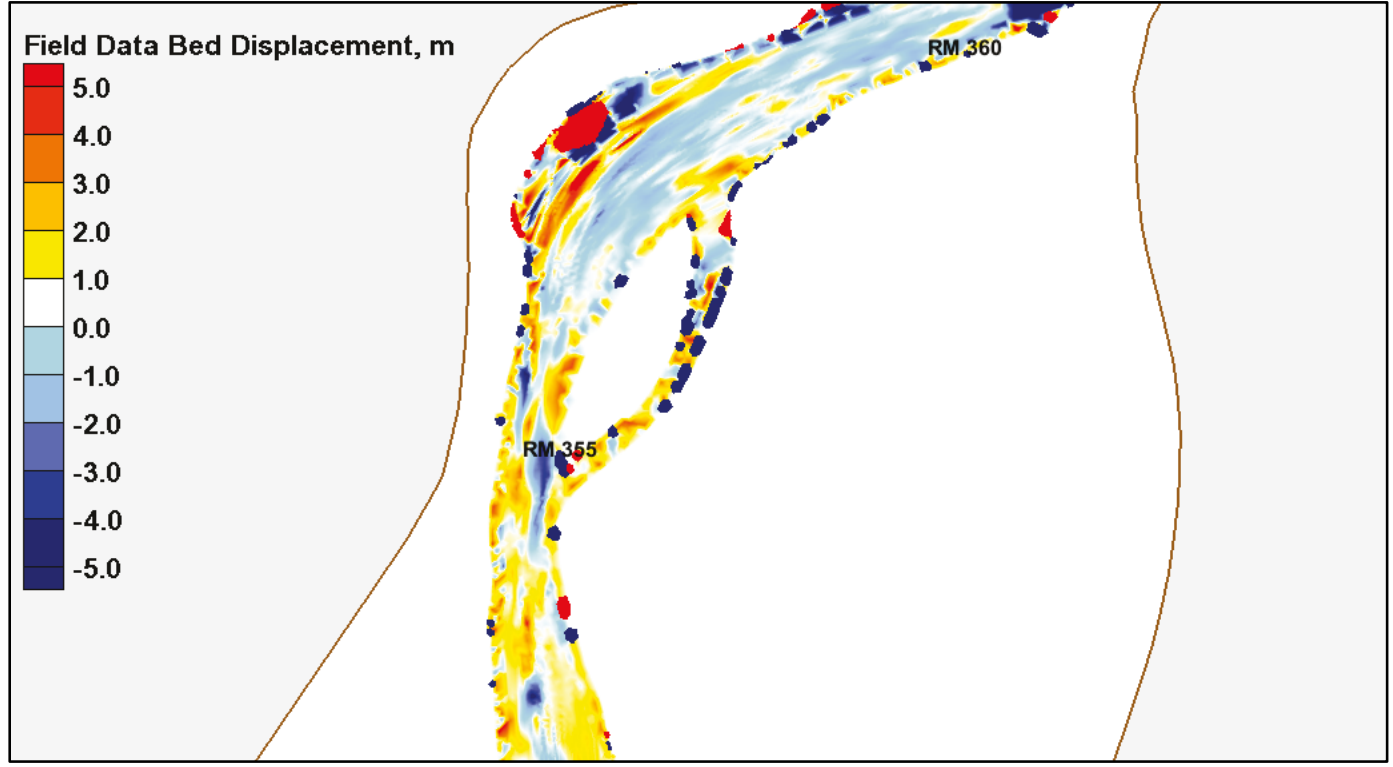

Figure A-2. Difference in 2013 and 2011 model results from RM 360 to RM 355.

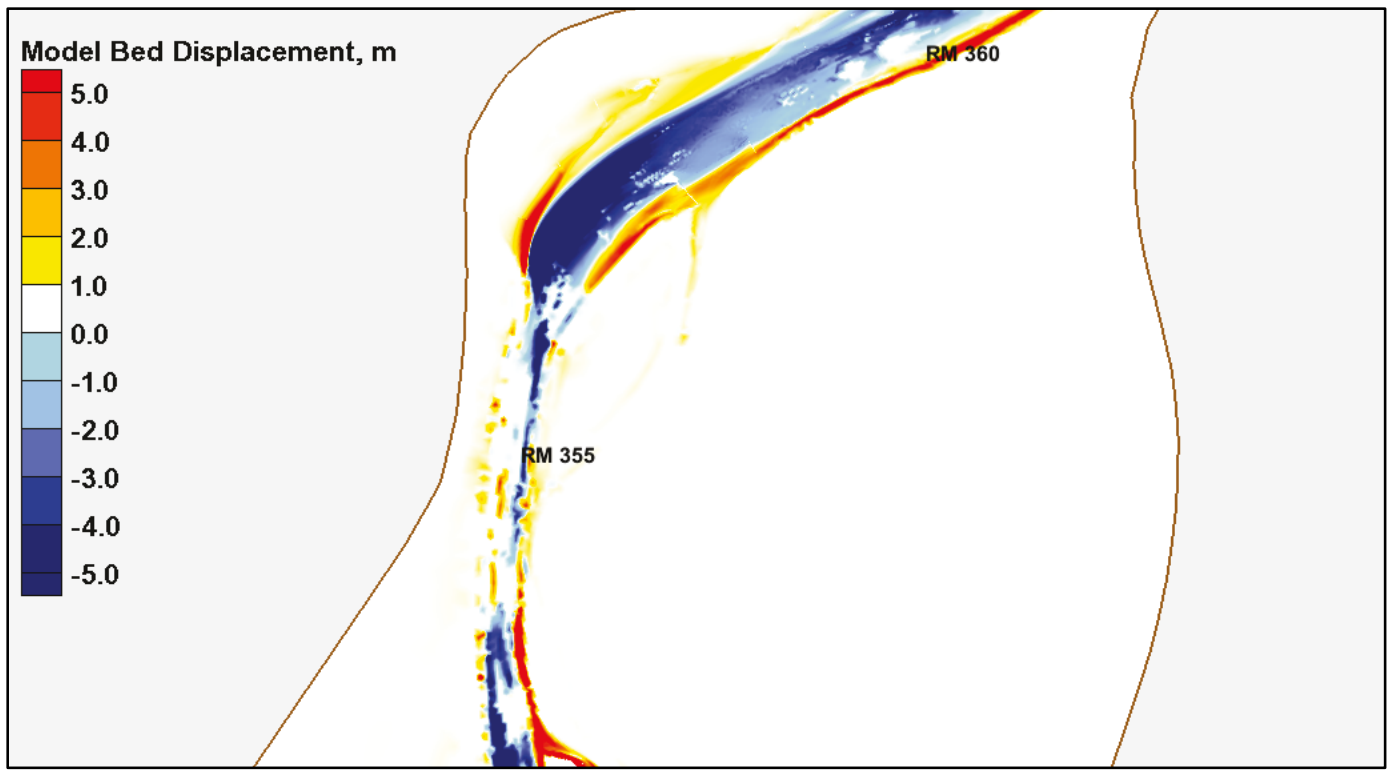


Figure A-3. Difference in 2013 and 2011 single beam survey data from RM 355 to RM 345.

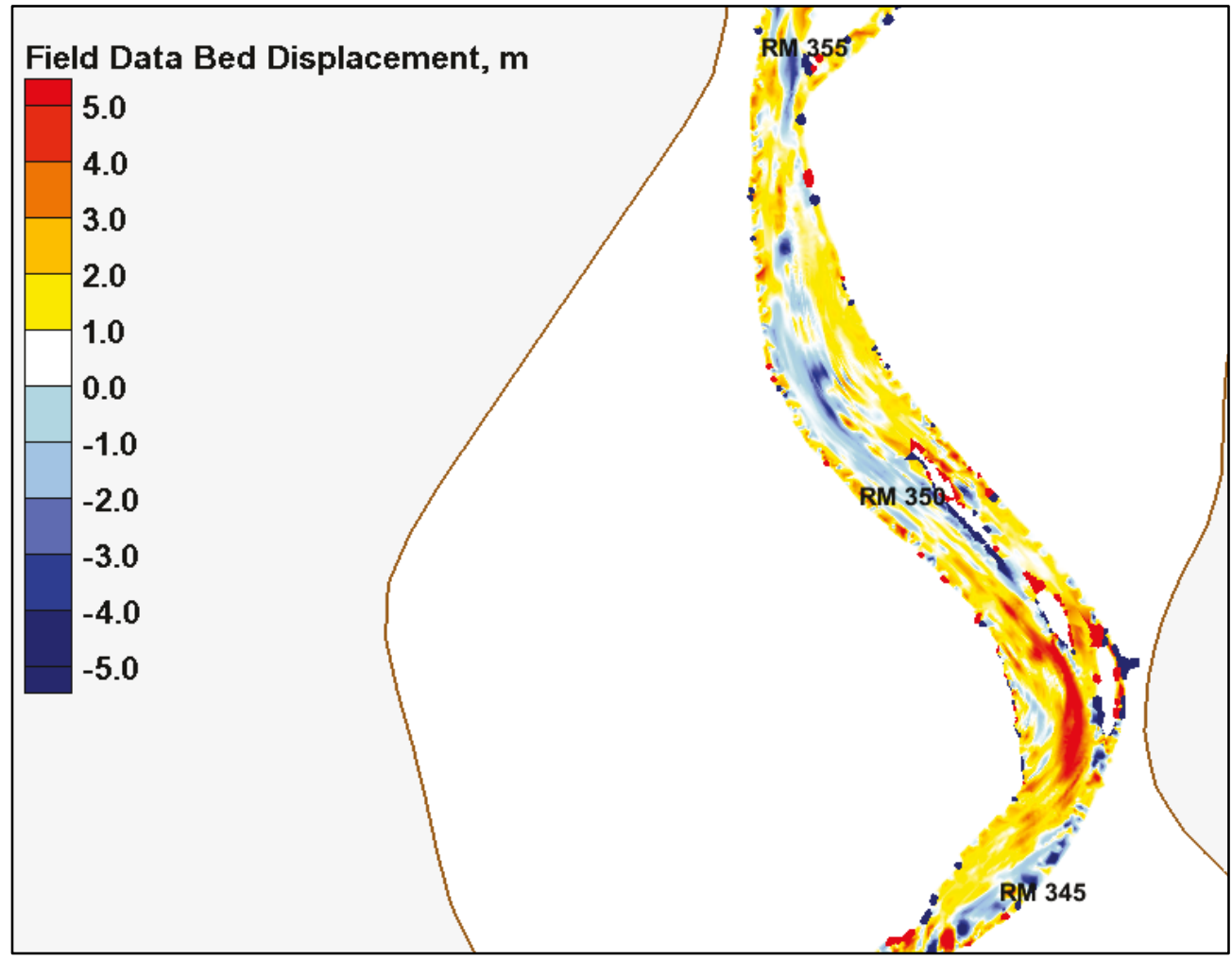

Figure A-4. Difference in 2013 and 2011 model results from RM 355 to RM 345.

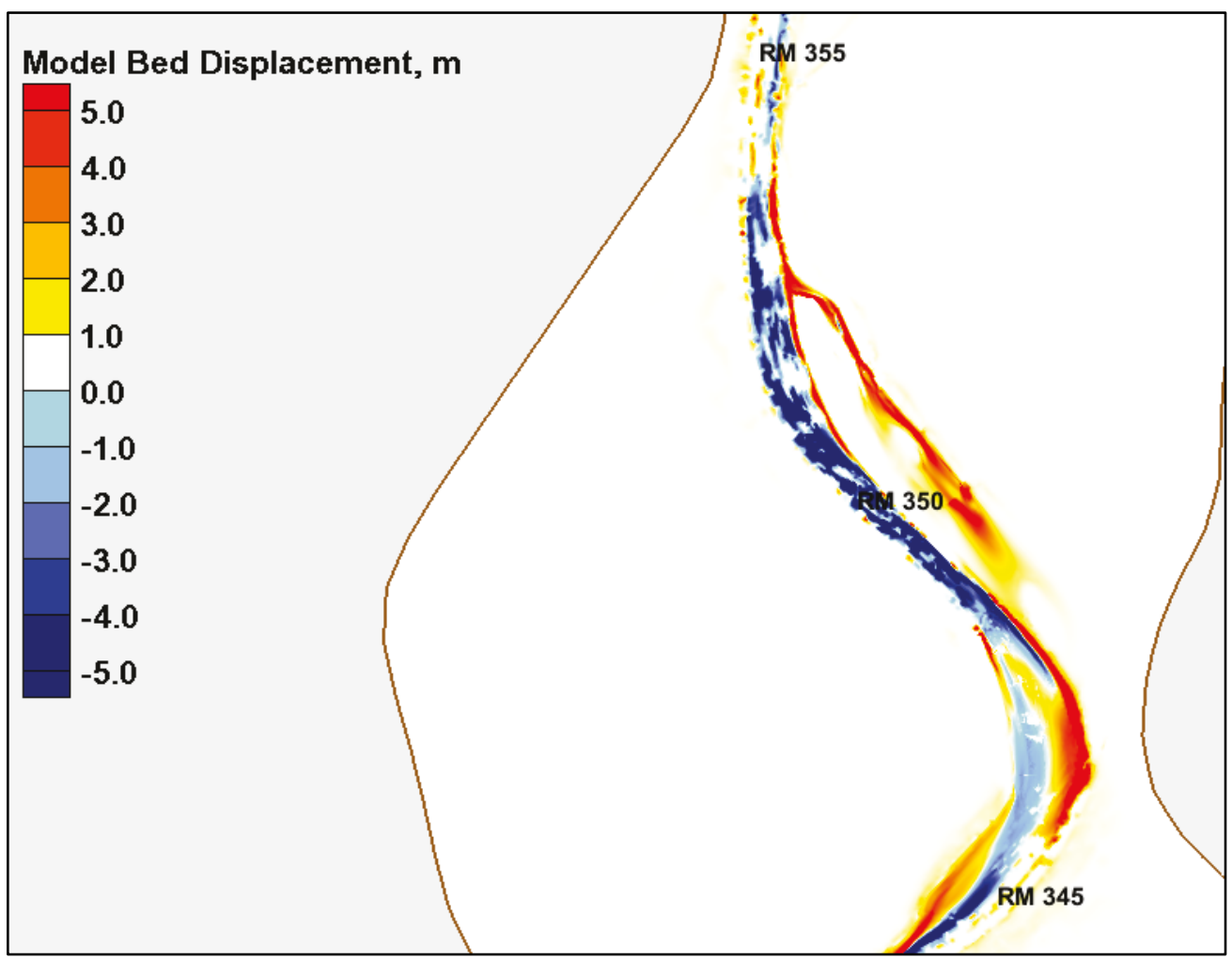


Figure A-5. Difference in 2013 and 2011 single beam survey data from RM 345 to RM 330.

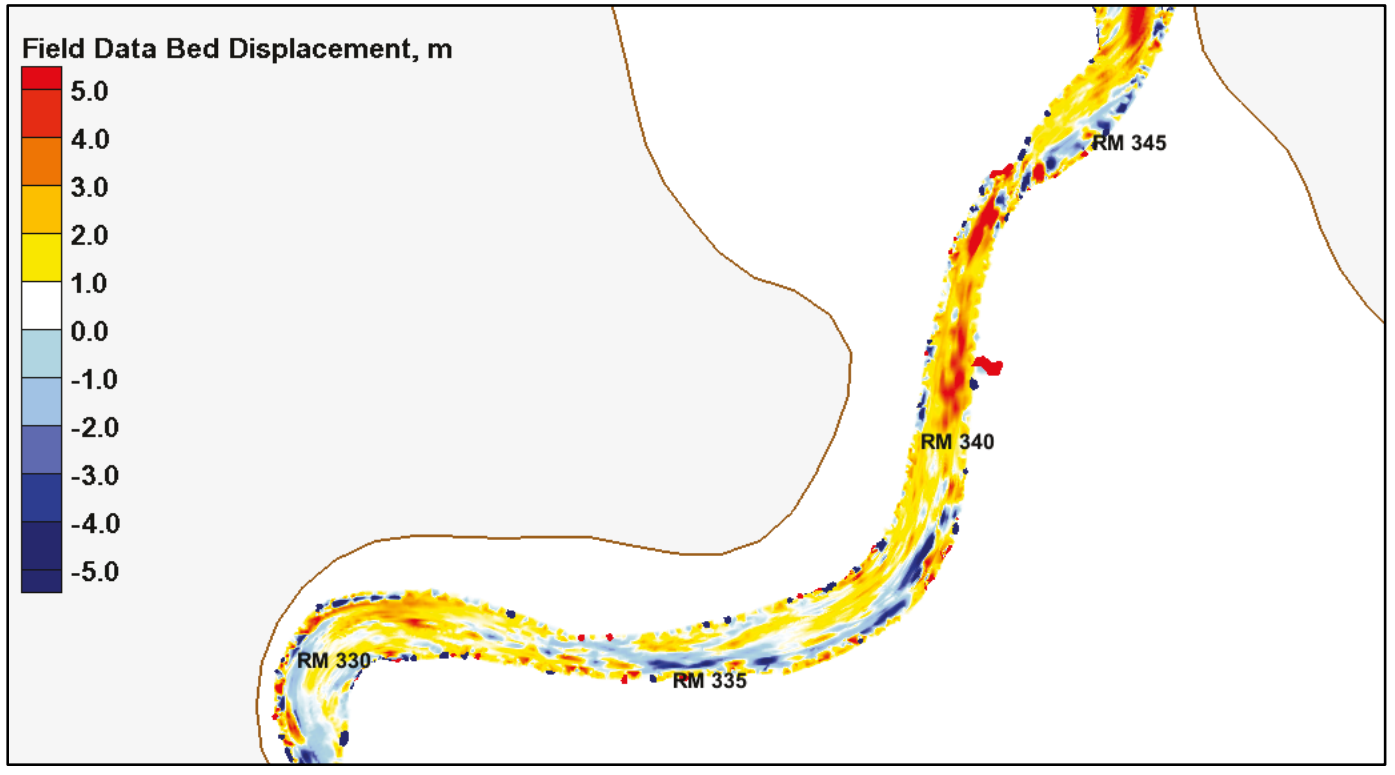

Figure A-6. Difference in 2013 and 2011 model results from RM 345 to RM 330.

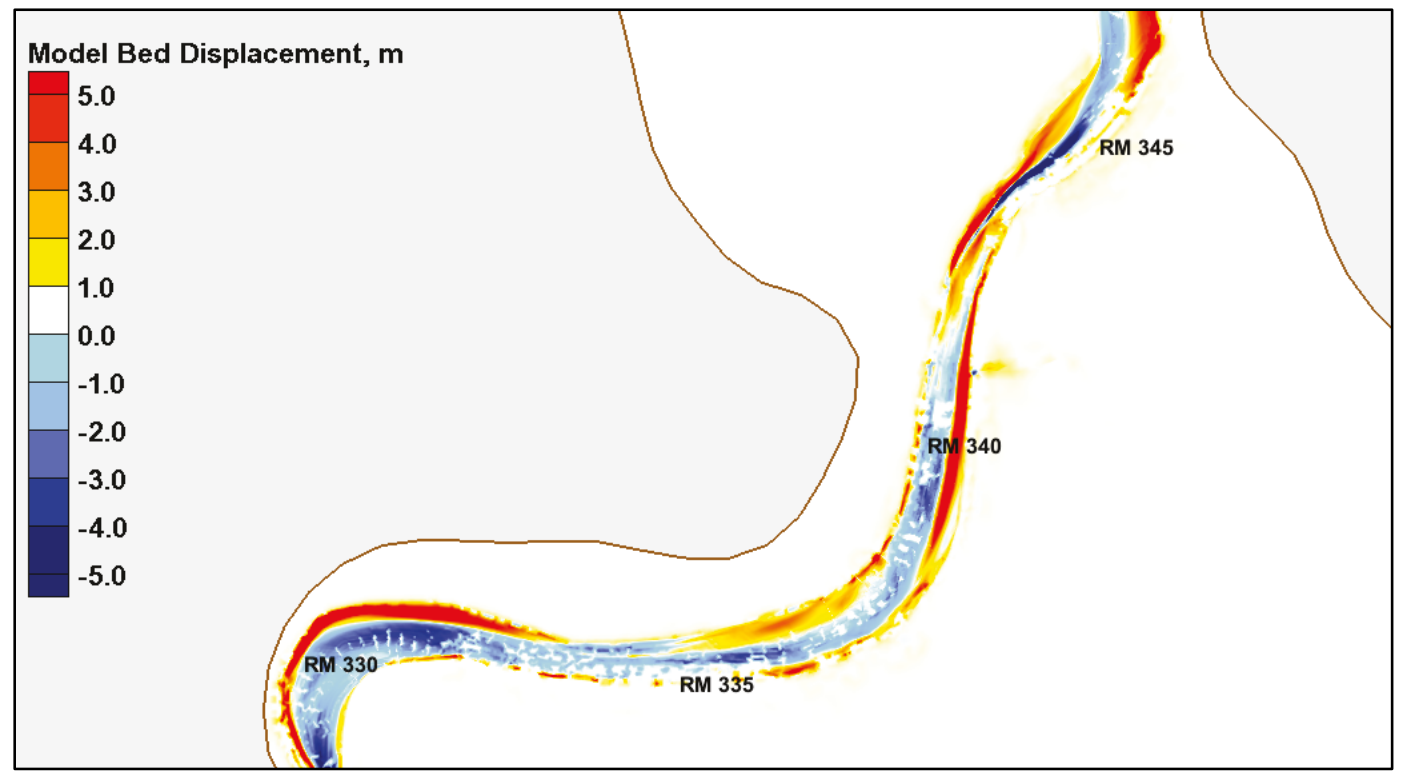


Figure A-7. Difference in 2013 and 2011 single beam survey data from RM 335 to RM 320.

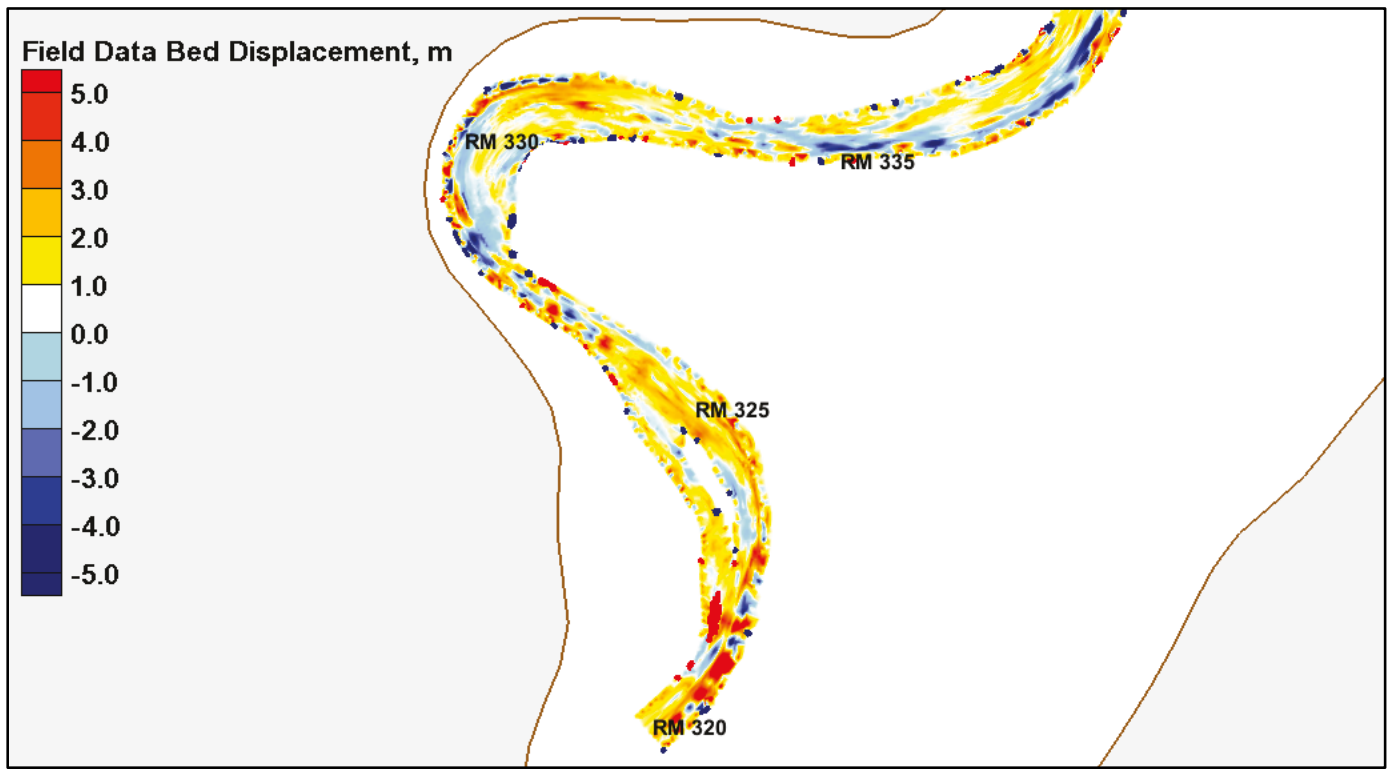

Figure A-8. Difference in 2013 and 2011 model results from RM 335 to RM 320.

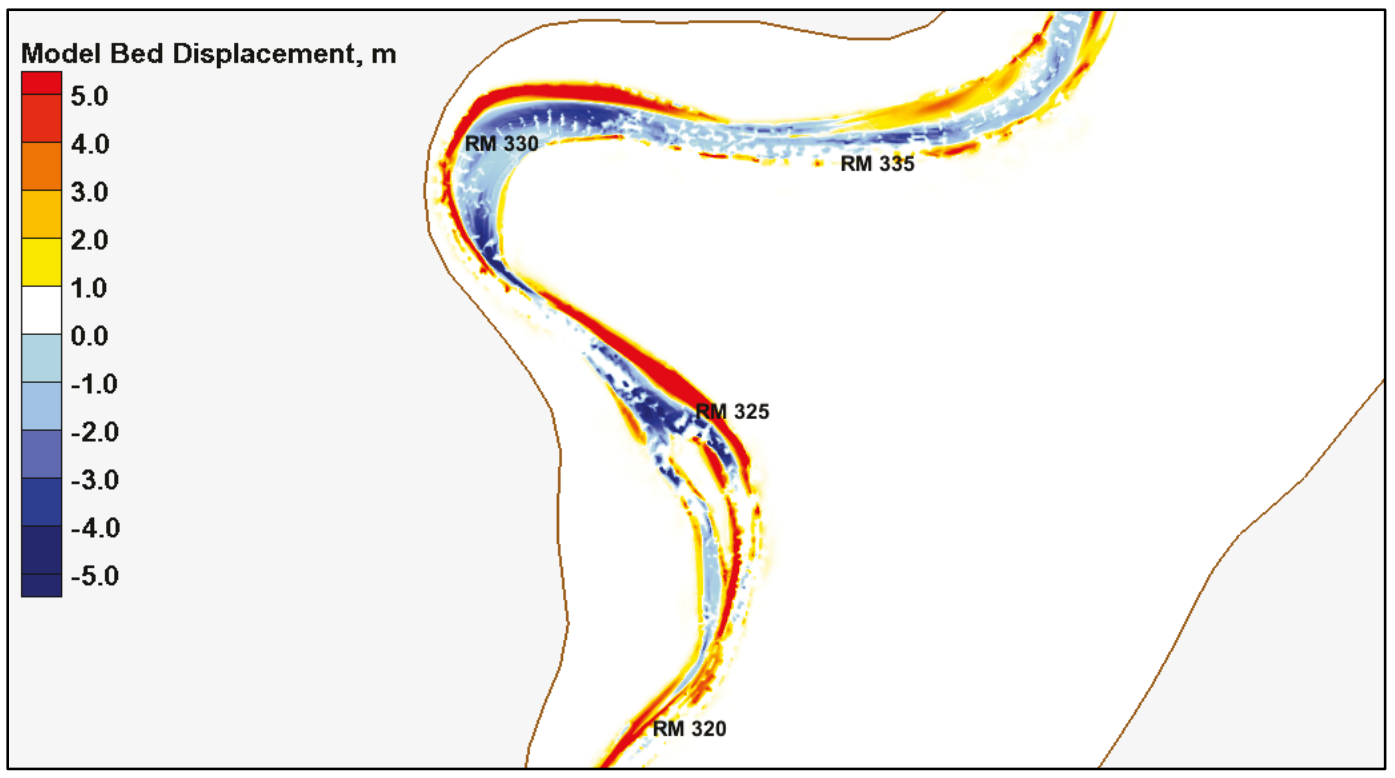




\section{Appendix B: 2015 Normalized Multi-beam Survey Yearly Bed Change Data and the Normalized AdH Model Yearly Bed Change, RM 320 to RM 228}

Figure B-1. Normalized observed yearly bed change, RM 324 to RM 305.

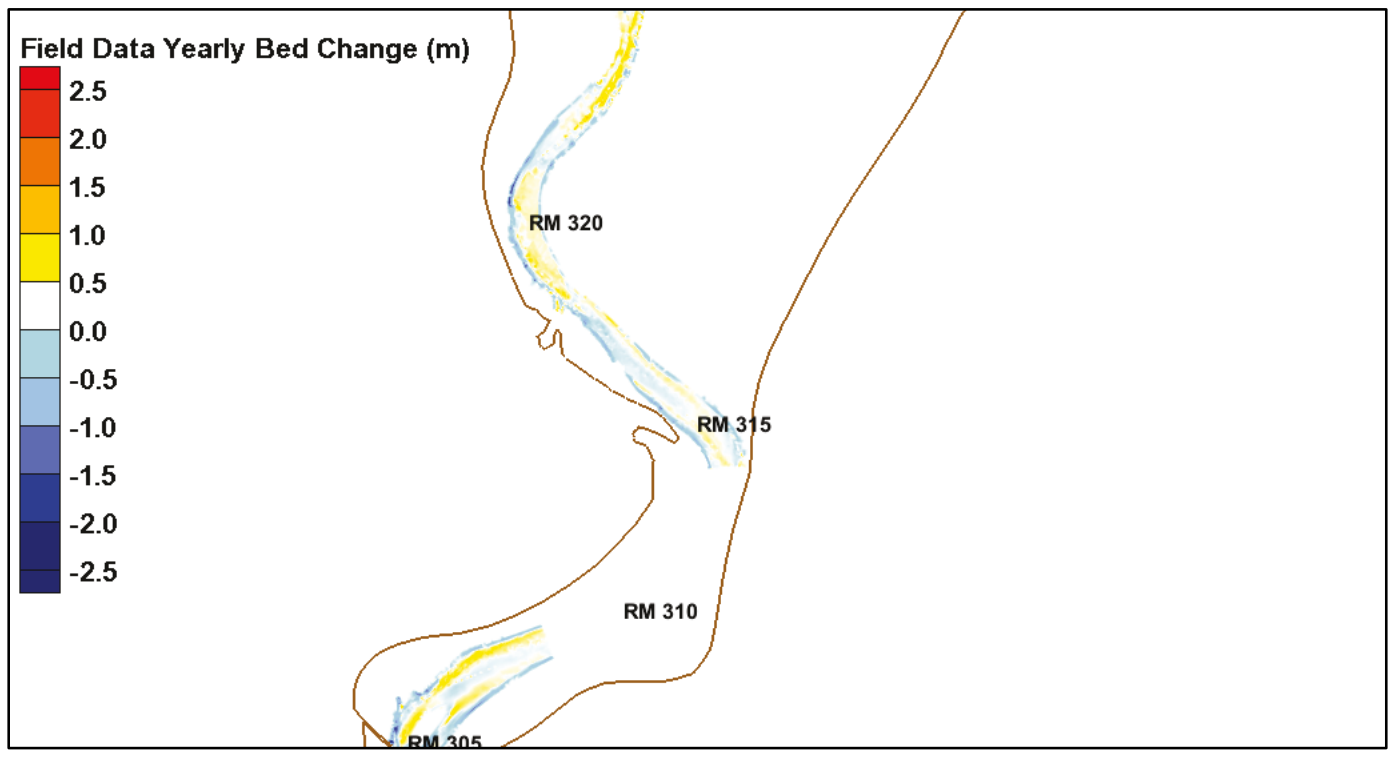

Figure B-2. Normalized model yearly approximation, RM 324 to RM 305.

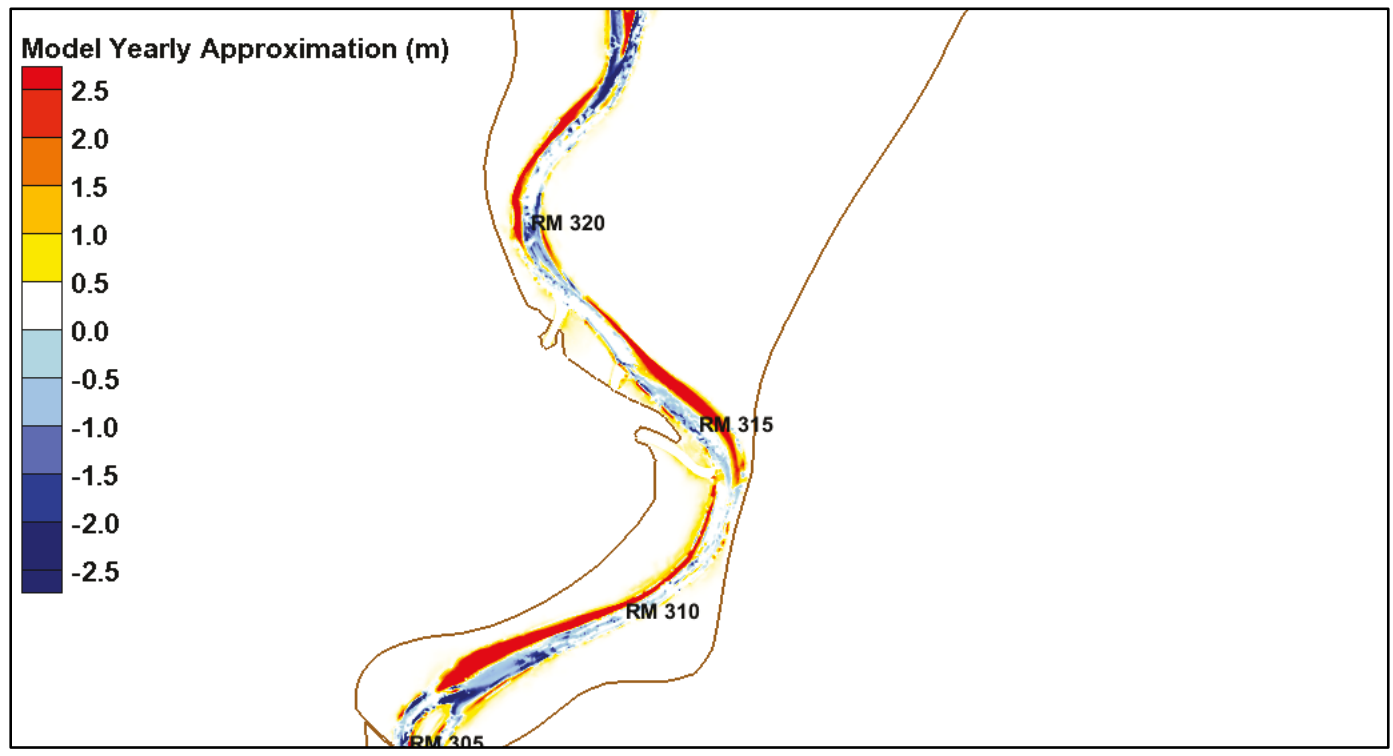


Figure B-3. Normalized observed yearly bed change, RM 305 to RM 285.

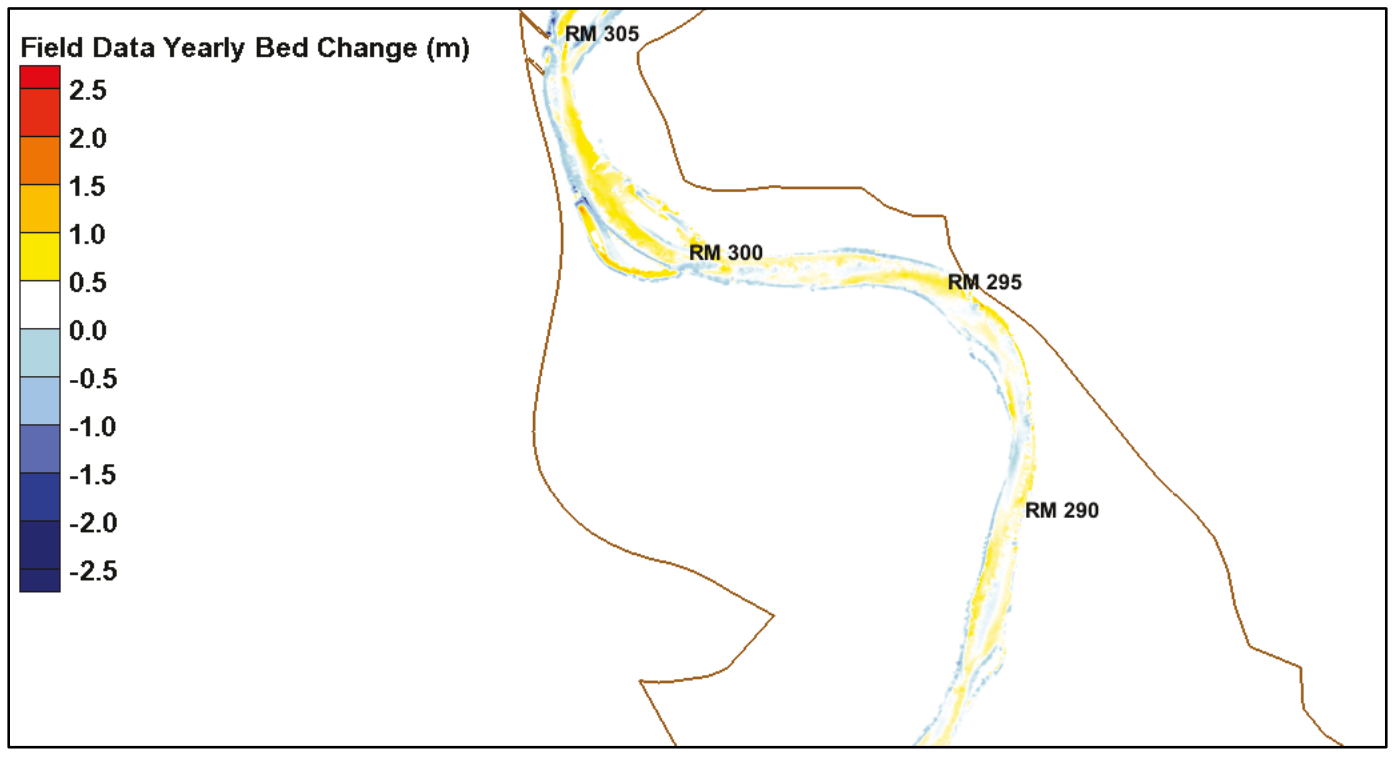

Figure B-4. Normalized model yearly bed change, RM 305 to RM 285.

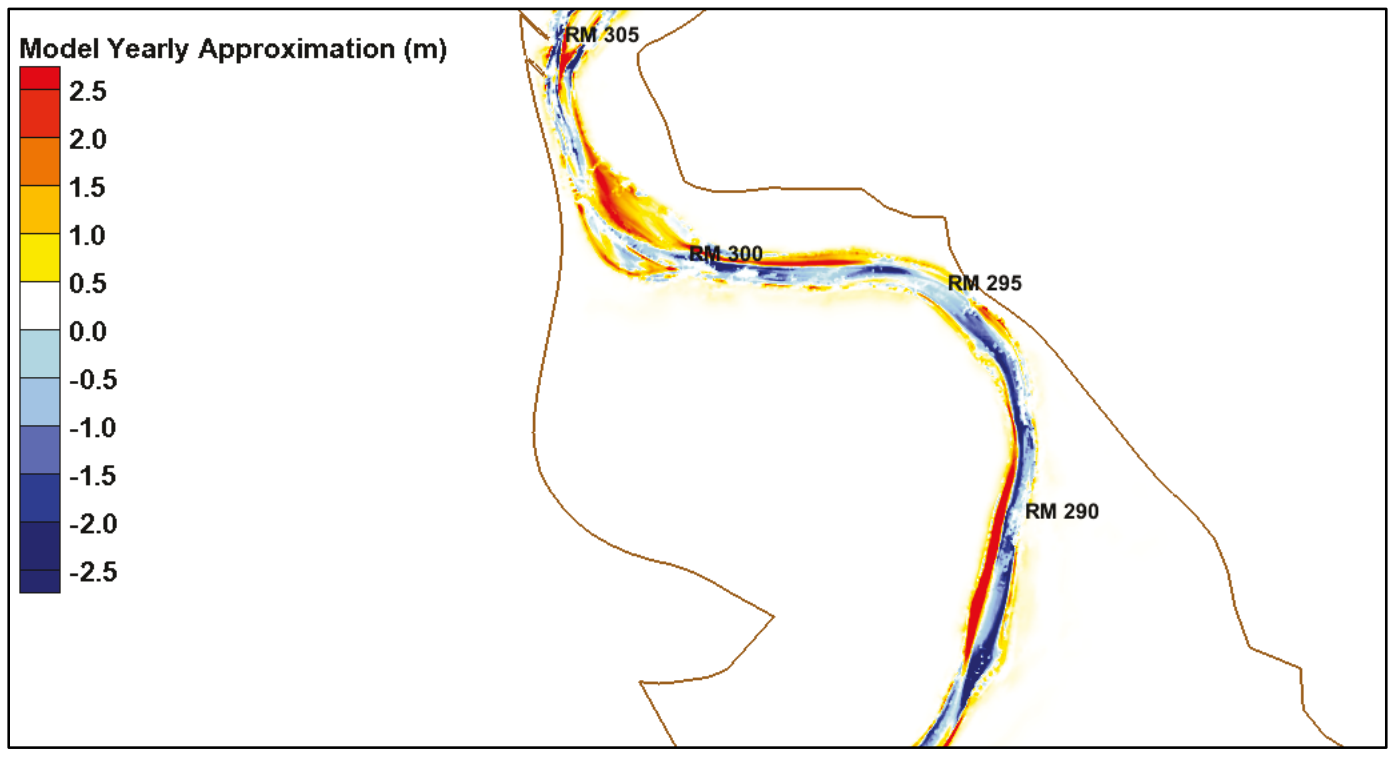


Figure B-5. Normalized observed yearly bed change, RM 285 to RM 255.

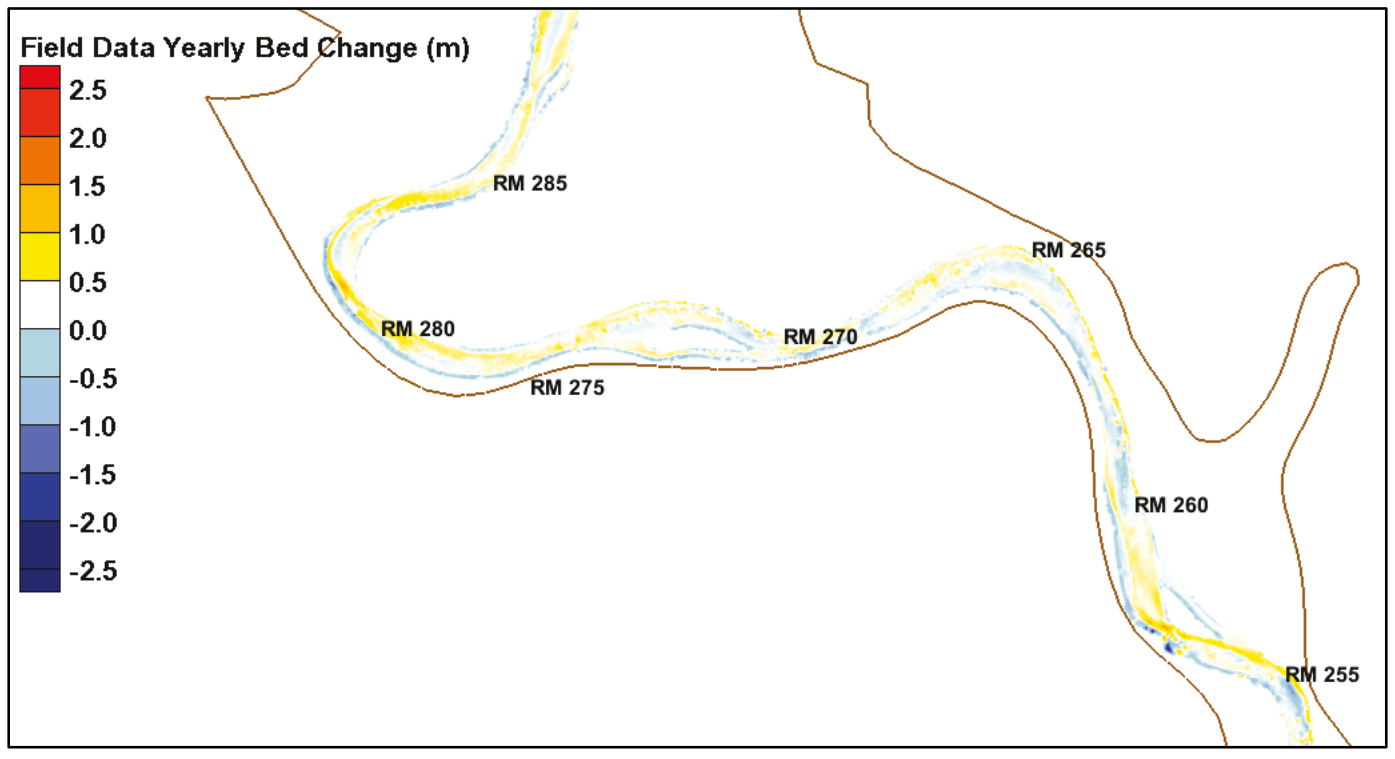

Figure B-6. Normalized model yearly bed change, RM 285 to RM 255.

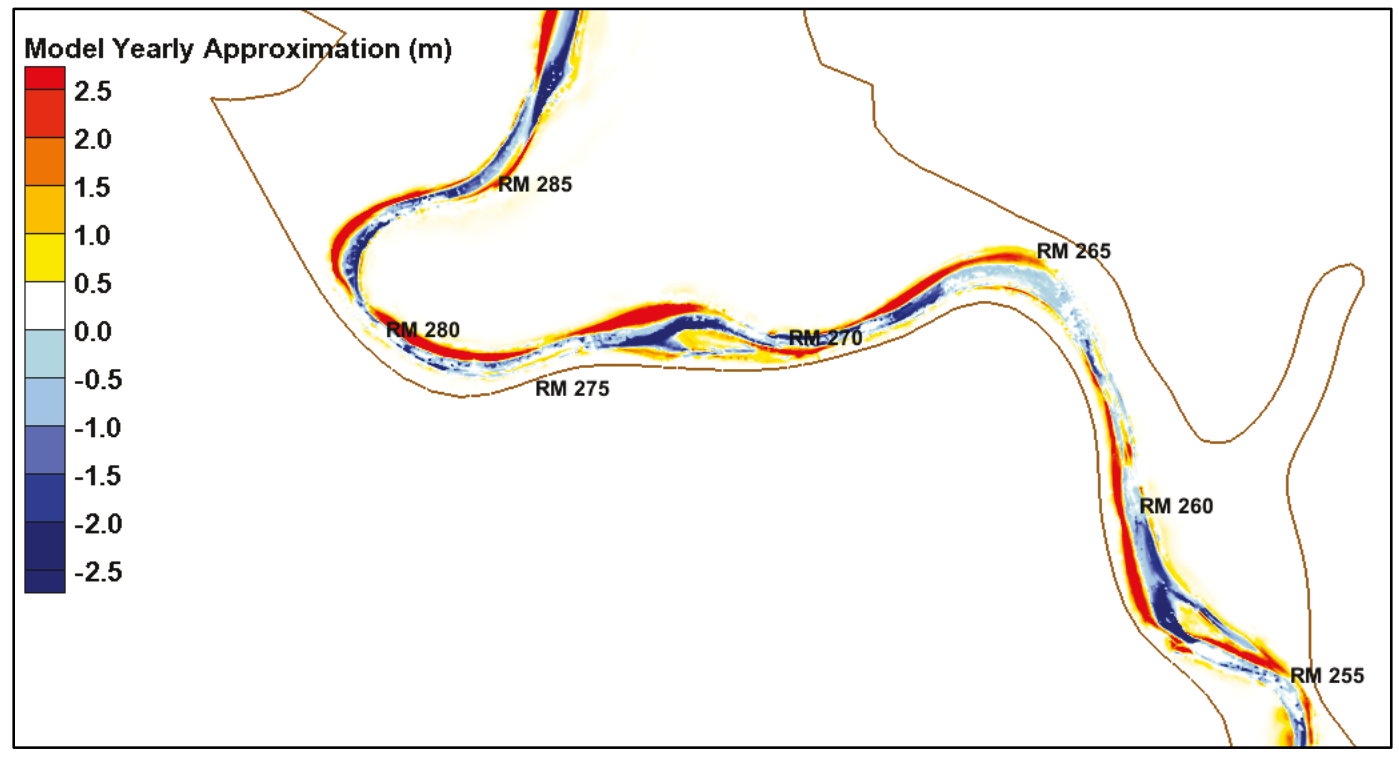


Figure B-7. Normalized observed yearly bed change, RM 255 to RM 230.

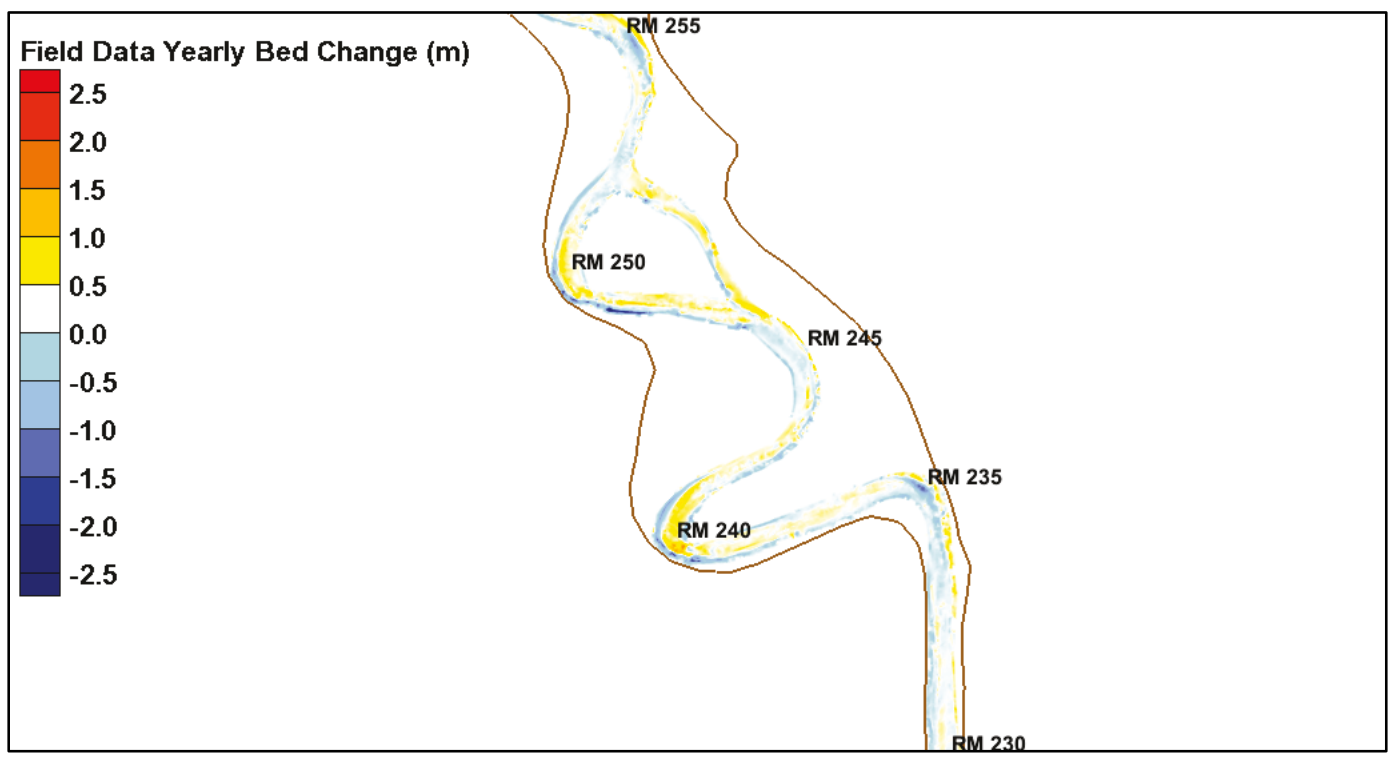

Figure B-8. Normalized model yearly bed change, RM 255 to RM 230.

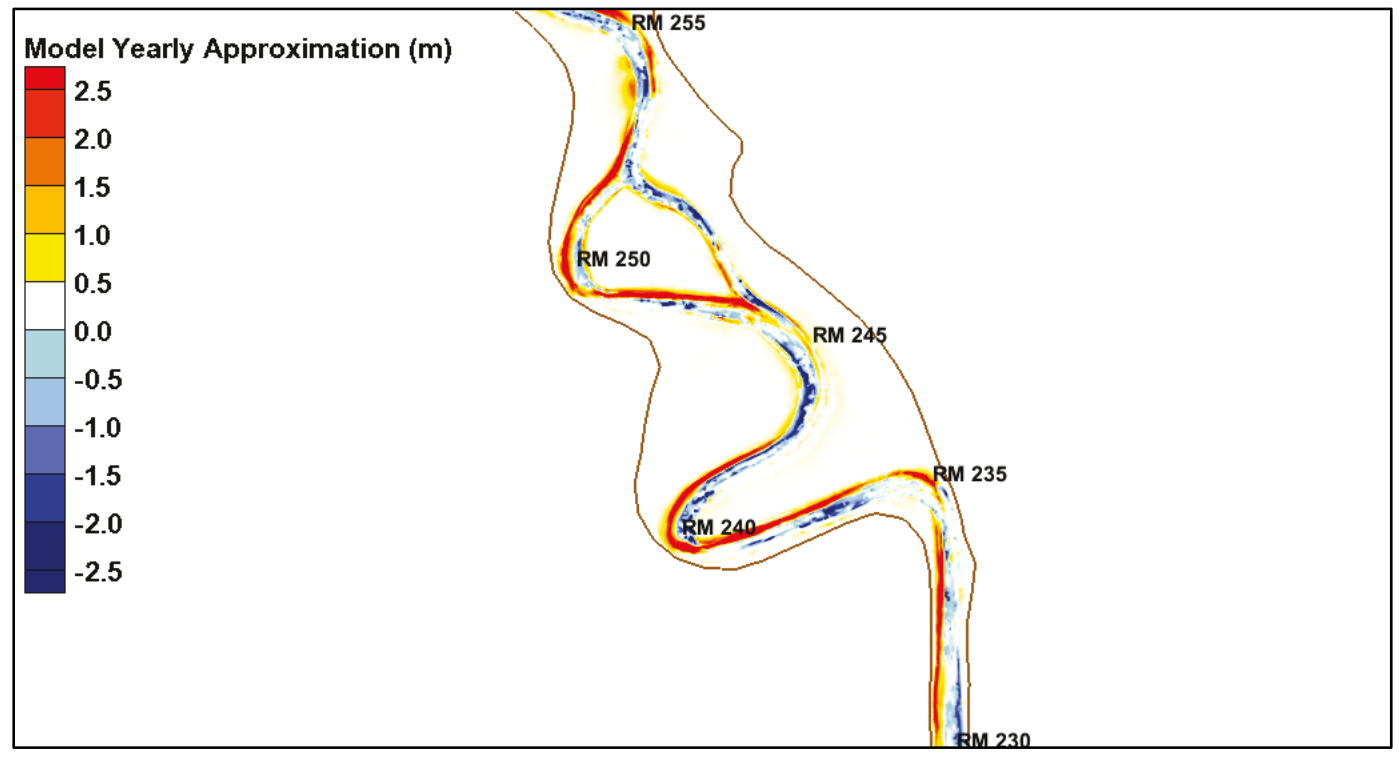


Figure B-9. Normalized observed yearly bed change, RM 240 to RM 228.

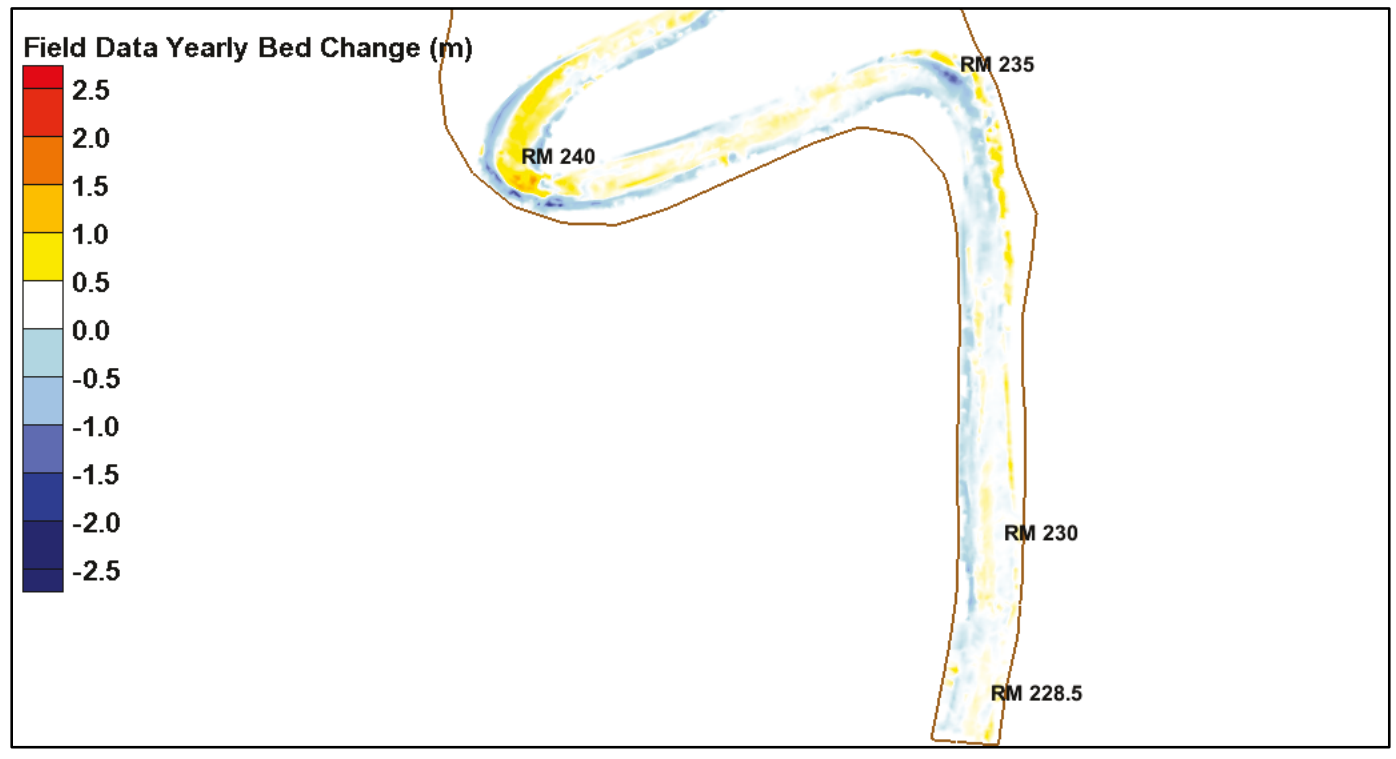

Figure B-10. Normalized model yearly bed change, RM 240 to RM 228.

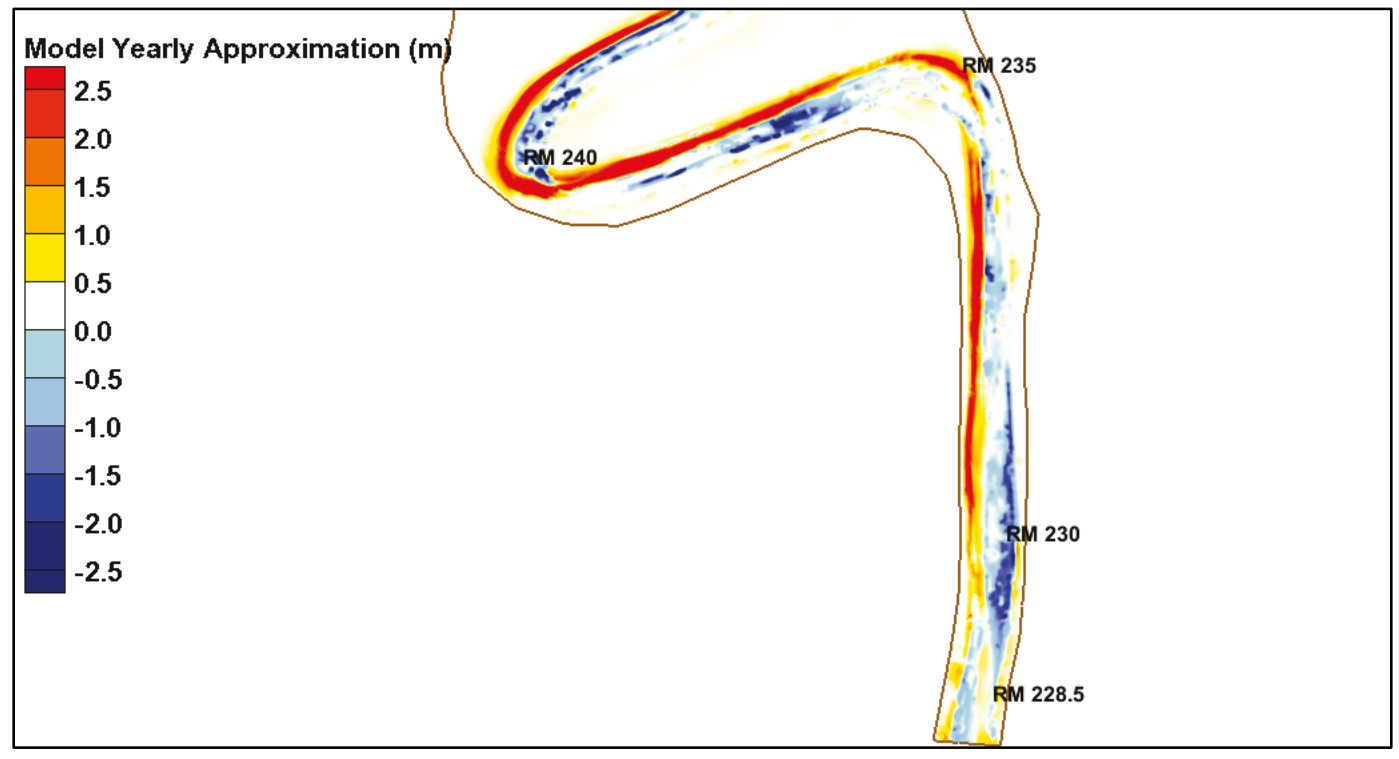




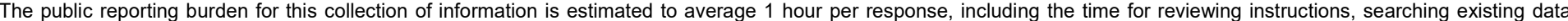

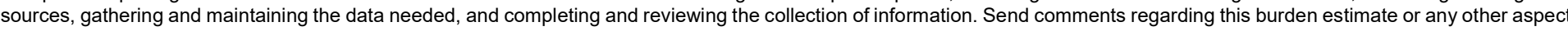

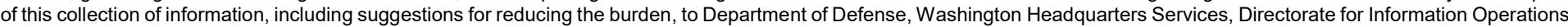

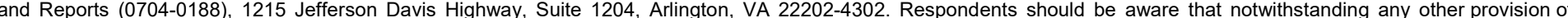
law, no person shall be subject to any penalty for failing to comply with a collection of information if it does not display a currently valid OMB control number.

PLEASE DO NOT RETURN YOUR FORM TO THE ABOVE ADDRESS.

\begin{tabular}{l|l|l}
\hline 1. REPORT DATE & 2. REPORT TYPE & 3. DATES COVERED (From - To) \\
August 2018 & Final Report
\end{tabular}

\section{TITLE AND SUBTITLE}

Final Report

Mississippi River: Natchez to Baton Rouge Hydraulic and Sediment Transport Model

5a. CONTRACT NUMBER

5b. GRANT NUMBER

5c. PROGRAM ELEMENT NUMBER

\section{AUTHOR(S)}

James R. Leech, David P. May, Tate O. McAlpin

5d. PROJECT NUMBER

470711

5e. TASK NUMBER

5f. WORK UNIT NUMBER

7. PERFORMING ORGANIZATION NAME(S) AND ADDRESS(ES) (see reverse)

Coastal and Hydraulics Laboratory

U.S. Army Engineer Research and Development Center

REPORT NUMBER

3909 Halls Ferry Road

Vicksburg, MS 39180-6199

\section{SPONSORING/MONITORING AGENCY NAME(S) AND ADDRESS(ES)}

U.S. Army Corps of Engineers, Mississippi Valley Division

Mississippi River Geomorphology \& Potamology Program

1400 Walnut Street

Vicksburg, MS 39180

MRG\&P Report No. 19

\section{DISTRIBUTION/AVAILABILITY STATEMENT}

Approved for public release; distribution is unlimited.

\section{SUPPLEMENTARY NOTES}

\section{ABSTRACT}

This report documents the development, calibration, and validation of a hydraulic and sediment transport model of the Mississippi River between Natchez, MS, and Baton Rouge, LA, conducted for the U.S. Army Corps of Engineers, Mississippi Valley Division, Vicksburg, MS, using the Coastal and Hydraulics Laboratory-developed Adaptive Hydraulics numerical code. The numerical model adequately replicates the water levels observed in the field including a wide range of conditions from an extreme flood (Flood of 2011) to an extreme drought (2012). The numerical model simulated both of these events concurrently indicating a wide range of applicability for this particular model. With the inclusion of the Old River Control Complex and Morganza Control Structure, this model is available to evaluate alternative operational procedures and associated relative water level impacts between these two structures for both normal and extreme flow conditions. This study further advanced the goal of the Mississippi River and Tributaries program in terms of developing numerical models to analyze the Lower Mississippi River in terms of short- and long-term impacts to the system.

\section{SUBJECT TERMS}

Hydraulic models, Mathematical models, Mississippi River, Numerical analysis, Sediment transport

\section{SECURITY CLASSIFICATION OF:}

a. REPORT

Unclassified

\begin{tabular}{|c|c|}
\hline b. ABSTRACT & c. THIS PAGE \\
Unclassified & Unclassified
\end{tabular}

17. LIMITATION OF ABSTRACT

SAR
18. NUMBER OF PAGES

60 19a. NAME OF RESPONSIBLE PERSON

Ty V. Wamsley

19b. TELEPHONE NUMBER (Include area code) 601-634-5062 